\title{
Temperature History and Microstructure of Alumina
}

\author{
LBL -32510 \\ Jiang Tsair Lin \\ DE92 041196 \\ (Ph.D. Thesis)
}
Department of Materials Science and Mineral Engineering,
University of California, Berkeley
and
Materials Sciences Division
Lawrence Berkeley Laboratory
University of California
Berkeley, CA 94720

May, 1992

This work was supported by the division of Materials Science, Office of Basic Energy Research, United States Department of Energy, under contract No. DE-AC0376SF00098 with the Lawrence Berkeley Laboratory. 


\title{
Temperature History and Microstructure of Alumina
}

\author{
by
}

Jiang Tsair Lin

\begin{abstract}
A simple process for the attainment of fully dense and improved microstructure for $\mathrm{Al}_{2} \mathrm{O}_{3}$ ceramics has been developed. High purity, narrow size distribution, and submicron alumina powder is used for this investigation. A homogenization heat treatment of $\mathrm{Al}_{2} \mathrm{O}_{3}$ powder compacts at $800^{\circ} \mathrm{C}$ for 50 hours allows the systern to have a more uniform pore structure and a higher green strength. Pore size distribution becomes narrower, as has been demonstrated by mercury porosimetry. Near fully derse $(>0.995$ T.D.), tine-grained (< $1.2 \mu \mathrm{r}$ ) ) and uniform grain size-distribution, unćoped $\mathrm{Al}_{2} \mathrm{O}_{3}$ ceramics can be produced by using a high quality powàr, a high-pressli., cold isostatic forming method, and a two step sintering technique. Improvements in the microstructure of $\mathrm{Al}_{2} \mathrm{O}_{3}$ ceramics homogenized at $800^{\circ} \mathrm{C} / 50 \mathrm{~h}$ include a smaller pore size and a more uniform pore size distribution. Prevention of differential der sification in the early stages and delay of pore channel closure to the later stages of sintering are believed to be the primary mechanisms for the microstructure improvement in two-step sintering of $\mathrm{Al}_{2} \mathrm{O}_{3}$ ceramics.
\end{abstract}

Two-step sintering technique gives an alternate way to improve the microstructure of $\mathrm{Al}_{2} \mathrm{O}_{3}$ ceramics compared to the fast firing or $\mathrm{MgO}$ doping. When a combination of the homogenization heat treatment and the fast firing technique is used, the final density is even higher than that resulting from fast firing alone. However, the two-step sintering technique is simple in nature and there is no limitation on the size of the samples. 
the samples. Generalization of two-step sintering to more systems is needed for practical applications.

For 250 ppm $\mathrm{MgO}$-doped $\mathrm{Al}_{2} \mathrm{O}_{3}$ ceramics, homogenization of powder compacts at $800^{\circ} \mathrm{C}$ for 50 hours produces a sintered body with a grain size of about $0.80 \mu \mathrm{m}$. The refintement of grain size is moie pronounced as a result of $\mathrm{MgO}$-doping. It is explained that not only $\mathrm{MgO}$ doping inhibits the grain growth kinetics of $\mathrm{Al}_{2} \mathrm{O}_{3}$ but also the homogenization hea! treatment improves the pore structure of the $\mathrm{Al}_{2} \mathrm{O}_{3}$ powder compacts. This :mprovement is tased on the explanation that the distribution of $\mathrm{MgO}$ becomes more uniform during the homogenization heat treatment, which enhances the effectiveness of $\mathrm{MgO}$ doping. 
Temperature History and Microstructure of Alumina

by

Jiang Tsair Lin

\begin{abstract}
A simple process for the attainment of fully dense and improved microstructure for $\mathrm{Al}_{2} \mathrm{O}_{3}$ ceramics has been developed. High purity, narrow size distribution, and submicron alumina powder is used for this investigation. A homogenization heat treatment of $\mathrm{Al}_{2} \mathrm{O}_{3}$ powder compacts at $800^{\circ} \mathrm{C}$ for 50 hours produces a more uniform pore structure and a higher green strength. Pore size distribution becomes narrower, as has been demonstrated by mercury porosimetry. Near fully dense (>0.995 T.D.), finegrained $(<1.2 \mu \mathrm{m})$ and uniform grain size-distribution, undoped $\mathrm{Al}_{2} \mathrm{O}_{3}$ ceramics can be produced by using a high quality powder, a high-pressure cold isostatic forming method, and a two-step sintering technique. Improvements in the microstructure of $\mathrm{Al}_{2} \mathrm{O}_{3}$ ceramics homogenized at $800^{\circ} \mathrm{C}$ for 50 hours include a smaller pore size and a more uniform pore size distribution. Prevention of differential densification in the early stages and delay of pore channel closure to the later stages of sintering are believed to be the primary mechanisms for the microstructure improvement in two-step sintering of $\mathrm{Al}_{2} \mathrm{O}_{3}$ ceramics.
\end{abstract}

The two-step sintering technique gives an alternate way to improve the microstructure of $\mathrm{Al}_{2} \mathrm{O}_{3}$ ceramics compared to fast firing or $\mathrm{MgO}$ doping. When a combination of the homogenization heat treatment and the fast firing technique is used, the final density is even higher thar that resulting from fast firing alone. However, the two-step sintering technique is simple in nature and there is no limitation on the size of 
the samples. Generalization of two-step sintering to more systems is needed for practical applications.

For $250 \mathrm{ppm} \mathrm{MgO}$-doped $\mathrm{Al}_{2} \mathrm{O}_{3}$ ceramics, homogenization of powder compacts at $800^{\circ} \mathrm{C}$ for 50 hours produces a sintered body with a grain size of about $0.80, \mathrm{~m}$. The refinement of grain size is more pronounced as a result of $\mathrm{MgO}$-doping. It is explained that not only $\mathrm{MgO}$ doping inhibits the grain growth kinetics of $\mathrm{Al}_{2} \mathrm{O}_{3}$ but also the homogenization heat treatment improves the pore structure of the $\mathrm{Al}_{2} \mathrm{O}_{3}$ powder compacts. This improvement is based on the explanation that the distribution of $\mathrm{MgO}$ becomes more uniform during the homogenization heat treatment, which enhances the effectiveness of $\mathrm{MgO}$ doping. 
Temperature History and Microstructure of Alumina

Table of Contents

1. Introduction and Objectives............................................

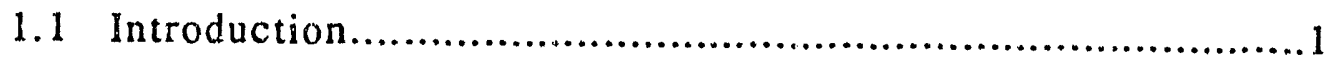

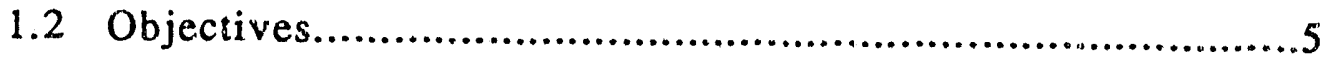

References for Chapter 1....................................................6

2. Background................................................................ 10

2.1 Microstructure and Mechanical Properties....................................10

2.2 Processing Parameters and Microstructural Evolution..................... 13

2.2.1 Raw Materials..................................................... 13

2.2.2 Packing Homogeneity .................................................14

2.2.3 Sintering Schedules...................................................16

2.3 Effects of Homogenization Heat Treatment..................................19

2.4 Pore Structure Change by Homogenization Heat Treatment.................21

References for Chapter 2......................................................23

3. Experimental Procedures................................................27

3.1 Starting Materials...........................................................27

3.1.1 Undoped Alumina.....................................................27

3.1.2 MgO-Doped Alumina...............................................29

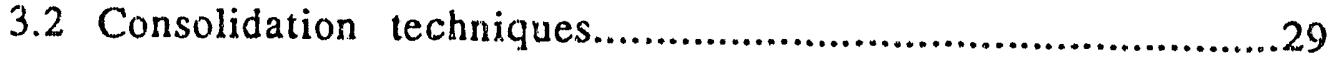

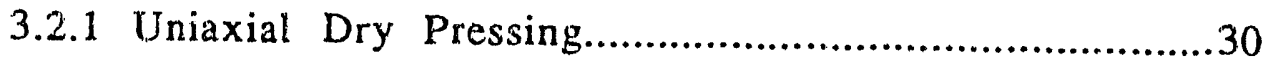

3.2.2 Cold Isostatic Pressing..................................................30

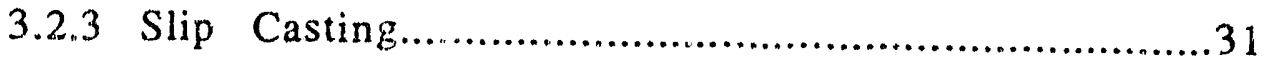

3.3 Homogenization Heat Treatment.............................................31

3.4 Characterization of Powder Compacts......................................32 
3.5 Sintering Schedules..........................................................33

3.5.1 Constant Heating Rate Sintering ...........................................33

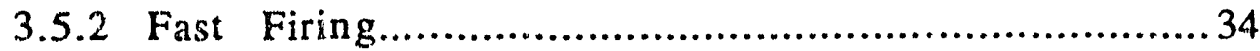

3.6 Microstructural Observation......................................................35

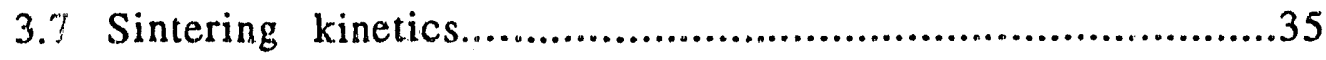

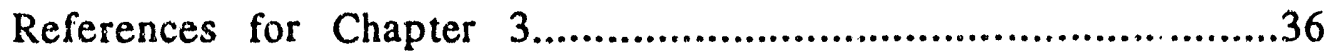

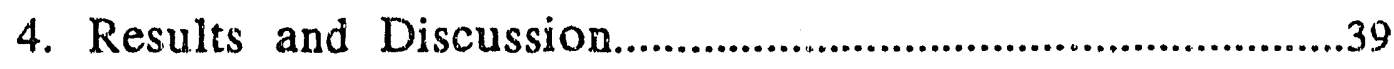

4.1 Undoped Alumina................................................................39

4.1.1 Effects of Homogenization Heat Treatment.............................39

4.1.1.1 Microstructure....................................................39

4.1.1.2 Surface Area and Pore Structure................................40

4.1.1.3 Driving Force for Sintering........................................41

4.1.1.4 Effects of Homogenization Temperatures........................42

4.1.1.5 Pore Size Distribution............................................. 43

4.1.1.6 Flexural Strength of the Green Body............................45

4.1.2 Pore Coarsening and Sintering.............................................46

4.1.3 Modeling of Pore Coarsening........................................... 47

4.1.4 Homogenization Heat. Treatment on Sintering.........................49

4.1.4.1 Density and Microstructure ..........................................49

4.1.4.2 Densification Kinetics..........................................51

4.1.4.3 Microstructural Evolution.........................................52

4.1.4.4 Pore Evolution........................................................ 55

4.1.4.5 Grain Size and Density Trajectories..............................56

4.1.5 Effects of Consolidation Techniques....................................56

4.1.6 Optimal Conditions of Homogenization Heat Treatment..............58 
4.2 $\mathrm{MgO}$-Doped Alumina..............................................61

4.2.1 Sintering and Microstructure of MgO-Doped Alumina..............61

4.2.1.1 Constant Heating Rate Sintering.............................61

4.2.1.2 Fast Firing.............................................62

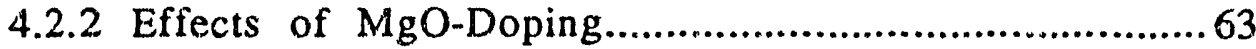

4.2.3 Role of MgO-Doping and Homogeniciation Heat Treatment........65

References for Chapter 4 .................................................66

5. Conclusions and Suggestions for Future Work..........................70

5.1 Conclusions.................................................................70

5.2 Suggestions for Future Work.............................................72

Tables .................................................................... 75

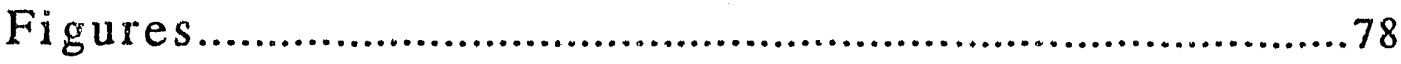




\section{Acknowledgments}

In the course of my study, I would like to express my sincere thanks to so many people who have helped me during these four years. Especially, Professor Lutgard C. De Jonghe, my research advisor, for his invaluable guidance throughout the period of my stay. His assistance and intensive discussion for the completion of the thesis are greatly appreciated.

My gratitude goes to Professor Alan W. Searcy for his enthusiastic assistance and for being the chairman of my Qualifying Examination Committee. I also wish to thank Dr. Rowland Cannon for constant and helpful discussion and comments on my research. Appreciation is also expressed to Professor Alan W. Searcy and Professor Angeiica M. Stacy for their reviewing and valuable comments on the manuscript.

All the members of De. Jonghe research group, especially Tim Kueper, Yves Boiteux, Naomi Naito, Pascal Gruffel, Chung-Hsin Lu, and Shun Wu for their suggestions, assistance, and friendship are gratefully thanked. Proofreading and comments on the manuscript by Shari Yokota and Tim Kueper are greatly thanked.

A four-year Ph. D. fellowship from the Industrial Technology Research Institute (ITRI), Taiwan, Republic of China provided the financial support for pursuing my graduate study at U. C. Berkeley is gratefully acknowledged. Thanks are also due to all the colleagues who helped me finish the work.

So many thanks should go to my lovely wife, Chi-Yun, and two children, Michael and Emily, for their continuous inspiration and patience. Without their support, love, and understanding, this work would have been impossible. 


\title{
Chapter 1 \\ Introduction and Objectives
}

\subsection{Introduction}

\begin{abstract}
Alumina $\left(\mathrm{Al}_{2} \mathrm{O}_{3}\right)$ is one of the most important ceramic materials for structural and electronic applications. The properties of sintered $\mathrm{Al}_{2} \mathrm{O}_{3}$ are primarily determined by the final microstructure and sintered density. Since $\mathrm{Al}_{2} \mathrm{O}_{3}$ ceramics have better mechanical, optical and thermal properties if they ore fully dense and fine-grained, numerous attempts have been made to improve processing. The properties of the sintered alumina depend on the starting particle size, particle size distribution, particle shape, and on the uniformity of particle packing . Densification kinetics are significantly enhanced, and grain growth is reduced for higher initial packing densities. If we can eliminate packing inhomogeneities in the green body, the sintering temperature can be reduced for very fine powders. $[1,2]$
\end{abstract}

Powder characteristics, uniformity of particle packing and sintering schedule are critical issues in determining the final microstructure of alumina ceramics. Narrow sizedistribution powders have been reported [3-5] to result in a higher densification rate and sintered density than powders with wide size distributions. Moreover, careful preparation of the green compact is crucial for the attainment of fully dense products. Particle packing during the consolidation step determines the pore size, pore size distribution, and pore coordination number in the green compact. Thus a homogeneous green microstructure is required to reduce variations in local sintering rate, and allow uniform densification throughout the bulk of the specimen. Therefore, homogeneous particle packing by a mono-sized powder received increasing attention during the past decade. [36] Most powder preparation routes involve a suspension which has to be dried. Drying is critical for the control of the characteristics of the primary particles; the final 
microstructure of sintered $\mathrm{Y}_{2} \mathrm{O}_{3}$ was non-uniform due to the formation of agglomerates during the powder drying stage. [6]

The influence of the microstructure of the green compact on sintering behavior has been extensively reviewed. [7-11] Agglomerates present in the fine powders, especially for submicron-sized powders, always cause inhomogeneities in the final microstructure. [12-15] A relationship between pore structure and densification rate was indicated by Roosen and Hausner, [16] who studied the sintering behavior of a $\mathrm{ZrO}_{2}$ powder compact. They found that the smaller the pore size, the lower the temperature of maximum densification rate. Large interagglomerate pores in the cornpact require higher sintering temperatures for elimination. By using a narrow-sized, well-dispersed powder and a colloidal forming technique, dense $\mathrm{Al}_{2} \mathrm{O}_{3}$ products can be achieved. [17] Narrow size-distribution powders and colloidal forming techniques can produce a high density, fine-grained $\mathrm{Al}_{2} \mathrm{O}_{3}$ product at very low temperature. [5] Pore size and pore size distribution are important factors that control the densification kinetics and final microstructure.

Numerous studies have been conducted on the manipulation of microstructure by controlling the sintering schedule. Reducing the time spent at non-densifying stages has been useful for improving the microstructure of $\mathrm{Al}_{2} \mathrm{O}_{3}$ ceramics. "Fast firing" [18-20] or "ultra-rapid sintering" [21,22] techniques are applicable for materials in which the activation energy of surface diffusion is lower than that of grain boundary diffusion, e.g., $\mathrm{Al}_{2} \mathrm{O}_{3}$. Along with the higher sintering temperature $\left(1850^{\circ} \mathrm{C}\right)$ needed for fast firing, the main drawbacks are that the very high heating rate may cause therr. $\therefore .20 k$ of samples which limits the size the products.

The "rate-controlled sintering" method was first proposed by Palmour $[23,24]$ to refine the microstructure of $\mathrm{Al}_{2} \mathrm{O}_{3}$ ceramics, but the detailed mechanism for the reduction of grain size is not understood. In addition, this technique is very complicated because it 
needs a feedback system to maintain a constant densification rate during the sintering process. The applications of the rate-controlled sintering techniques are still limited if the value of the activation energy of densification is similar to that of grain growth. [25]

The so called "two-step" (or two-stage) sintering as first suggested by Kuczynski [26] was shown to be an effective technique to improve the microstructure of heterogeneous $\mathrm{MgO}$ compacts. [27] $\mathrm{MgO}$ powder compacts were first homogenized at a lower temperature $\left(1200^{\circ} \mathrm{C}\right)$ before the sintering stage. Homogenization heat trearment of the compacts results in finer grain size and uniform grain size distribution. Chu, et al. [28, 29] reported that two-step sintering is also effective for agglomerated $\mathrm{ZnO}$ and $\mathrm{Al}_{2} \mathrm{O}_{3}$ ceramics. The theoretical basis for the homogenization heat treatment at a lower temperature is that surface diffusion is the most active mechanism for mass transport in $\mathrm{Al}_{2} \mathrm{O}_{3}$ because the evaporation/condensation mechanism is not dominant at low temperatures. Interparticle neck growth, smoothing of pore channel surfaces, and particle coarsening without densification through Ostwald ripening can be produced by surface diffusion, which has the lowest activation energy of all types of transport processes and thus dominates at low temperatures.

Coarsening occurs during sintering and competes with densification. Microstructure evolution during sintering reflects the relative rates of the coarsening and densification processes. The homogenization heat treatment increases the uniformity of the pore size distribution and as a result, the system remains longer in the open pore state. Pores which are small and more uniform in distribution can be eliminated easily during the final stages of sintering. Meanwhile, neck growth which occurs during the homogenization heat treatment leads to the additional benefit of increased green body strength.

Coarsening is defined as growth of grains and pores with negligible densification. The coarsening process reduces the specific surface area of the powder compacts and 
thus, consurnes the driving force for densification. In the case of coarsened compacts, e.g., $\mathrm{B}_{4} \mathrm{C}$, fully dense sintered bodies are not attainable. [30] The microstructure resulting from the two-step sintering technique is more uniform and finer than that of the as" pressed powder compacts which in turn suggests that the driving force for sintering is not the critical factor in determining the final microstructure. The pore morphology and pore size distribution as modified by the homogenization heat treatment are the most plausible reasons for microstructure improvement. During the homogenization heat treatment, the pore structure is modified significantly, while the driving force for densification is minimally affected as presented by Chu, et al. [29] Small isolated pores resulting from pore channel closure are distributed uniformly during sintering and lead to an improved final microstructure. Chu, et al. postulated that the reduction of differential denisifination. during the initial stages of sintering is responsible for the microstructure improvernent. but this postuiate has not yet been confirmed. [29]

Since Coble [31] discovered that 0.25 wt\% $\mathrm{MgO}$ was an effective additive in the sintering of $\mathrm{Al}_{2} \mathrm{O}_{3}$, the role of $\mathrm{MgO}$ in the sintering of $\mathrm{Al}_{2} \mathrm{O}_{3}$ [32] has been studied extensively. $\mathrm{MgO}$ has the effect of reducing the grain boundary mobility through a solid solution pinning mechanism. [33] The densification rate of $250 \mathrm{ppm} \mathrm{MgO-doped} \mathrm{Al}_{2} \mathrm{O}_{3}$ is enhanced compared to undoped $\mathrm{Al}_{2} \mathrm{O}_{3}$. The resultant microstructure is finer in grain size with higher final density. No abnormal grain growth can be attributed to the $\mathrm{MgO}$ doping in the sintered $\mathrm{Al}_{2} \mathrm{O}_{3}$. Impurities in $\mathrm{Al}_{2} \mathrm{O}_{3}$, especially a liquid phase formed during sintering, may affect the microstructural evolution. Ultra-pure alumina powder used as the starting material eliminated unfavorable abnormal grain growth. [34]

The objective of this research is to investigate the plausible mechanisms through which a homogenization heat treatment improves sintered microstructures. In addition, the optimal condition of homogenization heat treatment and subsequent sintering to near theoretical density for $\mathrm{Al}_{2} \mathrm{O}_{3}$ cerarnics will be examined. To avoid abnormal grain growth 
in the later stage of two-step sintering, high purity $\mathrm{Al}_{2} \mathrm{O}_{3}$ powder (>99.99\%) is used throughout this investigation. The sintering behavior of this pure, undoped $\mathrm{Al}_{2} \mathrm{O}_{3}$ powder is examined to compare with that of $250 \mathrm{ppm} \mathrm{MgO}$-doped $\mathrm{Al}_{2} \mathrm{O}_{3}$.

\subsection{Objective}

It is well known that the driving force for densification comes from the reduction of surface free energy. The non-densifying mechanisms such as evaporation/condensation and surface diffusion can only coarsen the microstructure and reduce the $d$ iving force for densification. The particle size and pore size are found to increase with time (coarsening) since no shrinkage occurs during surface diffusion processes. Final sintered density and grain size are characterized as indications of the effectiveness of a homogenization heat treatment for sintering $\mathrm{Al}_{2} \mathrm{O}_{3}$ ceramics. The characterization of heat treated microstructures by SEM and $\mathrm{Hg}$ porosimetry was carried out to study the change in particle morphologies and pore size distribution.

It is of fundamental interest to understand why a hornogenization heat treatment at low temperature and subsequent high temperature sintering can improve the microstructure of $\mathrm{Al}_{2} \mathrm{O}_{3}$ ceramics. The present approach is to isolate the low temperature heat treatment as the only process variable by careful ceramic processing techniques. Submicron, high purity, and narrow particle-size distribution $\mathrm{Al}_{2} \mathrm{O}_{3}$ powder is used as a model material in this study. Since the high green density of $\mathrm{Al}_{2} \mathrm{O}_{3}$ ceramic compacts prepared by high pressure cold isostatic pressing is proven to reduce the effect of unfavorable parameters on sintering, the powder compacts will be formed primarily by cold isostatic pressing. Slip casting (colloidal forming) will also be used to compare the effect of homogenization heat treatments on microstructural evolution.

The combined effect of heat treatment and $\mathrm{MgO}$ doping on the microstructure of sintered $\mathrm{Al}_{2} \mathrm{O}_{3}$ is also of fundamental interest. The effects of heat treatment schedule and 
sintering scl:edule (temperature, time, and heating rate) will be major concerns in this research.

\section{References (For Chapter 1)}

1. T.-S. Yeh and M.D. Sacks, "Effect of Green Microstructure on Sintering of Alumina"; pp. 309 - 31 in Ceramic Transactions, Vol. 7, Sintering of Advanced Ceramics. Edited by C.A. Handwerke-, J.E. Blendell, and W. Kaysser. American Ceramic Society, Westerville, $\mathrm{OH}, 1990$.

2. T.-S. Yeh and M.D. Sacks, "Low-Temperature Sintering of Aluminum Oxide," J. Am. Ceram Soc., 71 [10] 841 - 44 (1988).

3. E.A. Barringer and H.K. Bowen, "Ceramic Powder Processing," Ceramic Engineering and Science Proceedings, pp. 285 - 97, May-June (1984).

4. E.A. Barringer and H.K. Bowen, "Formation, Packing, and Sintering of Monodispersed $\mathrm{TiO}_{2}$ Powders," J. Am. Ceram. Soc., 65 [10] C-199 - C-201 (1982).

5. E.A. Barringer, R. Brook, and H.K. Bowen, "The Sintering of Monodispersed $\mathrm{TiO}_{2}$ "; pp. 1 - 21 in Materials Science Research, Vol. 16. Edited by G.C. Kuczynski, A.E. Miller, and G.A. Sargent. Plenum Press, New York, 1984.

6. D.J. Sordelet, and M. Akinc, "Sintering of Monosized, Spherical $\mathrm{Y}_{2} \mathrm{O}_{3}$ Powders"; pp. 332 - 44 in Ceramic Transactions, Vol. 7, Sintering of Advanced Ceramics. Edited by C.A. Handwerker, J. E. Blendell, and W. Kaysser. American Ceramic Society, Westerville, $\mathrm{OH}, 1990$.

7. A.V. Galakchov and V. Shevchenko, Jr, "Influence of Pore Structure Inhomogeneities in Green Compacts on Strength and Reliability of Y-TZP," J. Europ. Ceram. Soc., 6, $317-22(1990)$.

8. K. Kendall, "Microstructure of Submicron Powders and Green Compacts"; pp. 81 90 in British Ceramic Proceedings, Complex Microstructures, No. 42. Edited by R. 
Stevens and D. Taylor. Stoke-on-Trent, Staffs., U. K., 1989.

9. I.A. Aksay, F.F. Lange, B.I. Davis, "Uniformity of $\mathrm{Al}_{2} \mathrm{O}_{3}-\mathrm{ZrO}_{2}$ Composites by Colloidal Filtration," J. Am. Ceram. Soc., 66 [10] C-190 - C-192 (1983).

10. I.A. Aksay, "Microstructure Control through Colloidal Consolidation"; pp. 94 - 104 in Advances in Ceramics, Vol. 9, Forming of Ceramics. Edited by J.A. Mangles. American Ceramic Society, Columbus, OH, 1984.

11. C.P. Cameron and R. Raj, "Grain-Growth Transition During Sintering of Colloidally Prepared Alumina Powder Compacts," J. Am. Ceram Soc., 71 [12] 1031 - 35 (1988),

12. W.H. Rhodes, "Agglomerate and Particle Size Effects on Sintering Yttria-Stabilized Zirconia," J. Am. Ceram. Soc., 64 [1] 19 - 22 (1981).

13. F.F. Lange, "Sinterability of Agglomerated Powders," J. Am. Ceram. Soc., 67 [2] 83 $-89(1984)$.

14. F.W. Dynys and J.W. Halloran, "Influence of Aggregates on Sintering," J. Am. Ceram Soc., 67 [?] 596 - 601 (1984).

15. F.F. Lange and B.I. Davis, "Sinterability of $\mathrm{ZrO}_{2}$ and $\mathrm{Al}_{2} \mathrm{O}_{3}$ Powder i: The Role of Coordination Number Distribution"; pp.699 - 713, in Advances in Ceramics, Vol. 12, Science and Technology of Zirconia II. Edited by N. Claussen, M. Ruehle, and A.H. Heuer. American Ceramic Society, Columbus, OH, 1984.

16. A. Roosen and $\mathrm{H}$. Hausner, "Sintering Kinetics of $\mathrm{ZrO}_{2}$ Powders"; pp. $714-26$ in Advances in Ceramics, Vol. 12, Science and Technology of Zirconia II. Edited by N. Claussen, M. Ruehle, and A.H. Heuer. Ame tican Ceramic Society, Columbus, OH, 1984.

17. A. Roosen and H.K. Bowen, "Influence of Various Consolidation Techniques on the Green Microstructure and Sintering Behavior of Alumina Powders," J. Am. Ceram. Soc., 71 [11] 970 - 77 (1988).

18. M. Harmer, E.W. Roberts and R.J. Brook, "Rapid Sintering of Pure and Doped $\alpha$ $\mathrm{Al}_{2} \mathrm{O}_{3}$," Trans. J. Br. Ceram. Soc., 78, 22 - 25 (1979). 
19. R.J. Brook, "Fabrication Principies for Production of Ceramics with Superior Mechanical Properties," Proc. Brit. Ceram. Soc., 32, 7 - 24 (1982).

20. H. Pickup, U. Eisele, E. Gilbart, and R.J. Brook, "Analysis of Coarsening and Densification Kinetics during the Heat Treatment of Nitrogen Ceramics"; pp. 41 - 51 in Non-Oxide Technical and Engineering Ceramics. Edited by S. Hampshire. Elsevier Applied Science, New York, 1985.

21. D.L. Johnson, "Ultra-Rapid Sintering"; pp. 243 - 52 in Materials Science Research, Vol 16. Edited by G.C. Kuczynski, A.E. Miller, and G.A. Sargent. Plenum Press, New York, 1984.

22. D.L. Johnson, "Ultra-Rapid Sintering of Ceramics"; pp. 497 - 506 in Science of Sintering. Eaica by D.P. Uskokovic, H. Palmour III, and R.M. Spriggs. Plenum Press, New York, 1989.

23. H. Palmour III, "Rate Controlled Sintering for Cerarnics and Selected Powder Metals"; pp. 337 - 56 in Science of Sintering. Edited by D.P. Uskokovic, H. Palmour III, and R.M. Spriggs. Plenum Press, New York, 1989.

24. H. Palmour III and D.R. Johnson, "Phenomenological Model for Rate-Controlled Sintering"; pp. $779-91$ in Sintering and Related Phenomerta. Edited by G.C. Kuczynski, N.A. Hooton, and C.F. Gibbon. Gordon and Breach Science, New York, 1967.

25. S.J. Jamil and R.J. Brook, "Isothermal and Rate-Controlled Sintering of YttriaStabilized Thoria," Br. Ceram. Trans. J., 90, 39 - 44 (1991).

26. G.C. Kuczynski, "Towards the Understanding of the Process of Sintering"; pp. 3 16 in Sintering '85. Edited by G.C. Kuczynski, D.P. Uskokovic, H. Palmour III, and M.M. Ristic. Plenum Press, New York, 1987.

27. M.K.-F. Lin, "Sintering of the Heterogeneous MgO Compacts"; Ph.D. Thesis, University of California at Berkeley, April 1988.

28. M.-Y. Chu, "Sintering Stress and Microstructure in Ceramic Powder Compacts"; 
Ph.D. Thesis, University of California at Berkeley, August 1990.

29. M..Y. Chu, L.C. De Jonghe, M.K.-F. Lin, and t.J.T. Lin, "Precoarsening to Improve Microstructure and Sintering of Powder Compacts," J. Am. Ceram. Soc., 74 [11] $2902-11(1991)$.

30. S.L. Dole, S. Prochazka, and R.H. Doremus, "Microstructural Coarsening During Sintering of Boron Carbide," J. Am. Ceram. Soc., 72 [6] 958 - 66 (1989).

31. R.L. Coble, "Sintering of Crystailine Solids - II: Experimental Test of Diffusion Models in Porous Compacts," J. App. Phys., 32 [5] 793 - 99 (1961).

32. S.J. Bennison and M.P. Harmer, "A History of the Role of $\mathrm{MgO}$ in the Sintering of $\alpha-\mathrm{Al}_{2} \mathrm{O}_{3}{ }^{\prime \prime} ;$ pp. $13-49$ in Ceramic Transaction, Vol. 7, Sintering of Advanced Ceramics. Edited by C.A. Handwerker, J. E. Blendell, and W. Kaysser. American Ceramic Society, Westerville, OH, 1990.

33. A.K. Berry and M.P. Harmer, "Effect of MgO Solute on Micrcstructure Development in $\mathrm{Al}_{2} \mathrm{O}_{3}, "$ J. Am. Ceram. Soc., 69 [2] 143 - 49 (1986).

34. J. Zhao and M.P. Harmer, "Sintering of Ultra-High Purity Alumina Doped Simultaneously with $\mathrm{MgO}$ and FeO," I. Am. Ceram. Soc., 70 [12] 860 - 66 (1987). 


\section{Chapter 2}

\section{Background}

\subsection{Microstructure and Mechanical Properties}

Alumina has been regarded as an important structural ceramic for over three decades. Structural components are subjected to mechanical loads; therefore, researchers have concentrated on the attainment of high strength and improvement of fracture toughness. It has been widely accepted that the physical and mechanical properties of $\mathrm{Al}_{2} \mathrm{O}_{3}$ ceramics are determined mostly by the microstructure itself. [1-3] Hence, control of the final microstructure is critical in obtaining desirable mechanical properties. The most important variables controlling the properties of ceramic materials are grain size and porosity as well as the size and the spatial distribution of pores.

The relationship between strength and porosity of ceramics has been reviewed by Rice. [2] The dependence of strength on porosity is based on the fact that pores decrease the cross- sectional area on which a load is applied

$$
\sigma=\sigma_{0} \mathrm{e}^{-b P}
$$

where $s$ is the strength at volume fraction porosity $P, s_{0}$ is the strength of nonporous material and $b$ is an empirical constant ranging from 4 to 7 . The dependence of strength on grain size of a brittle polycrystalline material [1] can be expressed as:

$$
\sigma=k \mathrm{G}^{-a}
$$

where $\sigma$ is the strength, $\mathrm{G}$ is the grain size, and $k$ and $a$ are empirical constants. The value of $a$ is recognized to be $1 / 2$, i.e., $\sigma=k \mathrm{G}^{-1 / 2}$ for grain sizes in the range of 2 to 300 $\mu \mathrm{m}$. The room temperature strength of $\mathrm{Al}_{2} \mathrm{O}_{3}$ is reported to lie between 100 and $600 \mathrm{MPa}$ $\left(\mathrm{MN} / \mathrm{m}^{2}\right)$ as the grain size is varied between 2 and $100 \mu \mathrm{m}$. [4] If the value of $b$ is 
assumed to be independent of the grain size, [1] Eq (2-1) and (2-2) then can be combined to form the following relating strength to porosity, and grain size.

$$
\sigma=k \mathrm{G}^{-a} \mathrm{e}^{-b \mathrm{P}}
$$

In reality the mean value of porosity may not justify the strength of high density $\mathrm{Al}_{2} \mathrm{O}_{3}$ ceramics (>99\%) if only a trace amount of residual porosity is present. Moreover, uniformly distributed porosity consisting of many small pores is less subject to failure than a small number of large pores. Strength can be correlated with local extremes of the porosity rather than with the average grain size since fracture always follows the weakest path through the material. [2]

In addition, when considering the effects of flaws on the strength of ceramics, the strength can be expressed as:

$$
\sigma_{\mathrm{f}}=\frac{\mathrm{K}_{\mathrm{IC}}}{\mathrm{Y} \sqrt{\mathrm{C}}}
$$

where $\sigma_{\mathrm{f}}$ is fracture strength, $\mathrm{K}_{\mathrm{IC}}$ is fracture toughness, $\mathrm{C}$ is the length of a flaw, and $\mathrm{Y}$ is a geometric constant which depends on the ratio of flaw size over sample size. Generally, $\mathrm{K} I C$, does not change much with microstructure for $\mathrm{Al}_{2} \mathrm{O}_{3}$ ceramics $\left(\approx 3-4 \mathrm{MPa} \cdot \mathrm{m}^{1 / 2}\right)$; therefore the strength is mainly determined by he flaw size, $C$.

Flaws have been classified as extrinsic and intrinsic types. Extrinsic flaws are directly correlated with the process of fabrication and finishing conditions. Intrinsic flaws may be characterized as pores, large grains, second phase, or foreign inclusions. These are strongly dependent on the starting powder, processing conditions, and microstructure of alumina ceramics. In fine-grained $\mathrm{Al}_{2} \mathrm{O}_{3}$ extrinsic flaws induced by surface machining and large pores are major factors in determining the strength at failure. By reducing the 
extent of these extrinsic flaws by optimizing ceramic processing conditions and machining techniques, intrinsic flaws will determine the material strength as grain size is reduced. Microstructural inhomogeneities such as very large grains, elongated grains, large pores, and clu sers of large pores can act as strength-limiting flaws. [2] It has been shown by Rice [3] and Tressler, et al. [5] that large grains act as strength-limiting flaws in $\mathrm{Al}_{2} \mathrm{O}_{3}$ ceramics. Large grains can fracture by cleavage or along grain boundaries if the load is high enough. Large grains also can induce twin-nucleated microcracking which dramatically reduces the strength of $\mathrm{Al}_{2} \mathrm{O}_{3}$ ceramics. [4]

The largest flaw produces the greatest stress concentration. The simplest inherent flaw is the pore that is much larger than the surrounding grains. The largest pore as well as the smallest radius of curvature at the pore surface determine the stress to initiate and propagate cracks from the pore. Davidge and Tappin [5] found that the maximum grain size and pore size are approximately equal and that the mean strength is proportional to the stress necessary to propagate a crack equal in size to the sum of the largest pore size and the largest grain size.

The goal of researchers developing high strength $\mathrm{Al}_{2} \mathrm{O}_{3}$ ceramics for structural applications should be the production of a high density (minimum amount of residual porosity) and homogeneous microstructure characterized by uniformly distributed residual pores and uniform grain size distribution. [6] The strength of fine-grained $\mathrm{Al}_{2} \mathrm{O}_{3}$ ceramics is determined by the largest grains present in the sintered bodies if the flaw size generated by surface finishing is well controlled. Thus, a minimum amount of porosity and a very fine grain size are essential for strong ceramics. To approach this goal, the starting powder has to be very fine (submicron) and careful processing must be used to from the powder compact. Additionally, the sintering schedule is very critical in determining the final microstructure. The homogenization heat treatment in two-step sintering is found to be effective in reducing the final grain size and the broadness of the 
grain size distribution. [7] The homogenization heat treatment is expected to increase the strength of $\mathrm{Al}_{2} \mathrm{O}_{3}$ ceramics compared to the conventionally sintered ones with grain sizes in the range of 1 to $2 \mu \mathrm{m}$. The increased strength can be explained by the reduction of both the average grain size and the size of the largest grains by the homogenization heat treatment.

\subsection{Processing Parameters and Microstructure}

\subsubsection{Raw Materials}

For the manufacture of fine-grained $(1-2 \mu \mathrm{m})$ and fully dense ceramics, high quality powders should be considered first. A high quality powder can be defined as very fine, of high purity, free from agglomerates, spherical in shape, and narrow in size distribution. [8] It has been shown that the microstructure of sintered alumina becomes more uniform with increasing purity and decreasing particle size distribution of the starting powder. [9] In solid-state sintering an increased driving force (surface energy reduction) and faster densification kinetics (short diffusion distances) can be achieved by use of fine powders (typically submicron). Submicrometer powders spontaneously agglomerate due to van der Waals forces. [10] Agglomeration causes problems in ceramic processing. [11-18] Agglomerates in powder compacts prevent the attainment of full density after sintering because, as reported by Lange, [13] flaws produced by differential sintering are primarily responsible for low density product obtained by the sintering of dry-pressed powder compacts. Rhodes [16] has demonstrated that eliminating agglomerates in zirconia powder leads to fully dense sintered bodies with a fine grain size and uniform microstructure.

Most ceramic powders contain agglomerates, formed during the powder preparation and/or consolidation stages. Hard agglomerates, those which cannot be broken down during the compaction process, result in compacts having a non-uniform 
pore size distribution. The agglomerates can sinter to nearly theoretical density in the early stages of sintering, but the large pores tormed among agglomerates require higher temperatures or longer dwell times in order to be eliminated. Therefore it is essential to remove completely the agglomerates before the powder compaction stages. To take advantage of a high quality powder, a wet forming process [19] provide a solution to the agglomeration problem and will be used in this study.

\subsubsection{Packing Homogeneity}

Particle packing determines the pore size, pore size distribution, and pore coordination number in the green compact (unfired). The uniformity of packing throughout an unfired compact is important for uniform shrinkage and elimination of porosity during sintering. A uniform green microstructure will help reduce variations in local sintering rate, thereby allowing uniform densification throughout the bulk of the specimen. The final microstructure evolved after sintering will be uniform which allows better mechanical properties.

Dry pressing of fine particles always causes uneven die fi'ling because fine powder has poor flowability. The resulting powder compact will experience a nonuniform density distribution if the applied load is too high which induces differential stress and causes cracking after compacts are ejected from the die. Spray drying of fine powders into large agglomerated freely flowing granules $(50-150 \mu \mathrm{m})$ which fill the die cavity evenly reduces the inhomogeneity of the green microstructure. A few percents of binder $(1-5 \mathrm{wt} \%)$ are always added to the powder to provide enough green strength for handling or machining before the sintering stage. The compaction behavior depends on the characteristics of the granules as well as the amount and the properties of the binder. Frey and Halloran [20] found that the green density, median pore diameter, and the width of the pore size distribution decrease with the compartion pressure. For the compaction of 
spray-dried granules, a pressure higher than a yielding value was necessary to substantially deform the granules. The green density reached by dry pressing of spray dried alumina was only $50 \%$ of theoretical density at a maximum pressure of $350 \mathrm{MPa}$. [20]

It is well understood that large pores that form due to lack of complete plastic deformation of the agglomerated granules are the main reason ior the iow green density of traditionally dry pressed bodies. One way to reduce the extent of pore inhomugeneity generated by granules is by using cold isostatic pressing techniques with very high pressure which gives a higher green density. The cold isostatic pressing technique improves the packing homogeneity and sinterability. [18] The green density reached about $61 \%$ of theoretical density with isostatic pressing techniques at a pressure of 1380 $\mathrm{MPa}$ in this study. The resulting green microstructure is much more uniform than the microstructure of compacts made by dry pressing.

The formation of agglomerates and then effect on microstructure has been reviewed recently by Yan. [10] Densification of individual agglomerates leads to large pores between them becoming even larger. However common powder preparation and powder processing routes involve a suspension which has to be dried prior to the consolidating step. High processing temperatures leading to neck formation or bridging between particles is the primary reason for the formation of hard agglomerates. Therefore, agglomerates formed during the drying or calcination stages depend critically on the operating temperatures. Ultrasonication and sedimentation of a well-dispersed slurry is an effective technique for removing agglomerates and aggregates as reported by Bowen, et al. [21,22] Nevertheless, drying of the slurry after sedimentation cannot be avoided if one uses the dry pressing technique. Hence, the best way to avoid drying the suspension before forming a compact is to use a wet forming technique (e.g., slip casting). [19] The benefits of a wet forming technique come from the avoidance of drying 
before the consolidation stage. Particles can be deposited to form a compact from a welldispersed suspension. The green microstructure formed by slip casting is much more homogeneous than that produced by dry pressing.

There are some practical limitations to achieve high green density and a uniform green microstructure. First, the starting material has to be very fine and free from agglomerates because the spontaneous formation of agglomerates cannot be avoided during ceramic processing or even in storage for submicron powders. Second, conventional forming techniques (die pressing and isostatic pressing at pressures as low as $\approx 200 \mathrm{MPa}$ ) cannot give a homogeneous green microstructure (uniform pore size dis -in $^{-1}$ tion) and high green density. Therefore, it is necessary to sinter such powder compacts at higher temperatures and prolonged dwell times to attain a high final density, but in so doing an unfavorable final microstructure with large grain size may be produced. However in the slip casting technique, variations in the slurry and the plaster of Paris mold may not be easily controlled. The packing homogeneity and green density slip cast materials can vary since the uniformity of green microstructure depends strongly on rheological properties, particle size distribution, binders, mixing, molds, and casting conditions of the slurry. $[23,24]$ In this study the slip casting process is controlled to reproducibly produce powder compacts. Effects of consolidation techniques on the microstructural evolution of two-step and conventionally sintered ceramics will be examined.

\subsubsection{Sintering Schedules}

Sintering can be described as a process which transforms an assembly of fine particles to a strong, dense polycrystalline product by heating to a temperature of $0.7-0.8$ of the melting point of the material. Sintering is accompanied by the elimination of interparticle voids (pores) and by the resulting shrinkage of the powder compact. The 
driving force for sintering comes frum the reduction of surface free energy. The mass transport in evaporation/condensation $(E / C)$ consists of evaporation of atoms from convex surfaces of particles and condensation on concave necks. Such a mechanism does not result in an approach of particle centers, as is necessary for the shrinkage of the powder compact, but in growth of the neck region, which causes a decrease in the curvature of the neck and changes the pore structure. Because of $E / C$, neck growth becomes significant and the driving force for mass transport decreases in proportion to the radius of curvature of the neck surface. The importance of $\mathrm{E} / \mathrm{C}$ is usually obvious at higher temperatures and, moreover, is significantly enhanced for more volatile materials. The changes in the geometry of pore struciures and neck regions by surface diffusion are identical to the case of $\mathrm{E} / \mathrm{C}$. However high atomic diffusivity at surfaces make surface diffusion more active even at relatively low temperatures. As the particle size decreases, surface diffusion becomes more important in determining microstructural evolution during the initial stage of sintering.

Kuczynski [25] studied the isothermal sintering of metallic spheres by measuring the growth of the necks and concluded that the rate of neck formation among particles is a process controlled in the early stage by surface diffusion and in the later stage by bulk diffusion. It can be realized that densification kinetics anc microstructural evolution will be significantly influenced by the sintering schedule (temperature, time, heating and cooling rates). For the purpose of sintering ceramics to high density, the sintering conditions have to be such that non-densifying mechanisms are not very active since they dissipate the driving force for densification.

It is generally agreed that surface diffusion and $\mathrm{E} / \mathrm{C}$ mechanisms cause neck growth and coarsening of particles and pores which in turn reduce the driving force for densification; a significant reduction in densification rate can result. This reduction is particularly significant for prolonged heating at low temperatures since surface diffusion 
tends to predominate. [26] To avoid the adverse effects of non-densifying mechanisms ina the low temperature range, several investigators [27-30] suggest fast firing and/or uitrarapid sintering techniques. Fully dense $\mathrm{Al}_{2} \mathrm{O}$, ceramics with a fine grain size produced by fast firing have been reported. [26] The process of fast firing consists of minimizing the time spent in the low temperature range by using a very high heating rate $\left(>10^{9}{ }^{\circ} \mathrm{C} / \mathrm{min}\right.$.) and a brief hold $\left(5-10\right.$ minutes) at high temperature $\left(1850^{\circ} \mathrm{C}\right.$ for $\mathrm{Al}_{2} \mathrm{O}_{3}$ ) where densification is completed. The refinement of grain size is due to the fact that the soaking time at high temperature is so short that grain growth is suppressed and the high densification rate at high temperature allows the system to be completely densified. The beneficial effect of the fast firing technique is in producing more fine-grained $\mathrm{Al}_{2} \mathrm{O}_{3}$ ceramics than does the conventional isothermal sintering method, but the limitations on sample size by thermal shock due to the high heating rate and the uncertainty in applying it to other kinds of material (e.g., $\mathrm{MgO}$ ) make this method not so useful.

Temperature is the most important sintering variable since the diffusion coefficient $2 \mathrm{f}$ atoms is an exponential function of temperature. A practical sintering schedule inciudes a hold at sintering temperature for $1-2$ hours, depending on the initial green density and microstructure, for complete elimination of porosity. It is preferable to sinter the materials at temperatures as low as possible to prevent coarsening. Low temperature sintering of well-prepared $\mathrm{Al}_{2} \mathrm{O}_{3}$ powder compacts (green density $\approx 70 \%$ ) can obtain $>0.99$ of theoretical derısity with a grain size of $0.16 \mu \mathrm{m}$ (isothermally sintered at $1150^{\circ} \mathrm{C}$ for $6 \mathrm{~h}$ ) as reported by Yeh and Sacks. [31] The very fine-grained $\mathrm{Al}_{2} \mathrm{O}_{3}$ ceramics are attributed to the very fine starting particle size $(<0.1 \mu \mathrm{m})$ as well as to homogeneous particle packing and high green density by the slip castirg method. However it is practically difficult to prepare a powder compact of high green density and uniform packing homogeneity from such fine particles. For an ordinary $\mathrm{Al}_{2} \mathrm{O}_{3}$ powder with a particle size in the range of $0.3-0.5 \mu \mathrm{m}$, the usual sintering temperaturs are from $1450^{\circ} \mathrm{C}$ to $1650^{\circ} \mathrm{C}$. As sintering proceeds, densification and grain growth occur 
simultaneously and interact with each other. The higher the temperature for sintering the larger the grain size that evolves, which leads to a limiting end-point density achieved when the isolated pores are not attached to the grain boundaries. Therefore, densification rates can be significantly reduced by larger grains. The final grain size distribution is also nonuniform.

\subsection{Two-Step Sintering}

Two-step sintering consists of heat treatment at a low temperature for homogenization of the powder compact and subsequent sintering at a high temperature where densification occurs. This technique has been proved successful with very inhomogeneous $\mathrm{MgO}$ powder compacts by Lin [32] and with $\mathrm{Al}_{2} \mathrm{O}_{3}$ and $\mathrm{ZnO}$ materials by Chu and De Jonghe. $[33,7]$ The resulting grain size is finer and the grain size distribution obtained by the two-step sintering method is more uniform than obtained by conventional sintering. The improved of microstructure is attributed to the uniform isolated pores formed in the later stages of sintering and to the delayed pore channel pinch-off. There is no detailed study of the microstructural changes during the first-step, the homogenization heat treatment. Experimental evidence for the pore channel closure is not provided by Lin. [32] Only microstructures and density relations are presented without any details of the pore size distribution after the homogenization heat treatment.

In the two-step sintering study of $\mathrm{ZnO}$ by $\mathrm{Chu}$, et al., [7] the average particle size increases by $67 \%$ by the homogenization heat treatment at $450^{\circ} \mathrm{C}$ for 90 hours, but the densification rate is only slightly reduced by the homogenization heat treatment. Sintering stress is reduced by $20 \%$, which reveals that the reduction in driving force for sintering is not fully reflected by the increase in particle size. This may be due to the influence of other factors such as the change in pore structure, i.e., pore coordination number, which may play an important role in determining the effect of the 
homogenization heat treatment. The results are explained by the evolution of interpore spacing in the homogenization heat treated samples during subsequent sintering at high teinperature, particularly in the later stages of sintering. Chu, et al., concluded that the coarsening of interpore spacing by the homogenization heat treatment suppresses hightemperature coarsening. Two-step sintering of conventional $\mathrm{Al}_{2} \mathrm{O}_{3}$ powder [7] found that the final density reached about $95 \%$ of theoretical density and had a large grain size which was attributed to the low green density ( 0.53 of theoretical density) and the temperature limitations of the dilatometer. However their results suggest that two-step sintering reduces the final grain size and increases the uniformity of the grain size distribution in inhomogeneous $\mathrm{Al}_{2} \mathrm{O}_{3}$ powder compacts.

It is worthwhile studying the mechanism responsible for the microstructural improvement of homogeneous powder compacts, and applying this technique to $\mathrm{Al}_{2} \mathrm{O}_{3}$ ceramics to achieve a high sintered density ( $>0.99$ of theoretical density) and mechanical strength. It is interesting to indicate that the maximum densification rate occurs in the range of $0.75-0.85$ of theoretical density where a large fraction of the pores is eliminated. If the isolated pores that resulted from the decay of an interconnected pore network are homogeneously distributed the final microstructure can be very uniform because the path of microstructural evolution is mostly controlled by the intermediate stages of sintering. Therefore, the detailed microstructural evolution of homogenization heat treated as well as conventional samples during the intermediate stages of sintering is thoroughly examined to find mechanisms responsible for the microstructure improvement.

\subsection{Pore Structure Change by Homogenization Heat Treatment}

When particles of very different sizes are in contact, the growth of larger particles at the expense of smaller ones will reduce the surface free energy. The driving forcc comes from the difference in curvature between concave neck regions where particles are 
touching and convex surfaces of particles. The highly concave neck surfaces are filled in with material from the convex part of the particle surfaces. The process occurs by surface diffusion or evaporation/condensation at low temperatures because of lower activation energy than those by volume or grain boundary diffusion for mass transport. Neck growth without densification is known as coarsening. The chemical potential gradient between the sources and sinks for the mass transport can be shown from the Gibbs-Kelvin equation

$$
\Delta \mu=\gamma_{s} \Omega\left(\frac{1}{R_{2}}-\frac{1}{R_{1}}\right)
$$

where $\Delta \mu$ is the chemical potential gradient between two locations, $R_{1}$ and $R_{2}$ are the orthogonal radii of the sink and source, $\Omega$ is the atomic volume, and $\gamma_{s}$ is the surface energy. Since the radius of curvature of the sink (neck) is small and negative relative to the large and positive radius of the source (particle surface), it is expected that the kincties of mass transport to the neck region will dominate at the very beginning of heat treatment. Redistribution of material over the surface by surface diffusion and/or $E / C$ will not result in shrinkage of the cornpact but can only increase strength by increasing centact areas and reducing the notch effect of sharp pore contours. [34]

For fine-sized $\mathrm{Al}_{2} \mathrm{O}_{3}$ during the homogenization heat treatment at a low temperature surface diffusion is the only active mechanism for mass transport. Smoothing of pore surfaces, particle coarsening, and interparticle neck growth without densification can be produced by surface diffusion, which has the lowest activation energy of all types of transport processes and tius dominates at low temperatures. If the isolated pores resulting from pore channel pinch-off are uniformly distributed and small, the microstructure of sintered $\mathrm{Al}_{2} \mathrm{O}_{3}$ ceramics can be improved. 
As indicated by Lord Rayleigh, [35] cylindrical shapes are unstable under the influence of surface tension. Cylindrical pore channels are only stable within certain dimensional limits. $[36,37]$ Once the limit of stability is exceeded, the cylindrical pore channel will evolve into just one pore $(L / D<7.2)$ or breaks up into a series of pores (L/D >7.2). A pore channel can be roughly modeled as a cylindrical shape with length, $L$, and diameter, D. The average diameter of a pore channel should not change during a homogenization heat treatment because densification is negligible. Howerer, during prolonged low temperature heat treatment the pore channel areas with locally high curvature will be affected by surface diffusion and the shape of the pore channel becomes rnore smooth. In the early stages of sintering, the possibility of rapid pinch-off of pore channels at local regions having a short distance between particles can be much reduced. However, the soaking times at the temperatures for this homogenization heat treatment should be long enough to remove such early pinch-off of the pore channels. The smoothening of the pore channels will delay the pinch-off to a later stage of sintering. This in turn will lead to the break up of pore channels into a series of isolated pores during the later stages of sintering.

Neck formation between particles during homogenization heat treatment increases the green strength which in turn reduces the differential densification damages during the initial stage of sintering. The results indicate that the homogenization heat treatment increases the uniformity of the pore size distribution and allows the system to remain longer in a state of open porosity. The resultant pores are small and uniformly distributed and they can be eliminated easily during the final stages of sintering.

\section{References (For Chapter 2)}

1. F.P. Knudsen, "Dependence of Mechanical Strength of Brittle Polycrystalline Specimens on Porosity and Grain Size," J. Am. Ceram. Soc., 42 [8] 376 - 87 (1959). 
2. R.W. Rice, Microstructure Dependence of Mechanical Behavior of Ceramics"; pp. 199

- 381 in Treatise on Materials Science and Technology, Vol. 11: Properties and

Microstructure. Edited by R.K. MacCrone. Academic Press, New York, 1977.

3. R.W. Rice, "Fractographic Identification of Strength-Controlling Flaws and

Microstructure"; pp. 323 - 45 in Fracture Mechanics of Ceramics, Vol. 1, Concepts,

Flaws, and Fractography. Edited by R.C. Bradt, D.P.H. Hasselman, and F.F. Lange.

Plenum Press, New York, 1974.

4. E. Dorre and H. Hubner, "Alumina: Processing, Properties, and Applications"; pp. 74 110, Springer-Verlag, Berlin, Heidelberg, 1984.

5. R.W. Davidge and G. Tappin, "The Effects of Temperature and Environment on the Strength of Two Polycrystalline Aluminas," Proc. Br. Ceram. Soc., 15, 47 (1970).

6. R.E. Tressler, R.A. Langensiepen and R.C. Bradt, "Surface-Finish Effects on Strengthvs-Grain-Size Relations in Polycrystalline $\mathrm{Al}_{2} \mathrm{O}_{3}, "$ J. Am. Ceram. Soc., 57 [2] 226 27 (1974).

7. M.-Y. Chu, L.C. De Jonghe, M.K.-F. Lin, and F.J.T. Lin, "Pre-coarsening to Improve Microstructure and Sintering of Powder Compacts," J. Am. Ceram. Soc., 74 [11] 2902 - 11 (1991).

8. E.A. Barringer and H.K. Bowen, "Ceramic. Powder Processing," Ceramic Engineering and Science Proceedings, pp. 285 - 297, May-June (1984).

9. K. Yamada, "Present Situation and Future Technology of Alumina Chemicals in Japan"; pp. 561 - 67 in Alumina Chemicals: Science and Technology Handbook. Edited by L.D. Hart. The American Ceramic Society, Inc., Westerville, OH, 1990.

10. M.F. Yan, "Sintering of Cerarnics and Metals"; pp. 99 - 133 in Advances in Powder Technology. Edited by G.Y. Chin. Arnerican Society for Metals, Metals Park, OH, 1982.

11. I.A. Aksay, F.F. Lange, and B.I. Davis, "Uniformity of $\mathrm{Al}_{2} \mathrm{O}_{3}-\mathrm{ZrO}_{2}$ Composites by Colloidal Filtration," J. Am. Ceram. Soc., 66 [10] C-190 - C-192 (1983). 
12. F.F. Lange and B.M. Metcalf, "Processing-Related Fracture Origins: II, Agglomerate Motion and Cracklike Internal Surfaces Caused by Differential Sintering," J. Am. Ceram. Soc., 66 [6] 398 - 406 (1983).

13. F.F. Lange, "Sinterability of Agglomerated Powders," J. Am. Ceram. Soc., 67 [2] 83 - 89 (1984).

14. F.W. Dynys and J.W. Halloran, "Influence of Aggregates on Sintering," J. Am. Ceram. Soc., 67 [9] 596 - 601 (1984).

15. K. Kendall, "Microstructure of Submicron Powders and Green Compacts"; pp. 81 90 in British Ceramic Proceedings, Complex Microstructure, No. 42. Edited by R. Stevens and D. Taylor. Stoke-on-Trent, Staffs., March 1989.

16. W.H. Rhodes, "Agglomerate and Particle Size Effects on Sintering Yttria-Stabilized Zirconia," J. Am Ceram. Soc., 64 [1] 19 - 22 (1981).

17. A.V. Galakchov and V. Shevchenko, Jr., "Influence of Pore Structure Inhomogeneities in Green Compacts on Strength and Reliability of Y-TZP," J. Europ. Ceram. Soc., 6, 317 - 322 (1990).

18. F.F. Lange and B.I. Davis, "Sinterability of $\mathrm{ZrO}_{2}$ and $\mathrm{Al}_{2} \mathrm{O}_{3}$ Powders: The Role of Coordination Number Distribution"; pp. 699 - 713 in Advances in Ceramics, Volume 12, Science and Technology of Zirconia II. Edited by N. Claussen, M. Ruehle, and A.H. Heuer. The American Ceramic Society, Inc., Westerville, Ohio, 1984.

19. A.O. Boschi and E. Gilbart, "Wet Forming Processes as a Potential Solution to Agglomeration Problems"; pp. 73 - 93 in Advanced Ceramic Processing and Technology, Vol. 1. Edited by J.G.P. Binner. Noyes Publication, New Jersey, 1990.

20. R.G. Frey and J.W. Halloran, "Compaction Behavior of Spray-Dried Alumina," J. Am. Ceram. Soc., 67 [3] 199 - 203 (1984).

21. N. Parish and H.K. Bowen, "Narrow Size Distribution Powders from Commercial Ceramic Powders," Ceramics International, 10 [2] 75 - 77 (1984).

22. T.R. Gattuso and H.K. Bowen, "Processing of Narrow Size Distribution Alumina", 
pp. 644 - 55 in Advances in Ceramics, Vol. 10. Edited by W.D. Kingery. American Ceramic Society, Columbus, OH, 1984.

23. R.E. Cowan, "Slip Casting"; pp. 153 - 71 in Treatise on Materials Science and Technology, Vol. 9, Ceramics Fabrication Process. Edited by F.F.Y. Wang. Academic Press, New York, 1976.

24. E.F. Adams, "Slip-Cast Ceramics"; pp. 145 - 84 in Refractory materials, $A$ Series of Monographs, Vol. 5-IV. Edited by A.M. Alper. Academic Press, New York, 1971.

25. G.C. Kuczynski, "Self-Diffusion in Sintering of Metallic Particles," Trans. AIME, 85, 169 - 78 (1949).

26. D.L. Johnson, "Solid State Sintering"; pp. 454 - 58 in Concise Encyclopedia of Advanced Ceramic Materials. Edited by R.J. Brook. The MIT Press, Cambridge, MA, 1991.

27. M. Harmer, E.W. Roberts and R.J. Brook, "Rapid Sintering of Pure and Doped $\alpha-$ $\mathrm{Al}_{2} \mathrm{O}_{3}$," Trans. J. Br. Ceram. Soc., 78, 22 - 25 (1979).

28. R.J. Brook, "Fabrication Principles for Production of Ceramics with Superior Mechanical Properties," Proc. Brit. Ceram. Soc., 32, 7 - 24 (1982).

29. D.L. Johnson, "Ultra-Rapid Sintering"; pp. 243 - 252 in Materials Science Research, Vol. 16. Edited by G.C. Kuczynski, A.E. Miller, and G.A. Sargent. Plenum Press, New York, 1984.

30. D.L. Johnson, "Ultra-Rapid Sintering of Cerarnics"; pp. 497 - 506 in Science of Sintering. Edited by D.P. Uskokovic, H. Palmour III, and R.M. Spriggs. Plenum Press, New York, 1989.

31. T.-S. Yeh and M.D. Sacks, "Low-Temperature Sintering of Aluminum Oxide," J. Am. Ceram. Soc., 71 [10] $841 * 44$ (1988).

32. M.K.-F. Lin, "Sintering of the Heterogeneous MgO Compacts," Ph.D. Thesis, University of California at Berkeley, April 1988.

33. M.-Y. Chu, "Sintering Stress and Microstructure in Ceramic Powder Compacts," 
Ph.D. Thesis, University of California at Berkeley, August 1990.

34. H.E. Exner and E. Arzt, "Sintering Process"; pp. 1885 - 1912 in Physical Metallurgy, 3rd. edition. Edited by R.W. Cahn and P. Haasan. Elsevier Science Publishers BV, Amsterdam, Netherlands, 1983.

35. Lord Rayleigh, "On the Instability of Jets," Proc. London Math. Soc., 10, 4 - 13 (1879).

36. F.A. Nichols, "On the Spheroidization of Rod-Shaped Particles of Finite Length," $J$. Mat. Sci., 11, 1077 - 1082 (1976).

37. T.K. Gupta, "Instability of Cylindrical Voids in Alumina," J. Am. Ceram. Soc., 61 [5-6] $191-195$ (1984). 


\section{Chapter 3}

\section{Experimental Procedures}

In this chapter, experimental procedures for powder processing, forming techniques, characterization of green compact, sintering kinetics and microstructural evolution will be described in detail.

\subsection{Starting Materials}

\subsubsection{Undoped Alumina}

To investigate the influence of the homogenization heat treatment on the sintering of $\mathrm{Al}_{2} \mathrm{O}_{3}$, a starting material of very high purity with submicron size and narrow size distribution is essential. [1,2] Commercial high purity $\alpha-\mathrm{Al}_{2} \mathrm{O}_{3}$ powder $(99.995 \%)^{*}$ was used in this experiment. The major impurities were: 9 ppm Si, 9 ppm Fe, $<2$ ppm Na, 3 $\mathrm{ppm} \mathrm{Mg},<1 \mathrm{ppm} \mathrm{Cu}$; the other impurities were less than $5 \mathrm{ppm}$. The as-received powder was specified to have an average particle size of $0.18 \mu \mathrm{m}$ and the particle size distribution was very narrow. The specific surface area was reported to be $10.4 \mathrm{~m}^{2} / \mathrm{g}$. The morphology of the as-received $\mathrm{Al}_{2} \mathrm{O}_{3}$ powder is shown in Figure 3.1. In the preliminary sintering of the powder compact, agglomerates in the as-received powder resulted in a final density lower than the theoretical value of $3.986 \mathrm{~g} / \mathrm{cm}^{3}$. Therefore, the elimination of aggregates and/or hard agglomerates is critical to achieve high density or theoretical density in the sintering of $\mathrm{Al}_{2} \mathrm{O}_{3}$ ceramics.

For the elimination of hard agglomerates and aggregates, $\mathrm{Al}_{2} \mathrm{O}_{3}$ powder was dispersed in deionized water $(18.1 \mathrm{M} \Omega \cdot \mathrm{cm})$ with nitric acid $\left(\mathrm{HNO}_{3}\right)$ added to adjust the $\mathrm{pH}$ value to within 3 - 4. Zeta potential (surface charge) measurement of $\mathrm{Al}_{2} \mathrm{O}_{3}$ particles in a suspension shows that isoelectric point (IEP) is at $\mathrm{pH}=9$ where particle surfaces are neutral. The optimal $\mathrm{pH}$ value for a well-dispersed $\mathrm{Al}_{2} \mathrm{O}_{3}$ suspension was determined to

\footnotetext{
* AKP-50, Sumitomo Chemical America, Inc., New York, NY.
} 
lie in the range of $3-4$. [3,4] A dilute dispersed aqueous suspension of 2 vol\% solid concentration was prepared for the purpose of eliminating agglomerates. An ultrasonic probell was applied to the $\mathrm{Al}_{2} \mathrm{O}_{3}$ suspension for about 10 minutes to break down the soft agglomerates. The remaining hard agglomerates were eliminated by a gravitational sedimentation technique. [5-7] After $29 \mathrm{~h}$ of sedimentation, the slurry was decanted and then flash dried under an infrared lamp while being stirred continuously. Particle size distribution was measured by the centrifugal sedimentation technique based ol the principle of liquid phase photo-sedimentation ${ }^{E}$ with the rotational speed set at $3000 \mathrm{rpm}$. The specific surface area was measured by 5 point nitrogen adsorption $\S \S$. The powder was outgassed at $400^{\circ} \mathrm{C}$ for 4 hours under vacuum prior to surface area analysis. The average particle size after removing aggregates was $0.17 \mu \mathrm{m}$ and the specific surface area was $10.9 \mathrm{~m}^{2} / \mathrm{g}$. As shown in Figure 3.2, the particle size distribution of the powder is very narrow with the geometric standard deviation equal to 1.6 (defined as the ratio $\mathrm{d}_{84.1} / \mathrm{d}_{50}$ ) [7].

The dried powder cake was then lightly ground with mortar and pestle. After passing through a 100 mesh $(126 \mu \mathrm{m})$ nylon sieve, the powders were milled in a plastic jar on a ball mill to produce freely flowing granules. Non-uniform powder filling of the die cavity causes microstructural inhomogeneities in the dry-pressed samples. Granulation is a simple technique to form soft agglomerates in the dry state due to van der Waals forces or surface moisture. The morphology of the granules was uniform and spherical as shown in Figure 3.3. The sizes of the granules ranged from $10 \mu \mathrm{m}$ to $100 \mu \mathrm{m}$. These free flowing granules provided uniform pressed compacts during uniaxial die pressing.

\footnotetext{
I Model W-375, Heat System-Ultrasonics, Inc., Farmingdale, NY.

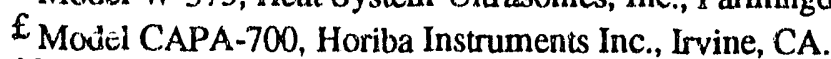

$\S \S$ Digisorb 2600, Micrometrics Instrument Corp., Norcross, GA.
} 


\subsubsection{MgO-Doped Alumina}

To understand the combined effect of $\mathrm{MgO}$ doping and homogenization heat treatment on the sintering behavior of $\mathrm{Al}_{2} \mathrm{O}_{3}, \mathrm{MgO}$-doped $\mathrm{Al}_{2} \mathrm{O}_{3}$ was subjected to a homogenization heat treatment before the sintering step. The MgO-doped material was produced by mixing $\mathrm{Al}_{2} \mathrm{O}_{3}$ powder with de-ionized water and $\mathrm{Mg}\left(\mathrm{NO}_{3}\right)_{2} \cdot 6 \mathrm{H}_{2} \mathrm{O}$ to introduce $250 \mathrm{ppm} \mathrm{MgO}$. The slurry was flash dried and prepared using the same procedure as for the undoped $\mathrm{Al}_{2} \mathrm{O}_{3}$ powders. Calcination of the doped- $\mathrm{Al}_{2} \mathrm{O}_{3}$ was carried out on powder compacts heated at $1^{\circ} \mathrm{C} / \mathrm{min}$. to $600^{\circ} \mathrm{C}$ and soaked for 1 hour. This calcination was done after powder compaction to reduce the possibility of reforming aggregates due to the fine particle size of the $\mathrm{Al}_{2} \mathrm{O}_{3}$ powder.

\subsection{Consolidation Techniques}

Sedimentation is one of the most simple techniques to remove agglomerates but subsequent drying of the slurry will introduce new agglomerates. One way to avoid drying the suspension before forming is by slip casting. Another method to reduce the degree of agglomeration is by using cold isostatic pressing at very high pressure, since isostatic pressing has been shown to improve the packing homogeneity. The green density reaches about $61 \%$ of theoretical for both forming methods.

In the present research, to study the effect of the particle packing, green density, and homogenization heat treatment on microstructural evolution, $\mathrm{Al}_{2} \mathrm{O}_{3}$ powder compacts were prepared by slip casting and ultra-high pressure isostatic pressing\# (maximum pressure $\approx 1380 \mathrm{MPa}$ ) to various densities. Compacts formed by uniaxial dry pressing were also used to address the effect of heterogeneity on the final microstructures

§ EM Industries Inc., Gibbstown, NJ.

\# Isostatic press, Materials Sciences Division, Lawrence Berkeley Laboratory, Berkeley, CA. 
of both conventional and hon. sgenized specimens. The forming techniques used in this research are described as follows.

\subsubsection{Uniaxial Dry Pressing}

Dry pressing is the most common forming technique used to consolidate powders into a desired shape. Disc shaped specimens $(6.35 \times 6.20 \mathrm{~mm})$ were prepared by the uniaxial dry pressing technique. The amount of powder was about $0.45 \mathrm{gm}$. The 6.35 mm-diameter WC-Co die was lubricated with a solution of steric acid in acetone before each compaction. The compacts were formed by dry pressing the granules on a laboratory press $^{* *}$ at $50 \mathrm{MPa}$ for 30 seconds. The density of the green bodies after die pressing was $\approx$ 0.53 of theoretical density. A duplicate set of specimens was prepared for subsequent isostatic pressing.

\subsubsection{Cold Isostatic Pressing}

In order to break down agglomerates formed during drying and to avoid a complex rearrangement of particles during the initial stage of sintering, green compacts formed by dry pressing were subsequently isostatically pressed at pressures up to 1380 $\mathrm{MPa}(200 \mathrm{ksi})$. Isostatic pressing not only. decreases the size of large pores but also reduces pore coordination number. $[8,9]$ A powder compact with a very high green density is expected to contain a higher fraction of pores with smaller pore coordination numbers when very high isostatic pressure is applied. Compacts made by uniaxial die pressing were vacuum sealed in balloon bags and isostatically pressed at maximum pressure for 3 minutes. Green density reached about $0.60 \pm 0.01$ of theoretical density for this narrow-sized powder. The increase in green density by the subsequent isostatic pressing is mainly due to the elimination of large interagglomerate pores which are formed during granulation. The removal of such large pores $(\approx 10 \mu \mathrm{m})$ decreases the

\footnotetext{
** Model C, Carver Laboratory Press, Menomonee Falls, WI.
} 
microstructural inhornogeneities and increases the final relative density (from 0.975 to > 0.99 of theoretical density).

\subsubsection{Slip Casting}

Slip casting is a forming method which directly consolidates powder from a welldispersed slurry. $[10,11]$ It has been reported that homogeneous green compacts can be produced by the slip casting technique. $[12,13]$ Green compacts formed by slip casting were compared with those formed by isostatic pressing. Aqueous suspensions were prepared by the same procedure as in the previous section with $\mathrm{pH} \approx 3.5$ and a solid content $\approx 40$ vol\%. The slurry was continuously poured into molds, made of plastic templates placed on the top of a block of plaster of Paris, until a solid sample was formed. Samples were dried at room temperature for 24 hours and then removed from the molds. The green density of the slip cast sample was about $0.61-0.63$ of theoretical density. The variance in green density was attributed to differences in the plaster mold and slurry conditions. However, the values were close to the green density of the samples made by isostatic pressing. The final microstructure of sintered $\mathrm{Al}_{2} \mathrm{O}_{3}$ would be significantly affected by different consolidation techniques as presented by Roosen and Bowen. [14] The reason is that the very large interagglomerate pores, formed by the incomplete deformation of granules in dry-pressed powder compact, could not be eliminated easily during sintering. All the green cumpacts were subjected to a heat treatment at $450^{\circ} \mathrm{C}$ for 1 hour to burn off any residual organics from the forming stage. The heating rate was kept as low as $0.5^{\circ} \mathrm{C} / \mathrm{min}$. to ensure complete removal of organics.

\subsection{Homogenization Heat Treatment}

From preliminary tests, densification was observed to start at $\approx 980^{\circ} \mathrm{C}$ under the constant heating rate of $4^{\circ} \mathrm{C} / \mathrm{min}$. to $1450^{\circ} \mathrm{C}$ in the dilatometer ${ }^{\dagger+}$. It was therefore

\footnotetext{
†† Harrop Industries, Inc., Columbus, $\mathrm{OH}$.
} 
determined that $800^{\circ} \mathrm{C}$ could be used to homogenize the powder compacts for different soaking duration (typically 50 hours) without detectable densification. The schedule of the homogenization heat treatment (temperatures and times) was varied to attain high density and fine-grained $\mathrm{Al}_{2} \mathrm{O}_{3}$. Combinations of temperature $-800^{\circ} \mathrm{C}, 900^{\circ} \mathrm{C}$, and $1000^{\circ} \mathrm{C}$, - and soaking duration - ranging from 25 hours to 200 hours were used. There was negligible deisitication at temperatures of $800^{\circ} \mathrm{C}$ and $900^{\circ} \mathrm{C}$ for prolonged soaking time. For the $1000^{\circ} \mathrm{C} / 25 \mathrm{~h}$ homogenization heat treatment, the density of the compact was found to increase about $2 \%$.

\subsection{Characterization of Pnwder Compacts}

To determine the effect of the homogenization heat treatment on the green microstructure and pore size distribution, sarnples were characterized by SEM of fracture surfaces and by mercury porosimetry 9 , respectively. Pore size distributions for both conventional and $800^{\circ} \mathrm{C} / 50 \mathrm{~h}$ homogenized samples were measured The pore diameter was determined from the pressure of intrusion by using the Washburn equation and assurning a contact angle of $130^{\circ}$ and a surface tension of $485 \mathrm{dyn} / \mathrm{cm}^{2}$. The volume distribution curves were calculated by taking the derivative of volume intruded with respect to the pore diameter.

A four-point bending strength test was conducted to reveal the difference in strength between conventional and homogenized samples. After homogenization heat treatment at $800^{\circ} \mathrm{C}$ for $50 \mathrm{~h}$ the strength of the powder compacts was sigrificantly improved compared with the conventionally processed compacts. The increase in strength was related to the neck formation and growth between particles during heat treatment. Rectangular testing pieces $552.5 \times 1.0 \mathrm{~mm}$ were prepared by the slip casting method. All specimens were heated at $1^{\circ} \mathrm{C} / \mathrm{min}$. to $400^{\circ} \mathrm{C}$ for 60 minutes to bum out organics. One

TI. Autopore 9220, Micrometrics Insinument Corp., Norcross, GA. 
set of specimens was homogenization heat treated at $800^{\circ} \mathrm{C}$ for 50 hours. Specimens were polished with $\mathrm{SiC}$ grinding papers down to $12 \mu \mathrm{m}$. The four-point bending strength test was performed on an Instron universal testing machine $d c$ at a cross-head speed of 0.5 $\mathrm{mm} / \mathrm{min}$. The flexural strength of four-point flexing $\left(\sigma_{b 4}\right)$ can be calculated from

$$
\sigma_{b 4}=\frac{3 P(L-U)}{2 w t^{2}}
$$

where $P$ : maximum load at fracture of test piece (kgf)

$\mathrm{L}:$ distance between lower supporting points $(19.5 \mathrm{~mm})$

$\mathrm{U}$ : distance between upper loading points $(6 \mathrm{~mm})$

w : width of test piece $(\mathrm{mm})$

$\mathrm{t}:$ thickness of the test piece $(\mathrm{mm})$

\subsection{Sintering Schedules}

Along with changing the homogenization heat treatment conditions, the sintering schedule was also varied to test the effectiveness of the homogenization heat treatment. Different sintering experiments were performed for comparison.

\subsubsection{Constant Heating Rate Sintering}

Sintering was carried out in a dilatometer under a constant heating rate of $4^{\circ} \mathrm{C} / \mathrm{min}$. in a temperature range from $800^{\circ} \mathrm{C}$ to $1450^{\circ} \mathrm{C}$ in air. Two sets of specimens were sintered under the same conditions, one was conventionally processed and the other was homogenized. Specimens were heated from $300^{\circ} \mathrm{C}$ to $800^{\circ} \mathrm{C}$ at $10^{\circ} \mathrm{C} / \mathrm{min}$. The changes in length of the specimen were monitored by a personal computer and the relative shrinkage $\left(\Delta \mathrm{L} / \mathrm{L}_{0}\right)$ of the specimen was calculated, taking into account the

C\$odel 1122, Instron Corp., Canton, MA. 
thermal expansion of the specimen holder and the specimen itself. The tinal density of the sintered specimen was measured by the Archimides principle with deionized water as the medium.

To study the microstructural evolution of both sets of specimens during sintering, conventional and homogenized samples were sintered to different final temperatures between $800^{\circ} \mathrm{C}$ and $1450^{\circ} \mathrm{C}$ at the same heating rate of $4^{\circ} \mathrm{C} / \mathrm{min}$. The relative densities as well as the open and closed porosities of these samples were measured by the Archimedes method in deionized water.

For $\mathrm{MgO}$-doped $\mathrm{Al}_{2} \mathrm{O}_{3}$ samples, sintering was carried out in an Orton dilatometer ${ }^{\infty}$ to final tempcratures of $1450^{\circ} \mathrm{C}, 1500^{\circ} \mathrm{C}$, and $1550^{\circ} \mathrm{C}$ at different heating rates $\left(4,5\right.$, and $12^{\circ} \mathrm{C} / \mathrm{min}$.) with and without soaking at final temperatures. This was done for the purpose of studying the effect of sintering schedule on the final microstructure of homogenized as well as conventional samples.

\subsubsection{Fast Firing}

Fast firing to high temperatures and soaking for very short periods of time are used to reduce the grain size of $\mathrm{Al}_{2} \mathrm{O}_{3}$ ceramics. [15,16] To investigate whether homogenization heat treatment still improves microstructure and final density under fast firing conditions, both conventional and homogenized samples were fast fired. Fast firing was carried out at a heating rate of $340^{\circ} \mathrm{C} / \mathrm{min}$. from room temperature to $1750^{\circ} \mathrm{C}$ and then the samples are held for 5 minutes under vacuum $\left(1 \times 10^{-5}\right.$ torr) in a tungsten mesh furnace. After firing, samples were furnace cooled at a cooling rate $>50^{\circ} \mathrm{C} / \mathrm{min}$. Final density and grain size were measured for these samples.

\subsection{Microstructural Observation}

\footnotetext{
${ }^{\infty}$ Model 1600D, Oron, Edward Jr., Ceramic Foundation, Westerville, OH.
} 
Final relative sintered density was measured by the Archimedes method with deionized water. In order to study microstructural evolution over a wide density range, specimens with low density (65 - $85 \%$ of theoretical density) were impregnated with epoxy to fill the pores before polishing. High density samples were mounted in transparent epoxy for grinding and polishing. Grinding was done with successively finer diamond wheels and final polishing was accomplished with diamond pastes down to 0.25 $\mu \mathrm{m}$. After the specimens were polished, they were removed from the epoxy mount and thermally etched in air at $1280^{\circ} \mathrm{C}$ for 1 hour to reveal grain boundaries. Surfaces of the samples were coated with Au/Pd before being examined by scanning electron microscope $(\mathrm{SEM})^{\dagger}$. Grain size was measured by the linear intercept method. $[17,18]$ For the calculation of grain size, more than 500 grains were measured on each sample.

\subsection{Sintering Kinetics}

The densification strain, $\varepsilon_{\rho}$, is directly related to the axial strain, $\varepsilon_{z}$, and radial strain, $\mathcal{E}_{\mathrm{r}}$, of the specimen since the shrinkage is nearly isotropic. Densification strain is then equal to the axial strain, $\varepsilon_{z}$

$$
\varepsilon_{\rho}=\varepsilon_{\mathrm{r}}=\varepsilon_{\mathrm{z}}=\ln \left(\frac{\mathrm{L}}{\mathrm{L}_{\mathrm{o}}}\right)
$$

where $L_{0}$ is the length of the sample before sintering, and $L$ is the instantaneous length of the sample that was recorded during the sintering process. Instantaneous sintered density, $\rho$, was calculated from final sintered density, $\rho_{\mathrm{f}}$ (measured by the Archimedes method), and $L_{f}$, the final length of the sample:

$$
\rho=\rho_{\mathrm{f}} \cdot\left(\frac{\mathrm{L}_{\mathrm{f}}}{\mathrm{L}}\right)^{3}
$$

\footnotetext{
† ISI-DS 130, International Scientific Instruments Inc., Pleasanton, CA.
} 
Furthermore, the densification strain rate is the time derivative of densification strain. We have

$$
\dot{\varepsilon}_{\rho}=\frac{d \varepsilon_{\rho}}{d t}=\frac{d \varepsilon_{\rho}}{d T} \cdot \frac{d T}{d t}
$$

where $\frac{\mathrm{dT}}{\mathrm{dt}}=$ heating rate $\left(4^{\circ} \mathrm{C} / \mathrm{min}\right.$ used for the sintering of undoped $\mathrm{Al}_{2} \mathrm{O}_{3}$ and $5^{\circ} \mathrm{C} / \mathrm{min}$. for $\mathrm{MgO}$-doped $\mathrm{Al}_{2} \mathrm{O}_{3}$.).

The densification strain, sintered density, and densification strain rate as a function of temperature were plotted for both conventional and homogenized samples.

\section{References (For Chapter 3)}

1. A. Roosen, S. Sumita and H.K. Bowen, "Powders, Interfaces, and Processing: Alumina as a Case Study": pp. 433 - 46 in Ceramic Microstructure '86: Role of Interfaces, Material Science Research, Vol. 21. Edited by J.A. Pask and A.G. Evans. Plenum Press, New York, 1987.

2. E.A. Barringer and H.K. Bowen, "Ceramic Powder Processing," Ceramic Engineering and Science Proceedings, pp. 285 - 97, May-June (1984).

3. M.D. Sacks, H.W. Lee, and O.E. Rojas, "Suspension Processing of $\mathrm{Al}_{2} \mathrm{O}_{3} / \mathrm{SiC}$ Whisker Composites," J. Am. Ceram. Soc., 71 [5] 370 - 79 (1988).

4. T. Ximura, Y. Matsuda, M. Oda, and T. Yamaguchi, "Effects of Agglomerates on the Sintering of Alpha- $\mathrm{Al}_{2} \mathrm{O}_{3}$," Ceramics International, 13 [1] 27 - 34 (1987).

5. M. Parish and H.K. Bowen, "Narrow Size Distribution Powders from Commercial Ceramic Powders," Ceramics International, 10 [2] 75 - 77 (1984).

6. "T.R. Gattuso and H.K. Bowen, "Processing of Narrow Size Distribution Alumina"; pp. 644 - 55 in Advances in Ceramics, Vol. 10. Edited by W.D. Kingery. American Cerarnic Society, Columbus, OH, 1984. 
7. J.S. Reed, Introduction to the Principle of Ceramic Processing, Chapter 7; John Wiley \& Sons, New York, 1988.

8. J.S. Reed and R.B. Runk, "Dry Pressing"; pp. 71 - 93 in Treatise on Materials Science and Technology, Vol. 9, Ceramic Fabrication Process. Edited by F.F.Y. Wang. Academic Press, New York, 1976.

9. F.F. Lange, "Sinterability of Agglomerated Powders," J. Am. Ceram. Soc., 67 [2] 83 -89 (1984).

10. C.P. Cameron and R. Raj, "Grain Growth Transition During Sintering of Colloidally Prepared Alumina Powder Compacts," J. Am. Ceram. Soc., 71 [12] 1031 - 35 (1988).

11. R.E. Cowan, "Slip Casting"; pp. 153 - 71 in Treatise on Materials Science and Technology, Vol. 9, Ceramic Fabrication Process. Edited by F.F.Y. Wang. Academic Press, New York, 1976.

12. E.F. Adams, "Slip-Cast Ceramics"; pp. 145 - 84 in Refractory Materials, A Series of Monographs, Vol. 5 - IV. Edited by A.M. Alper. Academic Press, New York, 1971.

13. T.-S. Yeh and M.D. Sacks, "Effect of Green Microstructure on Sintering of Alumina"; pp. 309 - 31 in Ceramic Transaction, Vol. 7, Sintering of Advanced Ceramics. Edited by C.A. Handwerker, J.E. Blendell, and W. Kaysser. American Ceramic Society, Westerville, OH, 1990.

14. A. Roosen and H.K. Bowen, "Influence of Various Consolidation Techniques on the Green Microstructure and Sintering Behavior of Alumina Powders," J. Am. Ceram. Soc., 71 [11] 970 - 77 (1988).

15. M. Harmer, E.W. Roberts and R.J. Brook, "Rapid Sintering of Pure and Doped $\alpha$ $\mathrm{Al}_{2} \mathrm{O}_{3}$," Trans. J. Br. Ceram. Soc., 78, 22 - 25 (1979).

16. D.L. Johnson, "Ultra-Rapid Sintering"; pp. 243 - 252 in Materials Science Research, Vol. 16. Edited by G.C. Kuczynski, A.E. Miller, and G.A. Sargent. Plenum Press, New York, 1984. 
17. M.I. Mendelson, "Average Grain Size in Polycrystalline Ceramics," J. Am. Ceram. Soc., 52 [8] 443 - 46 (1969).

18. J.C. Wurst and J.A. Nelson, "Lineal Intercept Technique for Measuring Grain Size in Two-Phase Polycrystalline Ceramics," J. Am. Ceram. Soc., 55 [2] 109 (1972). 


\section{Chapter 4}

\section{Results and Discussion}

\subsection{Undoped Alumina}

\subsubsection{Effects of Homogenization Heat Treatment}

\subsubsection{Microstructure}

A homogenization heat treatment at $800^{\circ} \mathrm{C}$ for 50 hours does not change the density of the $\mathrm{Al}_{2} \mathrm{O}_{3}$ powder compacts. Figure 4.1 compares the unfired fracture surfaces of the conventional (no heat treatment) and the homogenized samples. There is a small increase in the average particle size due to the homogenization heat treatment, but the actual value is laborious to assess from scanning electron micrographs of the fracture surfaces. Neck growth between particles makes it impossible to distinguish the original shape of particles after the homogenization heat treatment. From Figure 4.1(b), the rounding-off of edges and corners of the $\mathrm{Al}_{2} \mathrm{O}_{3}$ particles by heat treatment at $8000^{\circ} \mathrm{C}$ for 50 hours can be seen clearly. No grain boundary is observed directly from the fracture surfaces without thermal etching, but a dihedral angle is observed when two particles contact and form a neck. Grain boundaries would likely stay in the neck regions to minimize the total free energy of the system. This is the evidence for non-densifying mass transport as the dominant mechanism for the formation of necks with grain boundaries in between particles.

The change of pore structure by the homogenization heat treatment is a very important factor in controlling the subsequent sintering kinetics and microstructural evolution of the powder compacts. Unfortunately the variation in pore size and pore size distribution in the powder compacts cannot be seen directly from scanning electron micrographs because of the convoluted pore structure (Figure 4.1). 
Another feature seen in the scanning electron micrographs is that very fine particles are eliminated after the homogenization heat treatment. As a result of the negligible densification of powder compacts, it is believed that the very fine particles disappeared through a surface diffusion mechanism active at low temperatures. The elimination of very fine particles may have an important effect on the variation of the pore structure (pore size and pore size distribution). Although the relationship between the elimination of very fine particles by non-densifying mechanisms and later densification kinetics is not yet understood, it can be correlated with the delay of the densification onset temperature. If the disappearance of very fine particles is accomplished by densifying mechanisms during the sintering process then it would contribute to shrinkage as in the case of samples sintered conventionally. Furthermore, the onset temperature for densification of the homogenized samples $\left(\approx 1000^{\circ} \mathrm{C}\right)$ is raised $50^{\circ} \mathrm{C}$ above that of the conventional sample $\left(\approx 950^{\circ} \mathrm{C}\right)$.

\subsubsection{Surface Area and Pore Structure}

BET measurements show that there is a substantial amount of reduction in surface area by the homogenization heat treatment. The conventional and homogenized powder compacts were out-gassed at $400^{\circ} \mathrm{C}$ for 5 hours under vacuum prior to the BET analysis. The specific surface area decreased from 10.9 to $7.8 \mathrm{~m}^{2} / \mathrm{g}$ after the homogenization heat treatment at $800^{\circ} \mathrm{C}$ for 50 hours. The reduction in surface area suggests that the driving force for sintering is diminished and hence densification is suppressed by the homogenization heat treatment. However, the pore volume of the conventional sample is roughly twice as large as the homogenized sample $-0.04 \mathrm{vs} 0.02 \mathrm{cc} / \mathrm{g}$. The decrease in pore volume in the homogenized sample is so significant that the compacts are modified toward higher driving force for densification. Actually, the results of final density, microstructure, and densification kinetics clearly show that the homogenization heat treatment results in better sintering behavior. In contrast to the data already existing in the 
literature, the homogenization heat treatment at a low temperature where non-densifying mechanisms predominate offers an alternative route for the manufacture of better $\mathrm{Al}_{2} \mathrm{O}_{3}$ ceramics.

\subsubsection{Driving Force for Sintering}

The critical issues in determining the driving force for densification come from the contributions of curvature of pore and grain size (or particle size) as indicated by Raj. [1] The sintering stress (or sintering pressure) is expressed as:

$$
\Sigma=\frac{2 \gamma_{\mathrm{b}}}{\mathrm{G}} \pm \frac{2 \gamma_{\mathrm{s}}}{\mathrm{r}_{\mathrm{p}}}
$$

where $\Sigma$ is the sintering stress, $\gamma_{b}$ the free energy of the grain boundary, $\gamma_{s}$ the surface free energy, $G$ the particle size, and $r_{p}$ the radius of curvature of the pore. Although the analysis is complicated by the presence of positive and negative curvatures of pores in the real powder compacts, it is recognized that surface energy, grain boundary energy, dihedral angle, and pore coordination number are important parameters that govern the sintering driving force. The reduction of specific surface area alone cannot predict the extent of the reduced driving force for sintering and densification kinetics. In most cases the average particle size and surface area are not the critical factors controlling the driving force for sintering because a small average particle size may reflect a wide size distribution and particles with a very irregular surface may have a large surface area.

There is no detailed study on the relationship between driving force, surface area reduction, microstructure and temperature history of powder compacts. It has been frequently stated that coarsening at a low temperature for prolonged periods will be harmful to the final microstructure. [2] Optimization of the sintering schedule is then reported to result in heating up the powder compacts rapidly to pass through the low 
temperature ranges. Techniques such as fast firing, ultra-rapid sintering, and controlledrate sintering have been effective in refining the grain size in $\mathrm{Al}_{2} \mathrm{O}_{3}$ ceramics. However, the effects of a low temperature heat treatment on microstructure was published recently by $\mathrm{Chu}$, et al. [3] Their results show that the driving force for sintering (sintering stress) is slightly decreased by a low temperature heat treatment, while the microstructure is significantly improved. The difference in sintering behavior caused by various sintering schedules is strongly dependent on the pore structure and pore elimination during the sintering process. Studies of the role of pore structure and its effects on the sintering of powder compacts are concentrated on the evolution of the pore network into isolated pores during the later stages of sintering. $[4,5]$ The complicated nature of pore network makes it difficult to model the effects of sintering variables on microstructural evolution. However, Whittemore, et al. [6] pointed out that the evolution of the pore structure could be revealed by mercury porosimetry especially in the early and intermediate stages of sintering. By fixing a consolidation technique for the formation of powder compacts, microstructural evolution during different sintering paths can be monitored through the evolution of the pore structure by mercury porosimetry. From the SEM micrographs in Figure 4.1 , it is apparent that pore size ranged form submicron to several micrometers. The most substantial effect of the homogenization heat treatment is that the pore size distribution becomes narrower.

\subsubsection{Effects of Homogenization Temperature}

The temperature for the homogenization heat treatment of a powder compact is deduced from the densification vs. temperature curve for a constant heating rate of $4^{\circ} \mathrm{C} / \mathrm{min}$. to $1450^{\circ} \mathrm{C}$. Shrinkage of the conventional powder compact starts at about $950^{\circ} \mathrm{C}$. The homogenization heat treatment of $800^{\circ} \mathrm{C}, 900^{\circ} \mathrm{C}$, and $1000^{\circ} \mathrm{C}$ were used for dwelling times of 25 and 50 hours. No density change can be detected for powder compacts homogenized at the following conditions: $800^{\circ} \mathrm{C} / 25 \mathrm{~h}, 800^{\circ} \mathrm{C} / 50 \mathrm{~h}, 900^{\circ} \mathrm{C} / 25 \mathrm{~h}$. 
Only the samples homogenized at $1000^{\circ} \mathrm{C} / 25 \mathrm{~h}$ increase their densities from $0.61 \pm 0.01$ to $0.64 \pm 0.01$ of theoretical density. Shrinkage of the powder compact after the homogenization heat treatment at $1000^{\circ} \mathrm{C} / 25 \mathrm{~h}$ can be readily measured. The sintering behavior of samples homogenized at different conditions is only slightly affected by the temperature of homogenization. The higher the temperature of the homogenization heat treatment, the greater the delay in the onset temperature for densification. However, the final microstructure of homogenized samples does not change significantly.

\subsubsection{Pore Size Distribution}

The variation of pore size distribution obtained by mercury porosimetry as a function of pore diameter is presented in Figure 4.2. With the maximum applied pressure of $412 \mathrm{MPa}$, the pore diameter that can be intruded with mercury is $0.003 \mu \mathrm{m}$. As shown from the plot, pores with very small diameter are eliminated and the median pore diameter is shifted to a larger value (from $0.0438 \mu \mathrm{m}$ to $0.0527 \mu \mathrm{m}$ ) by the homogenization heat treatment. Another important feature of Figure 4.2 is a bimodal distribution of the pore size in the conventional powder compact, but there is only one peak in the distribution curve of the homogenized sample. The total pore area measured for the conventional and the homogenized. samples is $17.118 \mathrm{~m}^{2} / \mathrm{g}$ and $14.231 \mathrm{~m}^{2} / \mathrm{g}$, respectively.

It is clear that the homogenization heat treatment eliminates small pores and, thereby, reduces the total pore area of the powder compacts. This effect may result directly from the particle size increase during the homogenization heat treatment, since pore size is generally proportional to the particle size. However, there are as yet no data available which prove an increase of particle size by the treatment. Another explanation for the shift in pore size distribution to a larger value may be that neck formation in threedimension prevents access of the mercury into small pores. The SEM micrographs reveal 
that some closed pores formed after the treatment, but only trace amounts can be counted. It is reasonable to expect that the possibilities discussed above may occur simultaneously.

Careful powder processing to attain a high density, uniform microstructure in the sintered material through an optimal narrow pore size distribution in the green body has been demonstrated. [7,8] The importance of a homogeneous pore size distribution on the sintering process (densification and grain growth) has been the subject of several publications. [9-11] The relationship between pore size distribution and shrinkage has been examined by Carbone and Reed. [12] They find that the intermediate and the final stage shrinkage is strongly affected by the pore structure in the powder compact. Recently, Roosen and Hausner [13] have shown that the curves of the pore size distribution and the densification rate curves are similar in appearance. For a bimodal pore size tistribution in a powder compact, each pore size r quires a certain temperature for its elimination. More recently, Roosen and Bowen [14] also point out that low temperature sintering of $\mathrm{Al}_{2} \mathrm{O}_{3}$ ceramics without the addition of $\mathrm{MgO}$ as a sintering aid is possible if the compact is homogeneous with very small pores uniformly distributed.

Yeh and Sacks [15] prepared a very homogeneous $\mathrm{Al}_{2} \mathrm{O}_{3}$ powder compact by the slip casting method and achieved a sintered product with density $>0.99$ of theoretical density by sintering at $1150^{\circ} \mathrm{C}$ for 5 hours. The ordinary consolidation techniques, such as the dry pressing technique, cannot produce a homogeneous powder compact with uniform pore size distribution. Non-traditional techniques and careful powder processing appears to be the best route for producing a homogeneous green microstructure. However, as demonstrated by Chu, et al., [3] the homogenization of heterogeneous $\mathrm{MgO}$ and $\mathrm{ZnO}$ powder compacts and subsequent sintering (i.e., two-step sintering) effectively homogenizes the powder compacts and gives a better fired microstructure than formed in conventionally sintered compacts. This approach is an economical and simple treatment 
to improve the microstructure of most conventionally formed powder compacts without resorting to colloidal consolidation techniques.

\subsubsection{Flexural Strength of the Green Body}

The as-formed powder compact before heat treatment is so fragile that the strength cannot be measured in the testing machine. However, its strength can be approximated by using the weight of the testing fixture to break the test pieces. The estimated strength of the conventional sample is less than $0.9 \mathrm{MPa}$. Moreover, the fourpoint flexural strength for the $800^{\circ} \mathrm{C} / 50 \mathrm{~h}$ homogenized sample reaches $43.2 \pm 2.3 \mathrm{MPa}$ (average of 8 specimens). When the flexural strengths of the as-formed and the $800^{\circ} \mathrm{C} / 50$ $\mathrm{h}$ homogenized samples (before sintering) were compared, the enhancement of strength is significant. The strength of the homogenized powder compacts is 50 times as large as the strength of the as-formed samples. The increase in strength of the powder compacts by the homogenization heat treatment results from neck formation and growth among particles into a 3-dimensional network. The redistribution of material over the surface by surface diffusion and/or evaporation/condensation will not result in shrinkage of the compact but can increase strength by increasing contact areas and reducing the notch effect of sharp pore contours. [16]

The homogenization heat treatment also provides sufficient strength to resist differential densification during the subsequent sintering process. In a statistical study of a two-dimensional raft of copper spheres, Weiser and De Jonghe [17] found that differential densification resulted in particle rearrangement. In a real powder compact local packing variations, nonuniform particle size and packing may cause pronounced rearrangement. The regions that densify rapidly will exert tensile stresses on neighboring slow-densifying regions. If the differential densification is large enough, some pores will

grow rather than shrink. Evans [18] has shown that the stresses induced by inhomogeneous densification may be large enough to open cracks. Therefore differential 
densification can have a profound influence on the microstructural evolution and densification rate. The more homogeneous the green microstructure, the less the undesirable effects of differential densification will be imposed on the fired microstructure.

\subsubsection{Pore Coarsening and Sintering}

Prochazka and Coble [19] have shown that only surface diffusion contributes to neck growth during the initial stage of sintering of $\mathrm{Al}_{2} \mathrm{O}_{3}$ powder compacts at $750^{\circ} \mathrm{C}$ to $900^{\circ} \mathrm{C}$. From the study of grain growth in very porous $\mathrm{Al}_{2} \mathrm{O}_{3}$ compacts, Greskovich and Lay [20] also concluded that surface diffusion is the primary mechanism for neck growth. Densifying mechanisms such as volume diffusion and grain boundary diffusion do not contribute to neck growth during the homogenization heat treatment at $800^{\circ} \mathrm{C}$ for 50 hours. It is also noted from SEM micrographs (Figure 4.1) that a very small particle is not located between two large particles, but it sits on the surfaces of particles or among a few large particles.

One important feature concerning densification during the sintering process is that the interconnected pore channels gradually becomes isolated as the density increases with sintering temperature or time. The complex nature of the interconnected pore channel network in real powder compacts makes the modeling of pore channel decay difficult and unrealistic because of the necessity for modeling the pore channel as an ideal cylinder with a definite diameter. The elimination of very fine particles by the homogenization heat treatment could be interpreted that the extent of pore channel's pinch-off can be delayed by the enlargement of pore diameter (see Section 4.1.1). As sintering proceeds, the pore channels decrease in average diameter. Uniform diameter pore channels are unstable and can pinch off during the sintering process. The kinetics of pore channel pinch-off depend on many variables such as mass transport mechanism, dihedral angle of 
the system and, most critically, the initial diameter of the pore channel. Under identical conditions, the larger the diameter of the pore channel, the slower is the pore channel pinch-off. Early closure of the pore channel during the initial stages of sintering due to nonuniform pore diameter will promote an uneven distribution of isolated pores in the later stages of sintering.

Very fine particles may make the kinetics of pore channel closure faster by increasing the nonuniformity of the pore cylinder diameter. In the homogenized sample the elimination of very fine particles provides a pore channel with a more uniform and larger diameter which delays the pore channel pinch-off to later stages of sintering. Therefore more uniform and smaller isolated pores could be generated. As can be demonstrated later from the densification rate of the conventional and the homogenized samples, the onset temperature of densification of the homogenized sample is delayed and the maximum densification rate is higher and shifted to higher temperatures.

\subsubsection{Modeling of Pore Coarsening}

The densification of clusters of fine particles and of more dense regions with isolated pores formed early in the sintering process will raise the problem of differential densification. The elimination of very fine particles reduces the extent of local differential densification during the early stages of sintering, thereby, promoting uniform densification of the powder compact at higher temperatures. The elimination of very fine particles during the homogenization heat treatment is believed to influence the pore size distribution which in turn changes the kinetics of densification and the final microstructure of sintered $\mathrm{Al}_{2} \mathrm{O}_{3}$. Particle packing can also affect the pore size and pore size distribution. Ceramic powder always has a continuous particle size distribution. For powders with a wide particle size distribution or a bimodal particle size distribution, if the interparticle voids can be filled with small particles, the packing density can be increased. Yet, particle packing may be nonuniform, hence the voids formed during powder 
consolidation cannot be filled completely. The variations in particle packing, strongly dependent on the method of powder consolidation, leads to a wide distribution of pore size in powder compacts. The spatial distribution of porosity affects the diffusion distance and therefore controls the rate of pore elimination. [21] Consequently, a limiting endpoint density and a microstructure with varied grain size will result from such an inhomogeneous pore size distribution.

By facilitating pore structure modification, the homogenization heat treatment may play an important role in controlling the pore size distribution of powder compacts. The pore structure can be simply modeled in two-dimensions with a close packing of three spheres having radius $=D$. The radius, $d$, of the interparticle pore formed by the three large recking particles is calculated by simple geometry to be $0.1547 \cdot \mathrm{D}$. As shown in Figure 4.3, if a small particle with a radius $d$ is to just fill in the pore then, the radius ratio of large particles to small particles should be $D / d \approx 6.5$. The powder used in this work (particle size in the range of $0.01-0.70 \mu \mathrm{m}$ from Figure 2.2) satisfies this condition.

When the particle array is homogenized at $800^{\circ} \mathrm{C}$ for 50 hours, the small particles are unstable owing to the difference in the radius of curvature between large and small particles. The small $\mathrm{Al}_{2} \mathrm{O}_{3}$ particle then disappears by a surface diffusion mechanism. In addition, neck formation among the large particles will produce a pore having radius of curvature $R=d=0.1547 \cdot \mathrm{D}$. In contrast, if the particle array is directly sintered to high temperatures, the small particle is stable against disappearance by surface diffusion and necks will be formed between these large and small particles. Hence, the radius of the three pores formed by these four particles is calculated to be $r=0.065 \cdot D$. [22] Then, the ratio of the radii of the pores in the homogenized and the conventional particle arrays $R / r$ $=0.1547 / 0.065=2.4$; the size of the pore in the homogenized array is then 2.4 times that formed in the conventional array. The pore diameter enlargement by the homogenization 
heat treatment has been verified by mercury porosimetry. The median pore diameter measured has been shifted to a larger value (see Figure 4.2) by the homogenization heat treatment at $800^{\circ} \mathrm{C}$ for 50 hours.

In the conventional samples, small pores are eliminated in the locally densified regions and large pores become even larger due to differential densification which, in turn, promotes the inhomogeneity of pore size distribution significantly. The enlargement of pore size by the homogenization heat treatment may also reduce the local densification rates between regions of inhomogeneities. The densification kinetics shifted to higher temperatures and with higher maximum densification rate due to the homogenization heat treatment are resulted from the more homogeneous pore structure produced.

\subsubsection{Homogenization Heat Treatment on Sintering}

\subsubsection{Density and Microstructure}

Microstructures of the conventional and the homogenized samples sintered in air at a constant heating rate of $4^{\circ} \mathrm{C} / \mathrm{min}$. to $1450^{\circ} \mathrm{C}$ without soaking are shown in Figure 4.4 . As presented in the micrographs, the average final grain size is significantly reduced in the homogenized sample. Also noted from the micrographs is the frequent occurrence of large grains and some elongated grains in the conventional sample while for the homogenized sample, grain size is refined and very large grains are rarely found. The largest grain in the conventional sarnple is about 2 times larger than the largest grain in the homogenized sample. In addition, the presence of a few small grains indicates that grain size distribution is very wide in the conventional sample, that is, the microstructure is very nonuniform. From the micrographs shown in Figure 4.5 the distribution of grain sizes in the conventional sample is much wider than for the homogenized sample. The standard deviation of grain size should be measured by an image analyzer but no data are available in the present study. However comparison of the microstructures in Figure 4.4 
and Figure 4.5 gives a qualitative indication of when the sample is homogenized before sintering. In both samples, most pores are located at the grain corners. It is rare to find pores trapped inside the grains and there is no exaggerated grain growth in either set of samples. The effect of the homogenization heat treatment on the grain size is very similar to the effect of $\mathrm{MgO}$-doping on $\mathrm{Al}_{2} \mathrm{O}_{3}$ ceramics.

Table 4.1 summarizes the values of green density, final sintered density, and average grain size for the conventional and the homogenized samples. Table 4.1 shows that the homogenization heat treatment slightly increases the final apparent density. An increase in final density of about $2 \%$ is observed due to the homogenization heat treatment. The grain size as measured by the linear intercept method is $1.52 \mu \mathrm{m}$ for the conventional sample compared to $1.18 \mu \mathrm{m}$ to the homogenized sample. There is about a $22 \%$ reduction in final average grain size. If a constant sintered density is considered the conventional sample should have a much larger grain size compared to the homogenized sample.

The difference in final microstructure between both sets of samples results from the difference in green microstructure before sintering since the pore structure of the homogenized sample has been modified by the treatment at a low temperature. The most striking microstructural feature is the uniformity of the grain size distribution resulting from this homogenization heat treatment. The reduction in grain size by this treatment is not trivial, however the final grain sizes are not very different $(1.18 \mu \mathrm{m}$ vs. $1.52 \mu \mathrm{m})$. The decrease in the size and volume fraction of the largest grains is much more significant with this treatment. The reduction of the largest diameters and the number of grains with diameter larger than the average grain size are believed to be more significant than the reduction in average grain size to increase the flexural strength of fine-grained $\mathrm{Al}_{2} \mathrm{O}_{3}$ ceramics. 
The four-point flexural strength of the conventional and the $800^{\circ} \mathrm{C} / 50 \mathrm{~h}$ homogenized samples is $540 \pm 156 \mathrm{MPa}$ and $600 \pm 145 \mathrm{MPa}$, respectively. The strength increases by about $10 \%$ with the use of the homogenization heat treatment. Although the strength seems high compared to samples prepared by conventional processing, the strength could be improved if the machining of the testing pieces could be well controlled. With surface finishing to about $9 \mu \mathrm{m}$ in this case, surface flaws may be the controlling factor in determining the flexural strength rather than the intrinsic dependence of strength on grain size. The standard deviation of strength for both the conventional and the homogenized samples in the measurement is very similar which is likely to predict that the increase of strength is possible if the final microstructure of the fired product is more uniform (as from the strength difference by $10 \%$ in this study).

\subsubsection{Densification Kinetics}

The evolution of instantaneous density during sintering is plotted for the conventional and the homogenized samples as a function of temperature in Figure 4.6. The instantaneous density was calculared using dilatometer data following Eq.(3-3). When the sintering temperature is below $1350^{\circ} \mathrm{C}$, the conventional samples are more dense; for temperatures above $1350^{\circ} \mathrm{C}$, the homogenized samples reach higher densities. As shown in the plot of densification versus temperature, the onset temperature for densification in the homogenized samples is $\approx 1000^{\circ} \mathrm{C}$, which is $50^{\circ} \mathrm{C}$ higher than the onset temperature for the conventional samples. This result indicates that local densification rates in the conventional sample are pronounced in the early stages of sintering. Densification rates calculated from Eq.(3-4) are plotted as a function of temperature in Figure 4.7 for both sets of samples. Furthermore, the sintered density is different for the conventional sample and the homogenized sample for a given sintering temperature. The densification rate plotted against sintered density is presented in Figure 4.8. For samples sintered to the same sintered density the densification rate is always 
higher for the homogenized samples. The homogenization heat treatment appears to reduce the local densification rates at low temperatures, and the maximum densification rate is shifted toward a higher temperature. As far as the densification rate is concerned, the effect of the homogenization heat treatment is very similar to the effect of increasing the heating rate. $[23,24]$ As already reported by Lange [24], the density at which the densification rate reaches its maximum is 0.77 for any heating rate. The maximum densification rate in this study occurs at a density of 0.80 for both the conventional and the hornogenized samples; this value is very close to that observed by Lange.

\subsubsection{Microstructural Evolution}

For both sets of samples, sintering was interrupted at different temperatures to study the effect of the homogenization heat treatment on the evolution of the microstructure. Figure 4.9 shows the microstructures of the homogenized and the conventional samples after a sintering treatment interrupted at $1200^{\circ} \mathrm{C}$. For the conventional sample, some areas containing many grains are already densified, an effect which is not observed in the homogenized sample; in it no dense regions are found. The sintered density of the conventional sample is higher than that of the sample homogenized at $800^{\circ} \mathrm{C}$ for $50 \mathrm{~h}(0.76 \pm 0.01$ vs $0.73 \pm 0.01$ of theoretical density). The microstructure of the homogenized sample is more open and the pores are more uniformly distributed. In contrast to the microstructure of the homogenized sample, the conventional sample has a microstructure typical of differential densification or sintering damage. The dense regions surrounded by some large pores are areas which formed by differential densification in the early stages of sintering; this behavior results in the nonuniform microstructure in the conventional sample.

After sintering to $1350^{\circ} \mathrm{C}$, at which temperature both kinds of samples have the same sintered density of 0.94 , the distribution of pores is significantly different, as seen in 
Figure 4.10. The conventional sample shows clustering of grains into dense domains that are surrounded by low density regions of large pores, which is typical of pronounced differential densification. The dense regions are greater than $10 \mu \mathrm{m}$ and typically contain more than 10 grains; these domains are larger than the regions still containing pores. For the homogenized sample, the microstructure is much more uniform, having small pores uniformly distributed as well as having smaller dense domains.

As presented in Figure 4.7 , the maximum densification rate occurs at $\approx 1260^{\circ} \mathrm{C}$ for both the conventional and the homogenized samples, where sintered density is about 0.80 of theoretical density. A comparison of the microstructures for both kinds of samples reveals a difference in the formation of dense regions below this temperature. In the microstructure shown in Figure 4.9(a) (the conventional sample), the formation of closed porosity is obvious, and this may not be measurable by mercury porosimetry; the amount of closed porosity appears to be higher in the conventional sample than in the homogenized sample. However, the variation of the pore structure above $1260^{\circ} \mathrm{C}$ is much more notable.

To recognize the microstructural evolution of the powder compacts which accompanies the densification kinetics presented in Figure 4.7 and Figure 4.8, sintering is interrupted at intermediate temperatures, such as $1260^{\circ} \mathrm{C}, 1300^{\circ} \mathrm{C}, 1350^{\circ} \mathrm{C}$, and $1400^{\circ} \mathrm{C}$. Figure 4.11 and Figure 4.12 show SEM micrographs of polished and thermally etched surfaces of the conventional and the homogenized samples sintered to the final temperatures, respectively. In the conventional sample sintered to $1260^{\circ} \mathrm{C}$, dense regions have formed and are nonuniformly distributed throughout the microstructure. Some loosely packed areas are interconnected with pores of large coordination number as seen in Figure 4.11(a). If the sintering temperature is raised, the growth of the dense domains becomes more clear and the uneven distribution of porosity is more pronounced, as noted in Figure 4.11(b) and $4.11(\mathrm{c})$. When the conventional sample is sintered to $1400^{\circ} \mathrm{C}$, the 
grain size is increased by about 4 times to reach $0.8 \mu \mathrm{m}$. Some large grains $(>2 \mu \mathrm{m})$ already exist, and an uneven pore size distribution resulted from the variation of pore sizes in the early and intermediate stages of sintering. Such an inhomogeneous microstructure results from locally different densification rates due to microstructural heterogeneity which formed during powder processing and consolidation. This effect is especially significant in the aarly stages of sintering because the stress generated by the differential densification may be high enough to break up the necks which, in turn, generate larger pores or even flaws in the microstructure.

Figure 4.12 shows the microstructures of the homogenized samples sintered to various temperatures. The microstructure appears to be rather uniform with only a small fraction of dense domains when the powder compact is sintered to $1260^{\circ} \mathrm{C}$. A comparison of microstructures for the two sets of samples treated at the same sintering temperature can be made using Figure 4.11 and Figure 4.12. The effectiveness of the homogenization heat treatment on the uniformity of pore size distribution can be seen. It can be summarized that not only the final microstructure of the homogenized sample is improved, but the evolution of microstructure throughout the sintering process is effectively modified. Using the linear row model for the interaction of densification and coarsening which was put forth by Carter and Cannon [25], the conditions for the breakup of the neck between spheres are established. Differential densification occurs when the system is constrained and only partially densified, resulting in the break-up of a sintering chain. In a real powder system, damage by break-up between partially densified regions and porous regions will occur if the green state has a significantly heterogeneous arrangement. In this case, the final microstructure which results can be very undesirable. 


\subsubsection{Pore Evolution}

In Figure 4.13, the variation of open porosity for both sets of samples during sintering is plotted as a function of the sintered density. For the temperature range in which there is only open porosity in the compacts, the volume of open porosity is slightly lower for the conventional samples. This is the result of earlier densification, that is, faster removal of porosity in the conventional sample when the sintering temperature is below $\approx 1350^{\circ} \mathrm{C}$. In addition, the closed porosity shown in Figure 4.14 is always smaller in the homogenized samples, and an extrapolation of the evolution of the closed porosity toward the low density region shows that the pores remain totally open at higher sintering temperatures in the homogenized samples. In the temperature range where there are only closed pores left, the porosity is higher in the conventional samples. This evolution of porosity can be directly correlated with the microstructural evolution during sintering of both sets of samples.

It is reasonable to expect that the delay of pore elimination in the homogenized samples during later stages of sintering is another reason for the more uniform pore size distribution in the microstructure. Upon sintering, the time needed for closure of the pore channels increases due to the reduction of perturbations which occurred during the homogenization heat treatment. This situation can be understood from the pore size distribution data obtained using mercury porosimetry; the pore size distribution is narrower and is shifted to larger values by the homogenization heat treatment. Consequently, the pore size will be smaller and more uniformly distributed for the homogenized sample sintered to the later stages. Furthermore, grain growth will be more uniform due to the effect of the continuous pore channels, which inhibit grain growth until the later stages of sintering. 


\subsubsection{Grain Size and Density Trajectories}

The evolution of average grain size during sintering for both the conventional and the homogenized samples is shown in Figure 4.15. Average grain size is measured from micrographs of dense regions of polished and thermally etched surfaces of the compacts sintered at desired temperatures. When the sintering temperature is lower than $1350^{\circ} \mathrm{C}$, the effect of the homogenization heat treatment is not obvious. When temperature is raised to above $1350^{\circ} \mathrm{C}$, the average grain size of the conventional samples increases much more rapidly than that of the homogenized samples. The larger average grain size in the conventional sample sintered to higher temperatures results from the contribution of a higher fraction of very large grains existing in the microstructure. When the sintering temperature is higher, the driving force for grain growth becomes more significant if there are some dense regions formed in the early stage of sintering, as in the conventional sample. The attainment of fine-grained $\mathrm{Al}_{2} \mathrm{O}_{3}$ ceramics with a higher sintered density is clearly achievable through the use of such a simple homogenization heat treatment.

\subsubsection{Effects of Consolidation Technique}

To study the influence of powder consolidation techniques, on the two-step sintering of $\mathrm{Al}_{2} \mathrm{O}_{3}$ ceramics, slip cast compacts are homogenized at $800^{\circ} \mathrm{C}$ for 50 hours and subsequently sintered to $1450^{\circ} \mathrm{C}$ without soaking. Figure 4.16 shows the resultant microstructures of the conventional and the homogenized samples. Both samples have nearly the same grain size under isothermal sintering conditions. The average grain size of the conventional sample is $2.16 \mu \mathrm{m}$ and it is $1.84 \mu \mathrm{m}$ in the homogenized sample as seen from Table 4.2 . The reduction of average grain size is only $15 \%$ with the homogenization heat treatment when the powder compacts are slip cast. Compared with a $22 \%$ reduction of average grain size by isostatic pressing, the slip casting technique seems less effective as a method of microstructure improvement. 
The initial density of powder compacts formed by slip casting is almost identical to that of compacts formed by isostatic pressing, but the mean grain size after sintering is larger for the samples formed by slip casting. The volume fraction of the largest grains (which are elongated and plate-like) in the conventional sample is higher than in the homogenized sample. The final density is similar for both sets of samples $(0.988$ of theoretical density). The microstructure is more uniform in the homogenized sample.

The difference could result from the packing uniformity of particles for these forming techniques. The particles can be packed more homogeneously by the slip casting method if the powder is dispersed well by adjusting the pH value to between 3 and 4 . If this is accomplished, the degree of agglomeration in the powder compacts formed by the slip casting technique is less serious. Nevertheless, agglomerates cannot be removed completely. The homogenization heat treatment still provides a modification of the pore structure which benefits the microstructural evolution as stated previously. The homogeneity of particle packing is less in the isostatic pressing method because large interagglomerate pores are formed by large powder granules. A comparison of sintered density and densification kinetics for powder compacts formed by isostatic pressing and slip casting techniques is shown in Figure 4.17 and Figure 4.18. The delay of densification in the homogenized samples made by isostatic pressing and slip casting is almost identical. As can be seen from the densification rate curves given in Figure 4.18, samples formed by both isostatic pressing and slip casting methods have higher densification rates and densification is shifted to higher temperatures. However, the densification rate curves for the conventional samples prepared by slip casting and isostatic pressing are completely identical. From this observation of the sintering kinetics of both kinds of powder compacts, it is again demonstrated that the homogenization heat treatment is effective for densification rate enhancement for both forming techniques since in both cases the green powder compacts did not have a uniform pore structure. 
Another set of powder compacts were also prepared by the slip casting method, but with a higher initial density ( $\approx 0.63$ of theoretical density). As presented in Table 4.3, the use of the homogenization heat treatment does not decrease the mean grain size, but does slightly increase the final density. In this case the pore structure of green compacts should be more homogeneous due to the higher green density. The homogenization heat treatment does not seem to improve the pore structure in this case; therefore, the final microstructure for the conventional and the homogenized samples is almost identical. It is also noted that the grain growth of the powder compact in the later stages of sintering is more obvious if the initial density is higher. In general, the more homogeneous the green microstructure, the less residual porosity present. Therefore, the effect of pore drag on the grain boundaries becomes less pronounced, i.e., grain size will be larger after sintering. This result demonstrates that if the pore structure is more uniform due to good packing of particles, the benefit from a homogenization heat treatment before sintering is reduced.

As summarized from the effect of different forming techniques on the sintering kinetics and microstructural evolution, the slip casting technique appears to provide a better sintered microstructure for the production of fine-grained $\mathrm{Al}_{2} \mathrm{O}_{3}$ ceramics without resorting to the use of a homogenization heat treatment. However, if the pore structure of green powder compacts is inhomogeneous, the homogenization heat treatment is an effective and simple way to improve the microstructure of sintered, undoped $\mathrm{Al}_{2} \mathrm{O}_{3}$ ceramics.

\subsubsection{Optimal Conditions of Homogenization Heat Treatment}

From the previous results, the improvement in the microstructure of homogenized $\mathrm{Al}_{2} \mathrm{O}_{3}$ cerarnics sintered at a constant heating rate of $4^{\circ} \mathrm{C} / \mathrm{min}$. to $1450^{\circ} \mathrm{C}$ can be significant. It is interesting to study the effects of varying the conditions of the homogenization heat treatment on the final microstructure to find out the optimal 
conditions for microstructural evolution. Table 4.4 gives the results obtained from the sintering of various powder compacts homogenized under different conditions, such as $800^{\circ} \mathrm{C} / 25 \mathrm{~h}, 800^{\circ} \mathrm{C} / 50 \mathrm{~h}, 900^{\circ} \mathrm{C} / 25 \mathrm{~h}$, and $100^{\circ} \mathrm{C} / 25 \mathrm{~h}$. The final sintering temperature is also changed to determine the influence of the sintering temperature on the average grain size. The homogenization heat treatment at $1000^{\circ} \mathrm{C}$ for 25 hours results in an increase of the density from 0.61 to 0.64 of theoretical density. Homogenization heat treatments at lower temperatures do not change the initial density. The measurement of grain sizes for these samples sintered at a constant heating rate of $4^{\circ} \mathrm{C} / \mathrm{min}$. to $1400^{\circ} \mathrm{C}$ demonstrates that the average grain size is reduced for all the homogenized samples. However, this reduction is not very significant for samples sintered to $1400^{\circ} \mathrm{C}$. In addition, the sintered density for constant heating rate sintering to $1400^{\circ} \mathrm{C}$ is below 0.98 of theoretical density.

When the sintering temperature is raised to $1450^{\circ} \mathrm{C}$, both conventional and homogenized samples can be sintered to a density $>0.99$ and the average grain size is similar for all the homogenized samples. The reduction of average grain size is clear when the homogenization heat treatment is applied. Figure 4.19 is a plot of sintered density versus temperature for conventional and homogenized samples sintered at a constant heating rate of $4^{\circ} \mathrm{C} / \mathrm{min}$. to $1450^{\circ} \mathrm{C}$. Densification of the sample homogenized at $1000^{\circ} \mathrm{C}$ for 25 hours is significantly delayed compared to other homogenization conditions. Moreover, the densification rate from the data plotted in Figure 4.19 is calculated and shown in Figure 4.20. Only a slight improvement in densification rate can be obtained by homogenizing at $800^{\circ} \mathrm{C}$ for 25 hours. The higher the temperature for the homogenization heat treatment, the higher the shift in temperature of the maximum densification rate.

The determination of optimal conditions is, however, not complete using only the results of sintered density, average grain size, and sintering kinetics. It is necessary to incorporate a microstructural evolution study to fully determine the optimal conditions of 
the homogenization heat treatment. Micrographs of polished and thermally etched surfaces are shown in Figure 4.21 and Figure 4.22 for the sintering temperatures of $1400^{\circ} \mathrm{C}$ and $1450^{\circ} \mathrm{C}$, respectively. A difference in microstructure between the conventional sample and those of samples homogenized at different conditions is evident at both sintering temperatures. Evidently, the microstructures for the samples homogenized at $800^{\circ} \mathrm{C} / 50 \mathrm{~h}$ and $900^{\circ} \mathrm{C} / 25 \mathrm{~h}$ are more uniform than in all other cases. Very large grains are frequently seen in the conventional samples sintered to $1400^{\circ} \mathrm{C}$ or $1450^{\circ} \mathrm{C}$. Another striking feature of the microstructure for the sample homogenized at $1000^{\circ} \mathrm{C}$ for 25 hours is the trend toward a bimodal grain size distribution. These huge grains (sometimes with high aspect ratio) developed rapidly during sintering and are embedded in a matrix which has a fine grain size. This phenomenon is the result of ton high a temperature for the homogenization heat treatment, which causes some regions to densify during the treatment. Those densified regions allow further grain growth at high sintering temperatures. It should be noted that the microstructure of the $1000^{\circ} \mathrm{C} / 25$ homogenized sample is still denser and more uniform than that of the conventionally sintered sample.

As can be surnmarized from the results, the optimal condition for the homogenization heat treatment appears to be $800^{\circ} \mathrm{C} / 50 \mathrm{~h}$ or $900^{\circ} \mathrm{C} / 25 \mathrm{~h}$ when followed by constant heating rate sintering of $4^{\circ} \mathrm{C} / \mathrm{min}$ to $1450^{\circ} \mathrm{C}$. When a different sintering schedule is used, the optimization of the homogenization heat treatment still appears to work well because the modification of the pore structure seems appropriate for any subsequent sintering schedule. 


\subsection{MgO-Doped Alumina}

\subsubsection{Sintering and Microstructure of MgO-Doped Alumina}

To test whether the homogenization heat treatment has similar effects on the microstructural evolution of other systems, $\mathrm{MgO}$-doped $\mathrm{Al}_{2} \mathrm{O}_{3}$ ceramics were studied. $\mathrm{MgO}$ doping has been recognized as an effective way to improve the microstructure of $\mathrm{Al}_{2} \mathrm{O}_{3}$ for over three decades. [26] Abnormal grain growth is fully suppressed and the average grain size is greatly reduced in $\mathrm{MgO}$-doped $\mathrm{Al}_{2} \mathrm{O}_{3}$ ceramics. The effects of homogenization conditions, sintering schedules, and consolidation techniques are studied for $250 \mathrm{ppm} \mathrm{MgO}$-doped $\mathrm{Al}_{2} \mathrm{O}_{3}$ ceramics. The sintering behavior of undoped $\mathrm{Al}_{2} \mathrm{O}_{3}$ is examined to compare with that of $250 \mathrm{ppm} \mathrm{MgO}$-doped $\mathrm{Al}_{2} \mathrm{O}_{3}$.

\subsubsection{Constant Heating Rate Sintering}

From the previous results of undoped $\mathrm{Al}_{2} \mathrm{O}_{3}$ in section $4.1 .1,800^{\circ} \mathrm{C} / 50 \mathrm{~h}$ appears to be the optimal homogenization condition for undoped $\mathrm{Al}_{2} \mathrm{O}_{3}$. Therefore, in the case of $\mathrm{MgO}$-doped $\mathrm{Al}_{2} \mathrm{O}_{3}$, the condition for the homogenization heat treatment is fixed at $800^{\circ} \mathrm{C}$ for different durations, such as 50,100, and 200 hours. The prolonged duration of 200 hours at $800^{\circ} \mathrm{C}$ is designed to study the influence of densification and coarsening on the microstructure of $\mathrm{MgO}$-doped $\mathrm{Al}_{2} \mathrm{O}_{3}$ ceramics. From the results given in Table 4.5, the sintered density is increased by the various homogenization heat treatments compared to the conventional sample. Table 4.5 also shows that the mean grain size can be reduced by the homogenization heat treatment, even for a prolonged soaking time. The mean grain size for the conventional $\mathrm{MgO}$-doped $\mathrm{Al}_{2} \mathrm{O}_{3}$ ceramics is smaller then that of undoped $\mathrm{Al}_{2} \mathrm{O}_{3}$ ceramics. In addition to the reduction of mean grain size by $\mathrm{MgO}$ doping, further refinement of grain size is obtained by the homogenization heat treatment. However, the heating rate for the $\mathrm{MgO}$-doped $\mathrm{Al}_{2} \mathrm{O}_{3}$ ceramics is $5^{\circ} \mathrm{C} / \mathrm{min}$. compared to $4^{\circ} \mathrm{C} / \mathrm{min}$. for the undoped $\mathrm{Al}_{2} \mathrm{O}_{3}$ ceramics. It can be understood that a fast heating rate will reduce the total 
time spent at sintering temperatures, and thus may produce a finer grain size. As will be shown later, the mean grain size is reduced when $\mathrm{MgO}$ is added to $\mathrm{Al}_{2} \mathrm{O}_{3}$ ceramics and the same sintering conditions are used.

Micrographs showing the conventional and the homogenized samples are presented in Figure 4.23. Evidently, the mean grain size for the conventional sample is larger than those of samples homogenized at different conditions. Moreover, almost no difference can be found between these three homogenized samples. The mean grain size is reduced about $15 \%$ through the use of the homogenization heat treatment. It is hard to quantitatively specify any difference in grain size distribution without the use of an image analyzer. However, there is a slight improvement in the uniformity of grain size distribution as can be seen by comparing the micrographs shown in Figure 4.23. In the micrograph of the conventional $\mathrm{MgO}$-doped $\mathrm{Al}_{2} \mathrm{O}_{3}$ sample, a few elongated plate-like grains (aspect ratio $>2$ ) can be found. The occurrence of such elongated grains is frequently observed to a greater extent in the undoped $\mathrm{Al}_{2} \mathrm{O}_{3}$ ceramics sintered conventionally. Coble [27] proposed that $\mathrm{MgO}$ doping would increase the densification rate relative to the grain growth rate $s 0$ that the possibility for the formation of abnormal grain size is reduced. The homogenization heat treatment of the $\mathrm{MgO}$-doped $\mathrm{Al}_{2} \mathrm{O}_{3}$ ceramics is proven to suppress the formation of such elongated plate-like grains and to result in a uniform microstructure.

\subsubsection{Fast Firing}

A fast firing technique was used to study the effect of sintering schedule on the microstructural difference between the conventional and the homogenized $\mathrm{MgO}$-doped $\mathrm{Al}_{2} \mathrm{O}_{3}$ samples. Figure 4.24 shows that the difference in the microstructures resulting from various homogenization conditions is not obvious. The average grain size is very close for the three samples which were fast fired at a heating rate of $340^{\circ} \mathrm{C} / \mathrm{min}$. to $1750^{\circ} \mathrm{C}$ and held for 5 minutes. As seen from Table 4.6, the lower sintered density of the 
conventional sample, 0.993 compared to 0.999 for the homogenized samples $\left(800^{\circ} \mathrm{C} / 50 \mathrm{~h}\right.$ and $800^{\circ} \mathrm{C} / 100 \mathrm{~h}$ ), is significant. It is evident from Figure $4.24(\mathrm{a})$ that pores are mainly located at triple junctions in the microstructure of the conventional sample. The presence of pores in the homogenized samples is significantly reduced.

Fast firing of $\mathrm{MgO}$-doped $\mathrm{Al}_{2} \mathrm{O}_{3}$ ceramics allows sintered products with a high density and uniform microstructure to be obtained when the homogenization heat treatment is applied before the sintering step. However, from the mean grain size values given in Table 4.6, the grain size is almost the same for the conventional and the homogenized samples $(\approx 6 \mu \mathrm{m})$. It can be realized that grain growth kinetics are very similar for the conventional and the homogenized samples during soaking at such a high temperature $\left(1750^{\circ} \mathrm{C}\right.$ even for only 5 minutes). Therefore, the use of fast firing carnot be considered as a potential technique for the manufacture of fine-grained $\mathrm{Al}_{2} \mathrm{O}_{3}$ (of course, near full density). However, fast firing of $\mathrm{Al}_{2} \mathrm{O}_{3}$ powder compacts to such high temperatures and subsequent holding is suitable for the production of translucent ceramics because of the near full density and the very large grain size of the microstructure. For the manufacture of very fine-grained $(<1 \mu \mathrm{m}) \mathrm{Al}_{2} \mathrm{O}_{3}$ ceramics with high density, a two-step sintering (homogenization heat treatment at a low temperature and subsequent sintering) technique appears to be the best choice.

\subsubsection{Effects of MgO-Doping}

The green density, final density and grain size for the conventional and the homogenized samples formed by slip casting and sintered at a constant heating rate of $4^{\circ} \mathrm{C} / \mathrm{min}$. to $1450^{\circ} \mathrm{C}$ is shown in Table 4.7 . The average grain size is smaller for the homogenized sample than for the conventional sample. There is about a $26 \%$ reduction in average grain size due to the homogenization heat treatment. It should be noted that the mean grain size in the powder compacts made by slip casting is higher than that of compacts formed by cold isostatic pressing. However, the initial density of both kinds of 
samples is the same and is close to that of those samples formed by cold isostatic pressing. The packing of particles after the slip casting technique is far from fully homogeneous, state, but it is better than that of powder compacts formed by isostatic pressing. The final sintered microstructures for the conventional and the homogenized samples formed by slip casting are presented in Figure 4.25 . The grain shape in the homogenized sample is completely equiaxed. Improvement of uniformity in grain size distribution is clearly observed in the homogenized sample.

Comparing the results from Table 4.2 and Table 4.7 for undoped and $\mathrm{MgO}$-doped $\mathrm{Al}_{2} \mathrm{O}_{3}$ ceramics (formed by slip casting) sintered under the same conditions, the mean grain size is significantly reduced when $250 \mathrm{ppm}$ of $\mathrm{MgO}$ is added to $\mathrm{Al}_{2} \mathrm{O}_{3}$ ceramics. In the case of the conventional samples, the reduction of grain size by the $\mathrm{MgO}$ doping is about $33 \%$. On the other hand, in the case of the $800^{\circ} \mathrm{C} / 50 \mathrm{~h}$ homogenized samples, the decrease in mean grain size is about $42 \%$. Moreover, if the mean grain size of the undoped $\mathrm{Al}_{2} \mathrm{O}_{3}$ is compared with that of $\mathrm{MgO}$-doped $\mathrm{Al}_{2} \mathrm{O}_{3}$ sintered conventionally, the reduction of grain size is as large as $50 \%(2.16 \mu \mathrm{m}$ vs. $1.07 \mu \mathrm{m})$. From the above data, it can be seen that the combined effect of the homogenization heat treatment and $\mathrm{MgO}$ doping is significant for refining the mean grain size in the sintering of $\mathrm{Al}_{2} \mathrm{O}_{3}$ ceramics.

The effects of the homogenization heat treatment and $\mathrm{MgO}$ doping on the densification kinetics of $\mathrm{Al}_{2} \mathrm{O}_{3}$ during sintering can be seen in Figure 4.26. Sintered density as a function of temperature is plotted for powder compacts formed by slip casting. Sintering at a constant heating rate of $4^{\circ} \mathrm{C} / \mathrm{min}$. to $1450^{\circ} \mathrm{C}$ gives a density $>0.998$ of theoretical density for all the $\mathrm{Al}_{2} \mathrm{O}_{3}$ sintered bodies. As seen from Figure 4.27, the densification rates of $\mathrm{MgO}$-doped samples and of all homogenized samples are higher than the conventional and undoped $\mathrm{Al}_{2} \mathrm{O}_{3}$ ceramics. The homogenization heat treatment alone can also increase the densification rate of undoped $\mathrm{Al}_{2} \mathrm{O}_{3}$ ceramics compared to conventional samples. Evidently, the effect of the hornogenization heat treatment is 
similar to the function of $\mathrm{MgO}$ doping, but it might be through a different mechanism. The combination of the homogenization heat treatment and $\mathrm{MgO}$ doping can result in an even higher densification rate. This suggests that the homogenization heat treatment has a positive and additive influence on the improvement of microstructure of $\mathrm{Al}_{2} \mathrm{O}_{3}$ ceraniics or $\mathrm{MgO}$-doped $\mathrm{Al}_{2} \mathrm{O}_{3}$ ceramics.

\subsubsection{Role of MgO-doping and Homogenization Heat Treatment}

The addition of $\mathrm{MgO}$ is demonstrated to inhibit the rate of normal grain growth of $\mathrm{Al}_{2} \mathrm{O}_{3}$ in this work, which supports the idea that the role of $\mathrm{MgO}$ is to reduce the grain boundary mobility. [28-30] Despite such intensive study on the role of $\mathrm{MgO}$ doping and its effect on the sintering kinetics and microstructure of $\mathrm{Al}_{2} \mathrm{O}_{3}$ ceramics, there is still controversy about the mechanism by which $\mathrm{MgO}$ addition affects microstructural evolution. Recently, the role of $\mathrm{MgO}$ in the sintering of $\mathrm{Al}_{2} \mathrm{O}_{3}$ has been reviewed and summarized by Benison and Harmer. [26] The most important effect of $\mathrm{MgO}$ doping on the sintering of $\mathrm{Al}_{2} \mathrm{O}_{3}$ is the reduction of grain boundary mobility through a solid solution mechanism. It is not the intention of this work to find out the mechanism of $\mathrm{MgO}$ doping on the microstructure improvement of $\mathrm{Al}_{2} \mathrm{O}_{3}$ ceramics, because the chemical effects and characterization of $\mathrm{MgO}$ are still unknown. However the distribution of $\mathrm{MgO}$ in the $\mathrm{Al}_{2} \mathrm{O}_{3}$ matrix is extremely important to achieve homogeneous densific tion. It is found that the distribution of the $\mathrm{MgO}$ additive became more homogeneous if the powder compacts were prefired at $1000-1200^{\circ} \mathrm{C}$ prior to sintering. [31] The effect of the homogenization heat treatment on the microstructure improvement of $\mathrm{MgO}$-doped $\mathrm{Al}_{2} \mathrm{O}_{3}$ ceramics is believed to be that the distribution of the $\mathrm{MgO}$ addition becomes more uniform through prolonged heat treatment. The use of the homogenization heat treatment at $800^{\circ} \mathrm{C}$ for a dwelling time of up to 200 hours not only increases the densification rate but also provides a more homogeneous microstructure of $\mathrm{MgO}$-doped $\mathrm{Al}_{2} \mathrm{O}_{3}$ ceramics than that of those samples sintered conventionally. 
From the results of the sintering of undoped $\mathrm{Al}_{2} \mathrm{O}_{3}$ and $\mathrm{MgO}$-doped $\mathrm{Al}_{2} \mathrm{O}_{3}$ ceramics presented in this study, the effect of a low temperature heat treatment does not retard the densification kinetics, and in contrast it assists the improvement of microstructure, which is completely different from the concept of fast firing $[32,33]$ or ultra-rapid sintering [34,35] techniques. The present results strongly suggest that the homogenization heat treatment in the two-step sintering technique can homogenize the pore structure of the powder compacts which, in turn, improves the microstructure. It is necessary to study the detailed mechanism of the homogenization heat treatment on the microstructural evolution of different material systems to find general applications.

\section{References (For Chapter 4)}

1. R. Raj, "Analysis of the Sintering Pressure," J. Am. Ceram. Soc., 70 [9] C-210 . C-211 (1987).

2. D.L. Johnson, "Solid State Sintering"; pp. 454 - 58 in Concise Encyclopedia of Advanced Ceramic Materials. Edited by R.J. Brook. The MIT Press, Cambridge, MA, 1991.

3. M.-Y. Chu, L.C. De Jonghe, M.K.-F. Lin, and F.J.T. Lin, "Precoarsening to Improve Microstructure and Sintering of Powder Compacts," J. Am. Ceram. Soc., 74 [11] $2902-11(1991)$.

4. R.T. DeHoff, "A Cell Model for Microstructural Evolution during Sintering"; pp. 23 34 in Materials Science Research, Vol. 16. Edited by G.C. Kuczynski, A.E. Miller and G.A. Sargent, Plenum Press, New York, 1984.

5. F.N. Rhine and R.T. DeHoff, "Channel Network Decay in Sintering"; pp. 49 - 61 in Materials Science Research, Vol. 16. Edited by G.C. Kuczynski, A.E. Miller and G.A. Sargent, Plenum Press, New York, 1984.

6. O.J. Whittemore and J.A. Varela, "Pore Distribution and Pore Growth During the Initial Stages of Sintering"; pp. 51 - 60 in Materials Science Research, Vol. 13. Edited 
by G.C. Kuczynski, Plenum Press, New York, 1980.

7. M.A.C.G. van de Graaf, J.H.H. ter Maat, and A.J. Burggraaf, "Microstructural Development during Pressing and Sintering of Ultra-Fine Zirconia Powders"; pp. 783 - 94 in Ceramic Powders. Edited by P. Vincenzini. Elsevier, Amsterdam, Netherlands, 1983.

8. H.E. Exner and E. Arzt, "Sintering Process"; pp. 1885 - 1912 in Physical Metallurgy, 3rd edition. Edited by R.W. Cahn and P. Haasan. Elsevier Science Publishers BV, Amsterdam, 1983.

9. R.J. Brook, "Controlled Grain Growth"; pp. 331 - 64 in Treatise on Materials Science and Technology, Vol. 9, Ceramic Fabrication Process. Edited by F.F.Y. Wang. Academic Press, New York, 1976.

10. F.M.A. Carpy, "The Effect of Pore Drag on Ceramic Microstructure"; pp. 261 - 75 in Ceramic Microstructure '76. Edited by R.M. Fulrath and J.A. Pask. Westview Press, Boulder, CO, 1977.

11. T. Vasilos and W.H. Rhodes, "Fine Particulates to Ultrafine-Grain Ceramics"; pp. 137 - 72 in Ultrafine-Grained Ceramics. Edited by J.J. Burke, N.L. Reed, and V. Weiss. Syracuse University, Syracuse, NY, 1970.

12. T.J. Carbone and J.S. Reed, "Dependence of Sintering Response with a Constant Rate of Heating on Processing-Related Pore Distribution," Am. Ceram. Soc. Bull., 55 [8] $748-50,55(1978)$.

13. A. Roosen and $\mathrm{H}$. Hausner, "Sintering Kinetics of $\mathrm{ZrO}_{2}$ Powders"; pp. $714-26$ in Advances in Ceramics, Vol. 12, Science and Technology of Zirconia, II. Edited by N. Claussen, M. Ruehle and A. Heuer. American Ceramic Society, Columbus, OH, 1984.

14. A. Roosen and H.K. Bowen, "Influence of Various Consolidation Techniques on the Green Microstructure and Sintering Behavior of Alumina Powders," J. Am. Ceram. Soc., 71 [11] 970 - 77 (1988). 
15. T.-S. Yeh and M.D. Sacks, "Low-Temperature Sintering of Aluminum Oxide," J. Am. Ceram. Soc., 71 [10] 841 - 44 (1988).

16. R. Roosen and H. Hausner, "The Influence of Processing Conditions on the Sintering Behavior of Coprecipiated Calcia-Stabilized Zirconia Powders"; pp. 773 - 82 in Ceramic Powders. Edited by P. Vincenzini. Elsevier, Amsterdam, Netherlands, 1983.

17. M. Weiser and L.C. De Jonghe, "Rearrangement During Sintering in TwoDimensional Array," J. Am. Ceram. Soc., 69 [11] 82 2 - 26 (1986).

18. A.G. Evans, " Considerations of Inhomogeneity Effects in Sintering," J. Am. Ceram. Soc., 65 [10] 497 - 501 (1982).

19. S. Prochazka and R.L. Coble, "Surface Diffusion in the Initial Sintering of Alumina: III," Phys. Sintering, 2 [2] 15 - 33 (1970).

20. C. Greskovich and K.W. Lay, "Grain Growth in Very Porous $\mathrm{Al}_{2} \mathrm{O}_{3}$ Compact," J. Am. Ceram. Soc., 55 [3] 142 - 46 (1972).

21. W.D. Kingery, H.K. Bowen and D.R. Uhlmann, Introduction to Ceramics, Chapter 10. Wiley \& Sons, New York, 1976.

22. F.G.R. Gauthier and S.C. Danforth, "Packing of Bimodal Mixtures of Colloidal Silica," J Mater. Sci., 26, 6035 - 43 (1991).

23. M.-Y. Chu, M.N. Rahaman, L.C. De Jonghe, and R.J. Brook, "Effect of Heating Rate on Sintering and Coarsening," J. Am. Ceram. Soc., 74 [6] 1217 - 25 (1991).

24. F.F. Lange, "Powder Processing Science and Technology for Increased Reliability," J. Am. Ceram. Soc., 72 [1] 3 - 15 (1989).

25. W.C. Carter and R.M. Cannon, "Sintering Microstructures: Instabilities and the Interdependence of Mass Transport Mechanisms"; pp. 137 - 163 in Ceramic Transactions, Vol. 7, Sintering of Advanced Ceramics. Edited by C.A. Handwerker, J. E. Blendell, and W. Kaysser. American Ceramic Society, Westerville, OH, 1990.

26. S.J. Bennison and M.P. Harmer, "A History of the Role of MgO in the Sintering of $\alpha-\mathrm{Al}_{2} \mathrm{O}_{3}$ "; pp. 13 - 49 in Ceramic Transaction, Vol. 7, Sintering of Advanced 
Ceramics. Edited by C.A. Handwerker, J. E. Blendell, and W. Kaysser. American

27. R.L. Coble, "Sintering of Crystalline Solid - II: Experimental Test of Diffusion Models in Porous Compacts," J. App. Phys., 32 [5] 793 - 99 (1961).

28. S.J. Bennison and M.P. Harmer, "Effect of $\mathrm{MgO}$ Solute on the Kinetics of Grain Growth in $\mathrm{Al}_{2} \mathrm{O}_{3}, "$ J. Am. Ceram. Soc., 66 [5] C-90 - C-92 (1983).

29. S.J. Bennison and M.P. Harmer, "Grain Growth Kinetics for Alumina in the Absence of a Liquid Phase" J. Am. Ceram Soc., 68 [1] C-22 - C-24 (1985).

30. K.A. Berry and M.P. Harmer, "Effect of MgO Solute on Microstructure Development in $\mathrm{Al}_{2} \mathrm{O}_{3}, " J$. A.m. Ceram. Soc., 69 [2] 143 - 49 (1986).

31. I.D. Prendergast, D.W. Budworth, and N.H. Brett, "Densification and Grain Growth in Alumina," Trans. Brit. Ceram. Soc., 71 [1] $31-36$ (1972).

32. M. Harmer, E.W. Roberts, and R.J. Brook, "Rapid Sintering of Pure and Doped $\alpha-$ $\mathrm{Al}_{2} \mathrm{O}_{3}$," Trans. J. Br. Ceram. Soc., 78, 22 - 25 (1979).

33. R.J. Brook, "Fabrication Principles for Production of Ceramics with Superior Mechanical Properties," Proc. Brit. Ceram. Soc., 32, 7 - 24 (1982).

34. D.L. Johnson, "Ultra-Rapid Sintering"; pp. 243 - 52 in Materials Science Research, Vol. 16. Edited by G.C. Kuczynski, A.E. Miller, and G.A. Sargent. Plenum Press, New York, 1984.

35. D.L. Johnson, "Ultra-Rapid Sintering of Ceramics"; pp. 497 - 506 in Science of Sintering. Edited by Uskokovic, H. Palmour III, and R.M. Spriggs. Plenum Press, New York, 1989. 


\section{Chapter 5}

\section{Conclusions and Suggestions for Future Work}

\subsection{Conclusions}

A homogenization heat treatment of $\mathrm{Al}_{2} \mathrm{O}_{3}$ powder compacts at $800^{\circ} \mathrm{C}$ for 50 hours produces a more uniform pore structure and a higher green strength. Pore size distribution becomes narrower, as has been demonstrated by mercury porosimetry. Moreover, the strength of the homogenized samples can be increased by 50 times through the use of this treatment to reach $43 \mathrm{MPa}$. In contrast, there is negligible strength $(<0.9$ $\mathrm{MPa}$ ) for samples without the heat treatment. This extra strength provides strong resistance to damage from differential densification in the subsequent early sintering stages. Another important bessefit of the homogenization heat treatment is that green machining is possible, which reduces the generation of machining flaws and the need for machining after sintering.

Near fully dense (>0.995 T.D.), fine-grained ( $<1.2 \mu \mathrm{m})$ and uniform grain sizedistribution, undoped $\mathrm{Al}_{2} \mathrm{O}_{3}$ ceramics can be produced by using a high quality powder, a high-pressure isostatic forming method, and a two-step sintering technique. Improvements in the microstructure of $\mathrm{Al}_{2} \mathrm{O}_{3}$ ceramics homogenized at $800^{\circ} \mathrm{C} / 50 \mathrm{~h}$ include a smaller pore size and a more uniform pore size distribution. Prevention of differential densification in the early stages and delay of pore channel closure to the later stages of sintering are believed to be the primary mechanisms for the microstructure improvement in two-step sintering of $\mathrm{Al}_{2} \mathrm{O}_{3}$ ceramics. The flexural strength of sintered $\mathrm{Al}_{2} \mathrm{O}_{3}$ can be increased by about $10 \%$ after the homogenization heat treatment. This is due to the effects of reducing the size and volume fraction of the largest grains in the homogenized samples. 
Mechanisms responsible for the improvement of microstructure of sintered $\mathrm{Al}_{2} \mathrm{O}_{3}$ ceramics by a homogenization heat treatment in the present work are summarized as follows: 1. A homogenization heat treatment which enhances the neck growth between particles results in the reduction of sintering damage by differential densification in the early stages of sintering. 2 . The elimination of very fine particles by the homogenization heat treatment enlarges the pore size and narrows the width of pore size distribution, and thereby, homogenizes the pore size distribution. 3. Reduction of pore structure heterogeneity by the homogenization heat treatment which suppressing the earlier formation of the dense network regions minimizes the local differential densification rates. In turn, this effect increases the densification rate at higher sintering temperatures as the more uniform pore structure is being eliminated. 4. The delayed densification to higher sintering temperatures allows the system to stay longer in the open porosity stage, reducing high-temperature coarsening.

When the homogenization heat treatment is done at $800^{\circ} \mathrm{C}$ for 25 hours, the final sintered microstructure is only slightly improved. Apparently the duration is too short or the temperature for the homogenization of the pore structure is too low to give a substantial improvement through the above mechanisms. The higher the temperature for the homogenization heat treatment, the shorter the time needed to reach the homogenized condition. When the temperature for the homogenization heat treatment is $1000^{\circ} \mathrm{C}$, the final sintered microstructure tends toward a bimodal grain size distribution, although the sintered density is still higher than that of conventional samples. The optimal conditions for the homogenization schedule appear to be $800^{\circ} \mathrm{C} / 50 \mathrm{~h}$ or $900^{\circ} \mathrm{C} / 25 \mathrm{~h}$.

The two-step sintering technique gives an alternate way to improve the microstructure of $\mathrm{Al}_{2} \mathrm{O}_{3}$ ceramics compared to fast firing or $\mathrm{MgO}$ doping. When a combination of the homogenization heat treatment and the fast firing technique is used, the final density is even higher than that resulting from fast firing alone. However, the 
two-step sintering technique is sirnple in nature and there is no limitation on the size of the samples. Generalization of two-step sintering to more systems is needed for practical applications.

For $250 \mathrm{ppm} \mathrm{MgO-doped} \mathrm{Al}_{2} \mathrm{O}_{3}$ ceramics, the homogenization of powder compacts at $800^{\circ} \mathrm{C}$ for 50 hours produces a sintered body with a grain size of about 0.80 $\mu \mathrm{m}$. The refinement of grain size is more pronounced as a result of $\mathrm{MgO}$-doping. It is explained that not only $\mathrm{MgO}$ doping inhibits the grain growth kinetics of $\mathrm{Al}_{2} \mathrm{O}_{3}$ but also the homogenization heat treatment improves the pore structure of the $\mathrm{Al}_{2} \mathrm{O}_{3}$ powder compacts. This improvement is based on the explanation that the distribution of $\mathrm{MgO}$ becomes more uniform during the homogenization heat treatment, which enhances the effectiveness of $\mathrm{MgO}$ doping.

\subsection{Suggestions for Future Work}

1. Particle packing is the most critical factor in determining the green microstructure when ideal powder is used. The extent of differential densification can be significantly reduced and the effect of homogenization may be negligible if a very homogeneous green microstructure can be achieved through colloidal processing. It can be predicted that the more homogeneous the green microstructure, the less a homogenization heat treatment will influence or improve the final microstructure. However, it would be interesting to prove this phenomenon by preparing a very homogeneous powder compact by colloidal processing and examine the effects of the homogenization heat treatment on the microstructural evolution.

2. To realize the effects of particle size distribution on the homogenization heat treatment, the use of a bimodal distribution powder by mixing particles of two different sizes with a size ratio in the range of 6.5 - 10 can be studied. The volume fraction of fine particles in the bimodal powder may affect the particle packing homogeneity, and hence 
by varying of the fine particle fraction the effectiveness of the homogenization heat treatment can be examined. Moreover, particle packing by various consolidation techniques can be used to investigate the effects of particle packing homogeneity on the microstructural evolution during the homogenization heat treatment and subsequent sintering.

3. By using a powder with broad particle size distribution as a starting material to form a green compact having the same green density as those formed by narrow-sized powder, the effects of the homogen ization heat treatment on the microstructural evolution can be investigated.

4. By combining the $\mathrm{MgO}$-doping and a homogenization heat treatment finegrained $(\approx 0.8 \mu \mathrm{m}) \mathrm{Al}_{2} \mathrm{O}_{3}$ ceramics which are produced may possess very high strength (probably $>800 \mathrm{MPa}$ ). However, the surface flaws induced by the machining of testing pieces may give a lower value of strength, not the true intrinsic strength of the finegrained $\mathrm{Al}_{2} \mathrm{O}_{3}$ ceramics. Therefore, the manufacture of such $\mathrm{Al}_{2} \mathrm{O}_{3}$ ceramics by the optimization of the homogenization and sintering schedules together with controlled surface finishing of testing pieces would be important for the attainment of high strength.

5. It is widely recognized that the dielectric constant of $\mathrm{BaTiO}_{3}$ ceramics is increased when the grain size is reduced. The attainment of fully dense and fine-grained $\mathrm{BaTiO}_{3}$ ceramics by controlling the sintering schedules has been the subject of intensive study. Two-step sintering is a potential technique for the processing of $\mathrm{BaTiO}_{3}$ ceramics to high density and small grain size. By using a narrow-sized, agglomerate-free, and submicron $\mathrm{BaTiO}_{3}$ powder, the effects of the homogenization heat treatment on the microstructural evolution during subsequent sintering can be investigated. Application of two-step sintering to the commercial $\mathrm{BaTiO}_{3}$ powders may have a more substantial impact on the electronic ceramic industry. Applications to covalent bonded ceramics, 
such as $\mathrm{Si}_{3} \mathrm{~N}_{4}, \mathrm{SiC}$, and $\mathrm{B}_{4} \mathrm{C}$, piovide another possibility for gaining a better understanding of the two-step sintering technique.

6. The optimization of the conditions of the homogenization heat treatment with the aim of shortening the duration time of the heat treatment for the purpose of increasing productivity would be important for industrial applications. 
Tables

Table 4.1 Densities, and mean grain sizes of $\mathrm{Al}_{2} \mathrm{O}_{3}$ compacts are compared for the conventional and the $800^{\circ} \mathrm{C} / 50 \mathrm{~h}$ homogenized samples. Sintering was conducted at a constant heating rate of $4^{\circ} \mathrm{C} / \mathrm{min}$. to $1450^{\circ} \mathrm{C}$ in air.

\begin{tabular}{|c|c|c|c|}
\hline Sample Condition & Initial Density ${ }^{\dagger}$ & Final Density* & Mean Grain Size I \\
\hline $\begin{array}{c}\text { Conventional } \\
\text { (No Heat Treaunent) }\end{array}$ & $0.60 \pm 0.01$ & $0.975 \pm 0.005$ & $1.52 \mu \mathrm{m}$ \\
\hline $\begin{array}{c}\text { Homogenized } \\
\left(800^{\circ} \mathrm{C} / 50 \mathrm{~b}\right)\end{array}$ & $0.60 \pm 0.01$ & $0.996 \pm 0.005$ & $1.18 \mu \mathrm{m}$ \\
\hline
\end{tabular}

tGreen density is calculated from by dimension and weight.

*Final density is measured by Archimedes method in deionized water.

1 More than 2000 grains have been counted for the mean grain size.

Table 4.2 Density and mean grain size are compared for the conventional and the $800^{\circ} \mathrm{C} / 50 \mathrm{~h}$ homogenized samples. Powder compacts formed by slip casting were sintered at a constant heating rate of $4^{\circ} \mathrm{C} / \mathrm{min}$ to $1450^{\circ} \mathrm{C}$ in air.

\begin{tabular}{|c|c|c|c|}
\hline Sample Condition & Initial Density & Final Density & Mean Grain Size \\
\hline Conventional & 0.613 & 0.998 & $2.16 \mu \mathrm{m}$ \\
\hline $800^{\circ} \mathrm{C} / 50 \mathrm{~h}$ & 0.612 & 0.998 & $1.84 \mu \mathrm{m}$ \\
\hline
\end{tabular}

Table 4.3 Undoped $\mathrm{Al}_{2} \mathrm{O}_{3}$ powder compacts formed by slip casting technique were sintered at a constant heating rate of $4^{\circ} \mathrm{C} / \mathrm{min}$. to $1450^{\circ} \mathrm{C}$ in air. Densities and mean grain sizes are compared for the conventional and homogenized samples at different conditions.

\begin{tabular}{|c|c|c|c|}
\hline Sample Condition & Green Density & Final Density & Mean Grain Size \\
\hline Conventional & 0.629 & 0.997 & $1.80 \mu \mathrm{m}$ \\
\hline $800^{\circ} \mathrm{C} / 25 \mathrm{~h}$ & 0.628 & 0.997 & $1.88 \mu \mathrm{m}$ \\
\hline $800^{\circ} \mathrm{C} / 50 \mathrm{~h}$ & 0.632 & 0.999 & $1.88 \mu \mathrm{m}$ \\
\hline
\end{tabular}


Table 4.4 Final densities and mean grain size of $\mathrm{Al}_{2} \mathrm{O}_{3}$ powder compacts formed by isostatic pressing are compared for the conventional and various homogenized conditions. Sintering was conducted at a constant heating rate of $4^{\circ} \mathrm{C} / \mathrm{min}$. to $1400^{\circ} \mathrm{C}$ and $1450^{\circ} \mathrm{C}$.

\begin{tabular}{|c|c|c|c|c|}
\hline $\begin{array}{c}\text { Sample } \\
\text { Conditions } \\
\end{array}$ & Initial Density & $\begin{array}{l}\text { Final Density } \\
\left.\text { (To } 1450^{\circ} \mathrm{C}\right)\end{array}$ & $\begin{array}{l}\text { Grain Size } \\
\text { (To } 1400^{\circ} \mathrm{C} \text { ) }\end{array}$ & $\begin{array}{l}\text { Grain Size } \\
\text { (To } 1450^{\circ} \mathrm{C} \text { ) }\end{array}$ \\
\hline Conventional & 0.61 & 0.993 & $1.14 \mu \mathrm{m}$ & $2.10 \mu \mathrm{m}$ \\
\hline $800^{\circ} \mathrm{C} / 25 \mathrm{~h}$ & 0.61 & 0.994 & $1.02 \mu \mathrm{m}$ & $1.76 \mu \mathrm{m}$ \\
\hline $800^{\circ} \mathrm{C} / 50 \mathrm{~h}$ & 0.61 & 0.999 & $0.89 \mu \mathrm{m}$ & $1.71 \mu \mathrm{m}$ \\
\hline $900^{\circ} \mathrm{C} / 25 \mathrm{~h}$ & 0.61 & 0.998 & $0.89 \mu \mathrm{m}$ & $1.72 \mu \mathrm{m}$ \\
\hline $1000^{\circ} \mathrm{C} / 25 \mathrm{~h}$ & 0.64 & 0.998 & $0.93 \mu \mathrm{m}$ & $1.81 \mu \mathrm{m}$ \\
\hline
\end{tabular}

Table 4.5 Comparison of final density and mean grain size of $250 \mathrm{ppm} \mathrm{MgO-doped}$ $\mathrm{Al}_{2} \mathrm{O}_{3}$ compacts formed by isostatic pressing at $1380 \mathrm{MPa}$. Sintering was conducted at a constant heating rate of $5^{\circ} \mathrm{C} / \mathrm{min}$ to $1450^{\circ} \mathrm{C}$ in air for the conventional and different heat treatment conditions.

\begin{tabular}{|c|c|c|}
\hline Sample Conditions & Final Density & Mean Grain Size \\
\hline Conventional & 0.985 & $0.91 \mu \mathrm{m}$ \\
\hline $800^{\circ} \mathrm{C} / 50 \mathrm{~h}$ & 0.995 & $0.77 \mu \mathrm{m}$ \\
\hline $800^{\circ} \mathrm{C} / 100 \mathrm{~h}$ & 0.993 & $0.86 \mu \mathrm{m}$ \\
\hline $800^{\circ} \mathrm{C} / 200 \mathrm{~h}$ & 0.994 & $0.87 \mu \mathrm{m}$ \\
\hline
\end{tabular}


Table 4.6 Comparison of final density and mean grain size of $250 \mathrm{ppm}-\mathrm{MgO}$-doped $\mathrm{Al}_{2} \mathrm{O}_{3}$ for the conventional and the homogenized samples sintered by fast firing conditions $\left(340^{\circ} \mathrm{C} / \mathrm{min}\right)$ to $1750^{\circ} \mathrm{C}$ and soaking for $5 \mathrm{~min}$ in vacuum.

\begin{tabular}{|c|c|c|}
\hline Sample Conditions & Final Density & Mean Grain Size \\
\hline Conventional & 0.993 & $6.15 \mu \mathrm{m}$ \\
\hline $800^{\circ} \mathrm{C} / 50 \mathrm{~h}$ & 0.998 & $5.94 \mu \mathrm{m}$ \\
\hline $800^{\circ} \mathrm{C} / 100 \mathrm{~h}$ & 0.998 & $6.03 \mu \mathrm{m}$ \\
\hline
\end{tabular}

Table 4.7 Densities and mean grain size are compared for the conventional and the $800^{\circ} \mathrm{C} / 50 \mathrm{~h}$ homogenized samples. $\mathrm{MgO}$-doped $\mathrm{Al}_{2} \mathrm{O}_{3}(250 \mathrm{ppm})$ powder compacts formed by slip casting were sintered at a constant heating rate of $4^{\circ} \mathrm{C} / \mathrm{min}$ to $1450^{\circ} \mathrm{C}$ in air.

\begin{tabular}{|c|c|c|c|}
\hline Sample Condition & Initial Density & Final Density & Mean Grain Size \\
\hline Conventional & 0.616 & 0.997 & $1.44 \mu \mathrm{m}$ \\
\hline $800^{\circ} \mathrm{C} / 50 \mathrm{~h}$ & 0.619 & 0.998 & $1.07 \mu \mathrm{m}$ \\
\hline
\end{tabular}




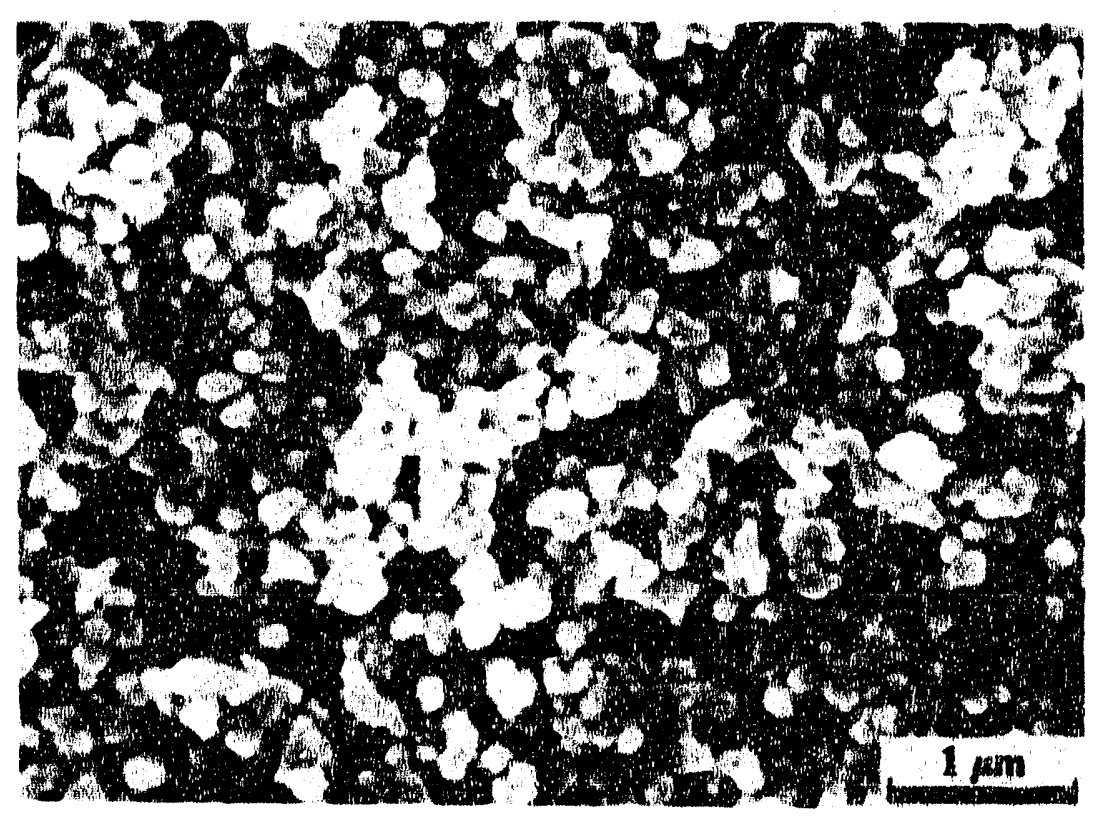

Figure 3.1 The morphology of $\mathrm{Al}_{2} \mathrm{O}_{3}$ powder after 29 hours sedimentation to remove agglomerates. The average particle size is $0.17 \mu \mathrm{m}$. 


\section{Particle Size Distribution}

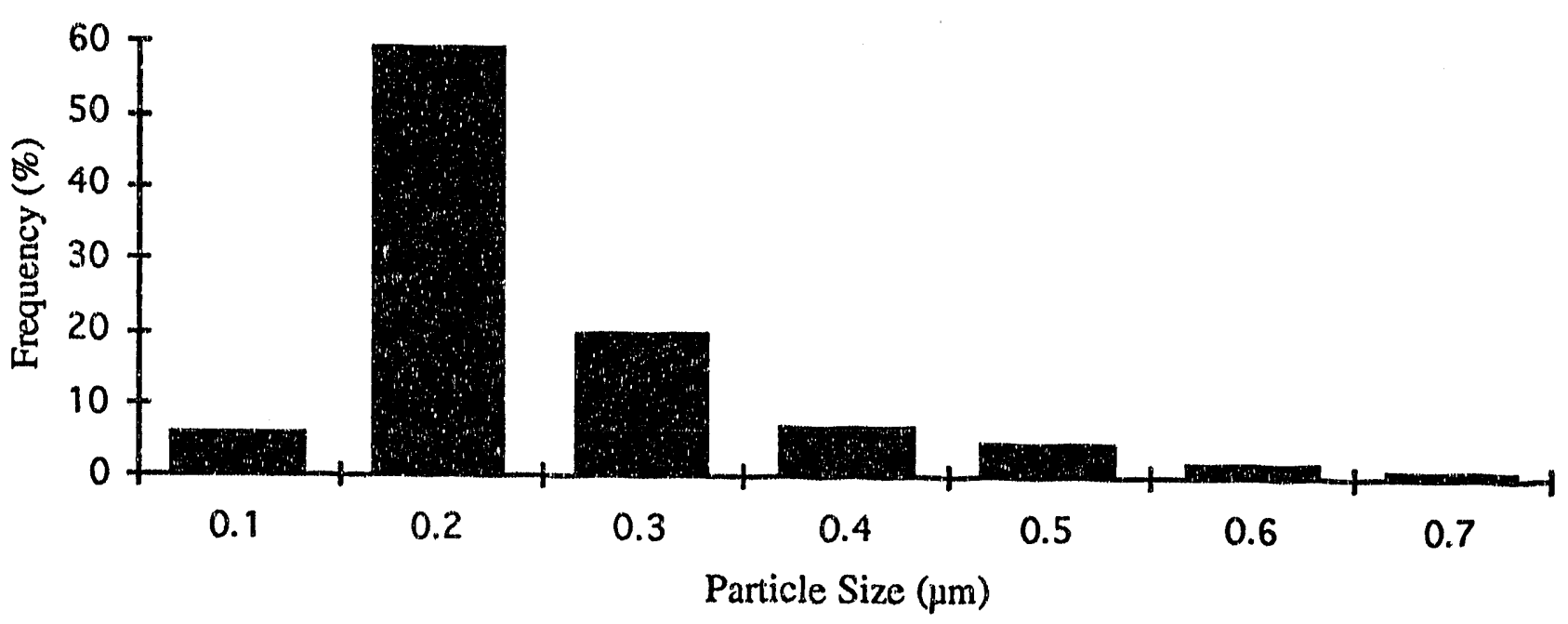

Figure 3.2 Particle size distribution of $\mathrm{Al}_{2} \mathrm{O}_{3}$ powder measured by the centrifugal sedimentation method. The size distribution is very narrow. 


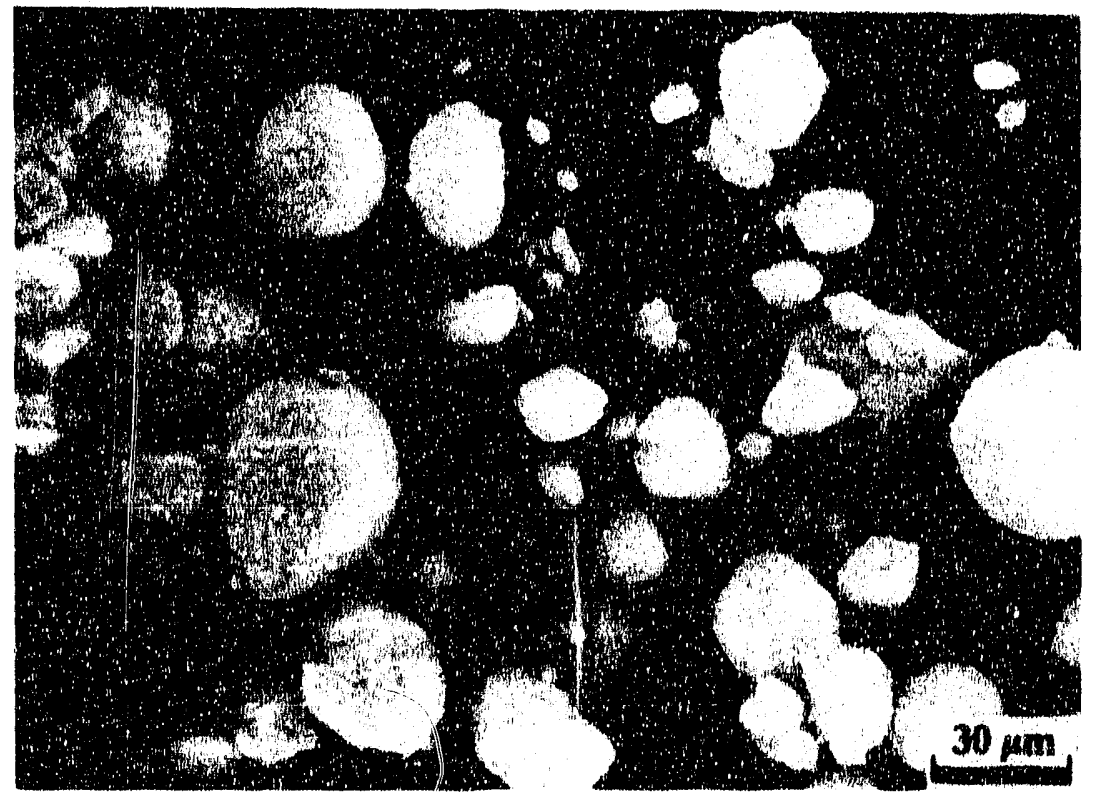

Figure 3.3 The morphology of $\mathrm{Al}_{2} \mathrm{O}_{3}$ granules. 

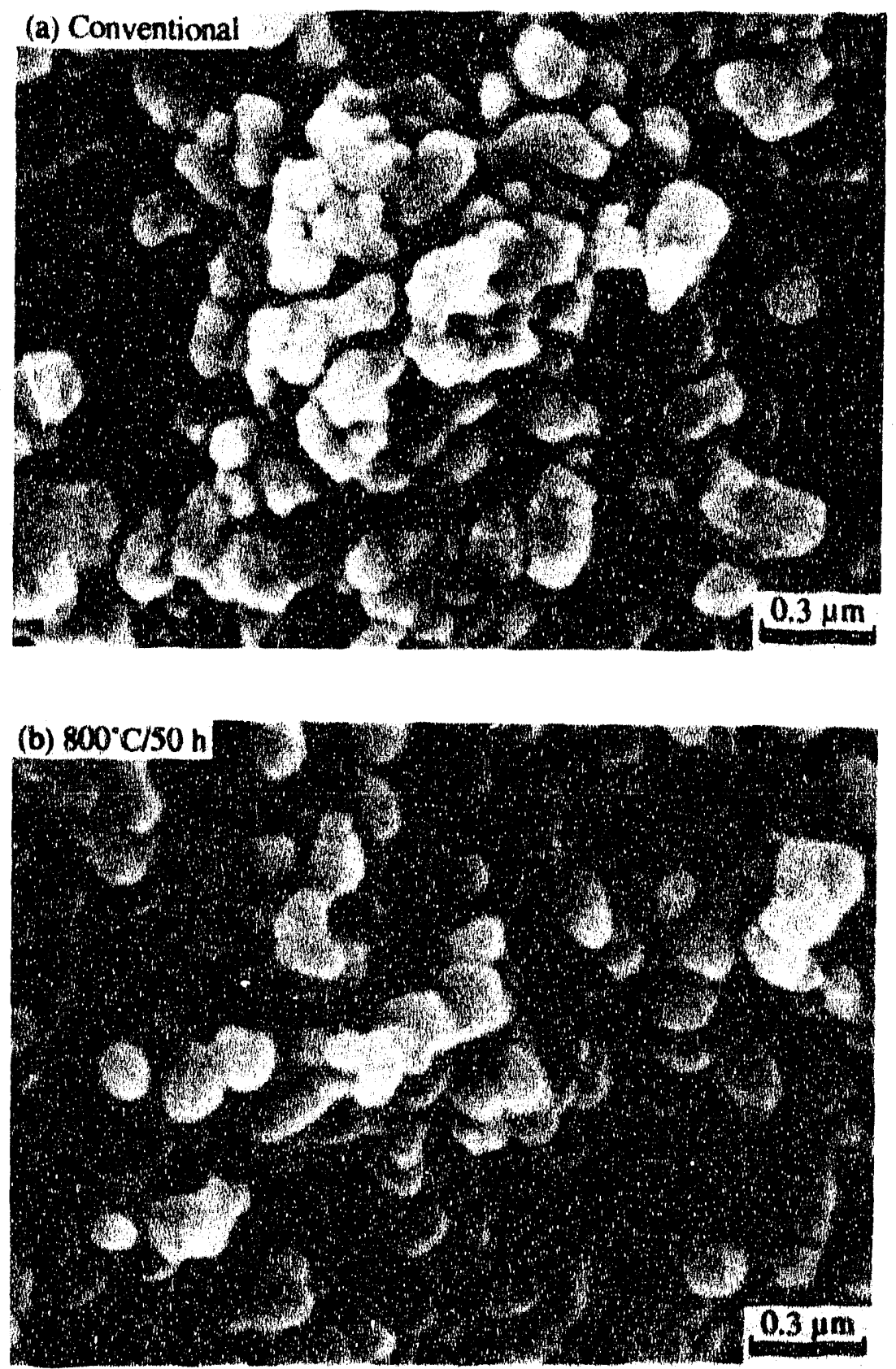

Figure 4.1 Scanning electron micrographs of fracture surfaces of unsintered $\mathrm{Al}_{2} \mathrm{O}_{3}$ compacts. Powder compacts were formed by isostatic pressing at $1380 \mathrm{MPa}$ : (a) asformed; (b) after $800^{\circ} \mathrm{C} / 50 \mathrm{~h}$ heat treatment. 


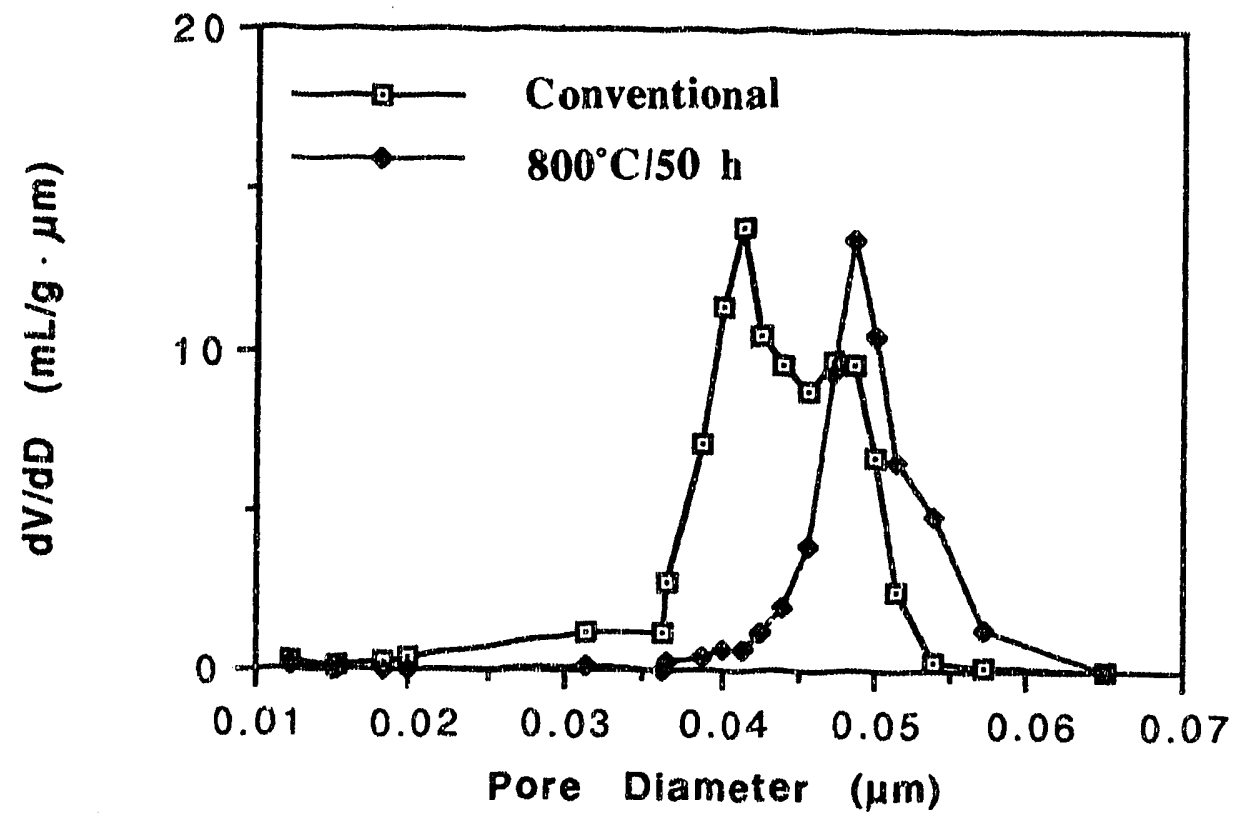

Figure 4.2 Plot of pore size distribution as a function of pore diameter obtained from mercury porosimetry for the conventional and $800^{\circ} \mathrm{C} / 50 \mathrm{~h}$ homogenized samples (before sintering). 
Two-dimensional four-sphere model for a small particle located in the internal pore.

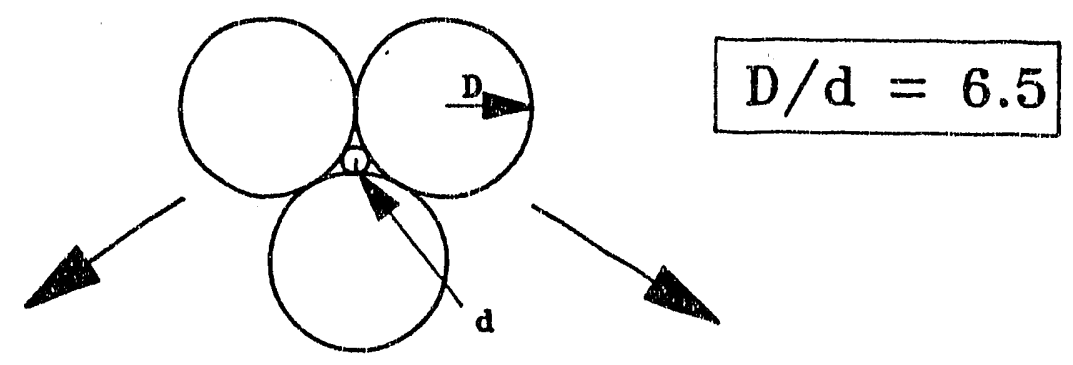

Homogenization Treatment Conventional Sintering Small particle disappears

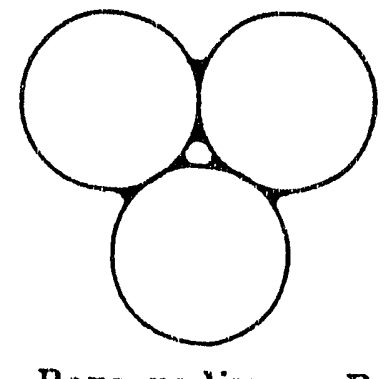

To the early stage

Pore radius $=\mathbf{R}$

$\mathrm{R} / \mathrm{r}=2.4$

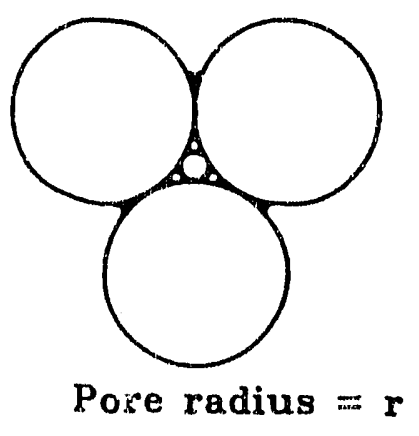

Figure 4.3 Schematic diagram of two-dimensional four-sphere model with the internal pore filled by a small particle. Pore radius of the array is varied for different thermal schedules. 

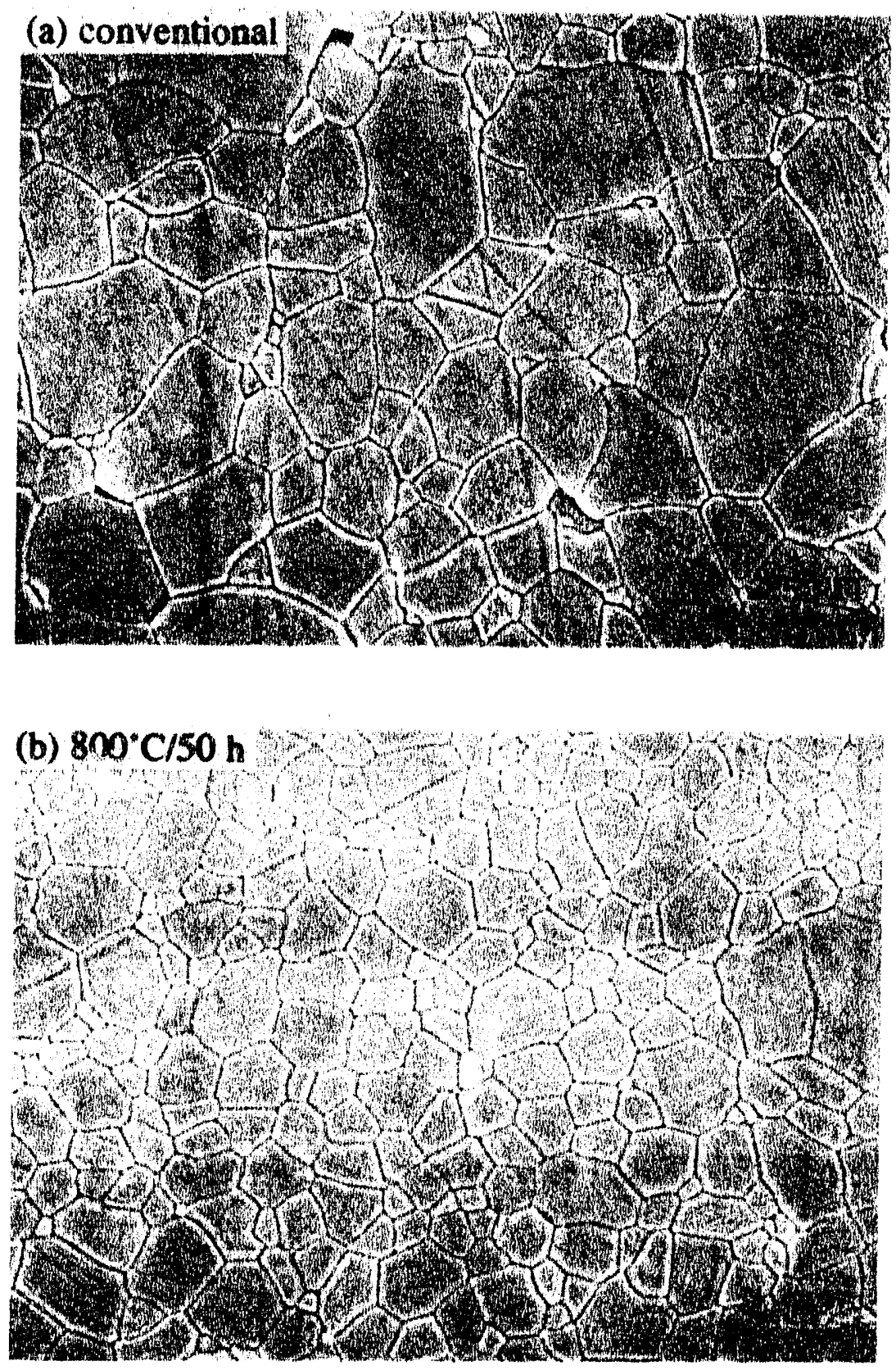

Fig ure 4.4 Scanning electron micrographs of polished and thermally etched surfaces of $\mathrm{Al}_{2} \mathrm{~J}_{3}$ samples sintened at a heating rate of $4^{\circ} \mathrm{C} / \mathrm{min}$. to $1450^{\circ} \mathrm{C}$ : (a) conventional sample, mean grain size is $1.52 \mu \mathrm{m}$; (b) $800^{\circ} \mathrm{C} / 50 \mathrm{~h}$ homogenized, mean grain size is $1.18 \mu \mathrm{m}$. 

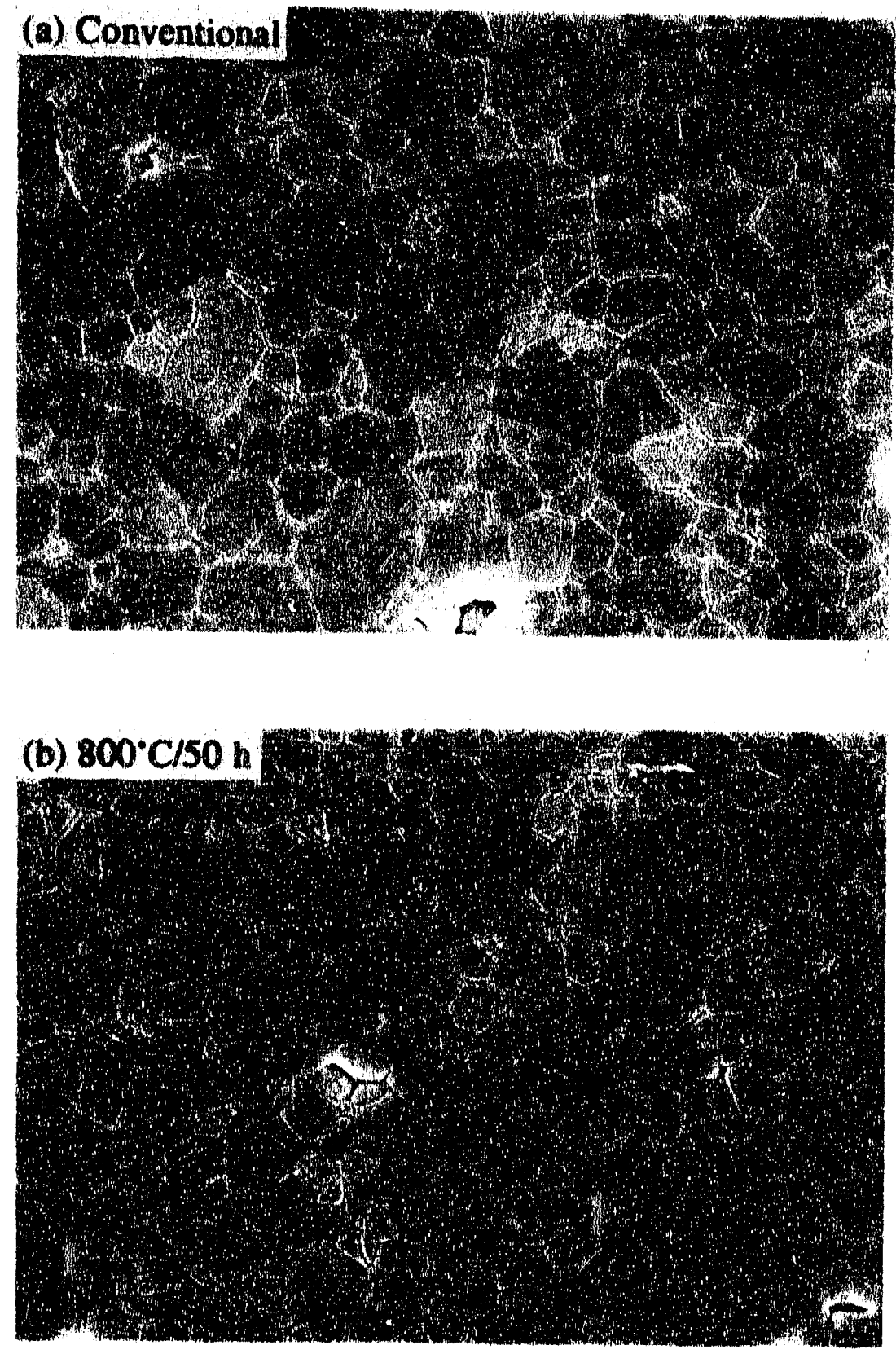

Figure 4.5 Another set of samples sintered at the same conditions as in Figure 4.4 with lower magnification showing nonuniform grain size distribution in the conventional sample. 


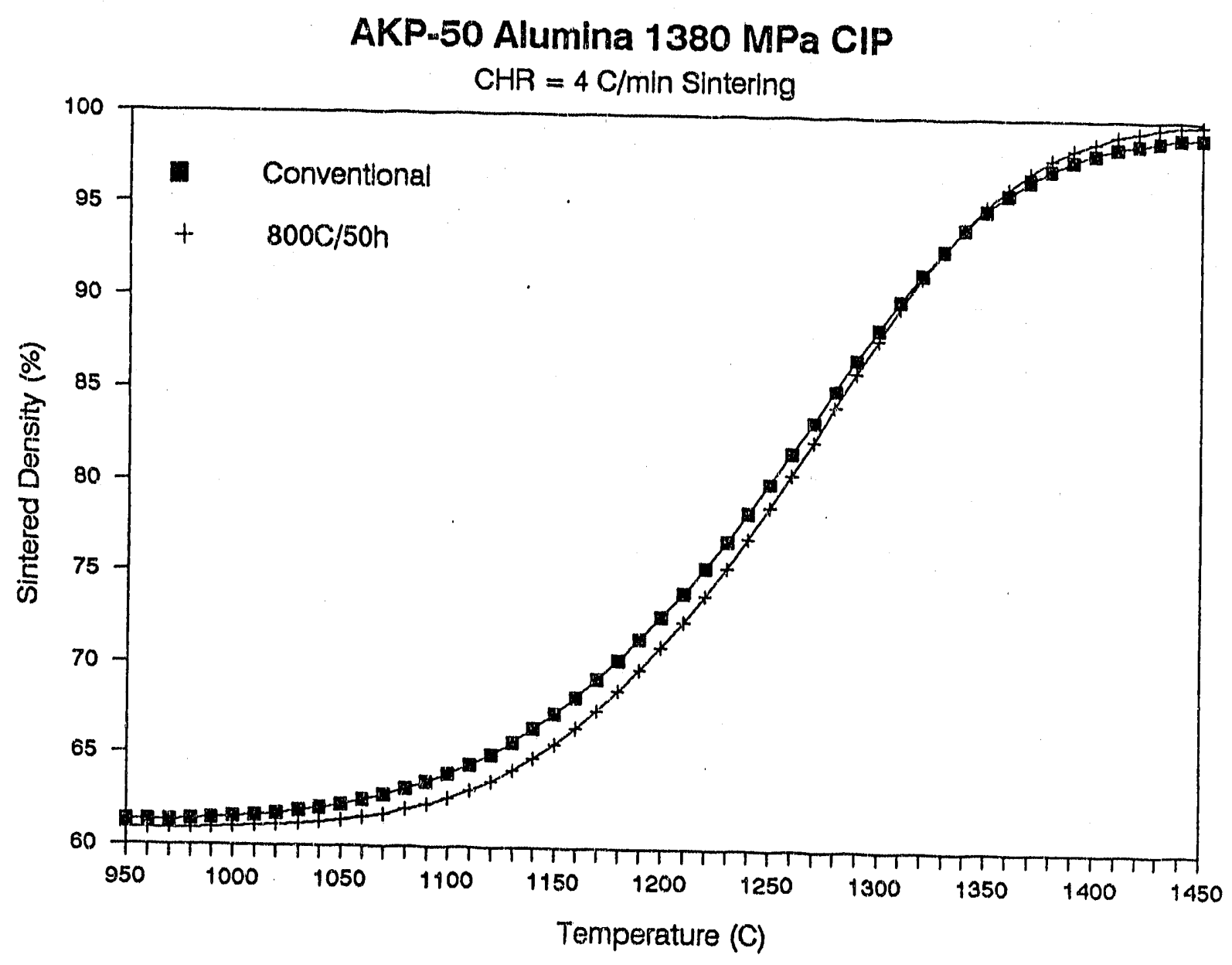

Figure 4.6 Evolution of instantaneous density as a function of temperature for the conventional and the homogenized samples sintered in air at a constant heating rate of $4^{\circ} \mathrm{C} / \mathrm{min}$. to $1450^{\circ} \mathrm{C}$ without soaking. 


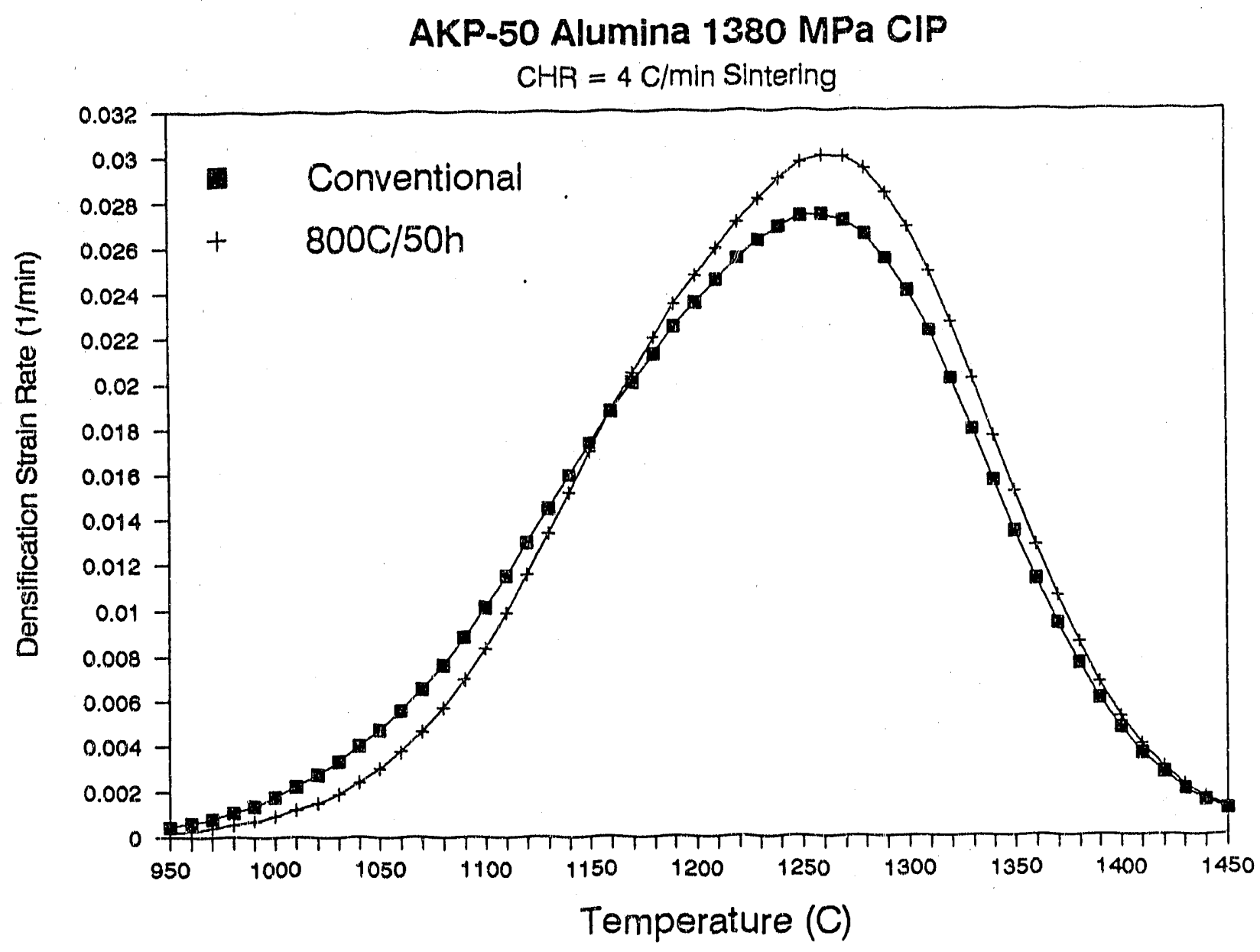

Figure 4.7 Plot of densification strain rate versus temperature for the conventional and the homogenized samples sirtered in air at a constant heating rate of $4^{\circ} \mathrm{C} / \mathrm{min}$. to $1450^{\circ} \mathrm{C}$ without soaking. 


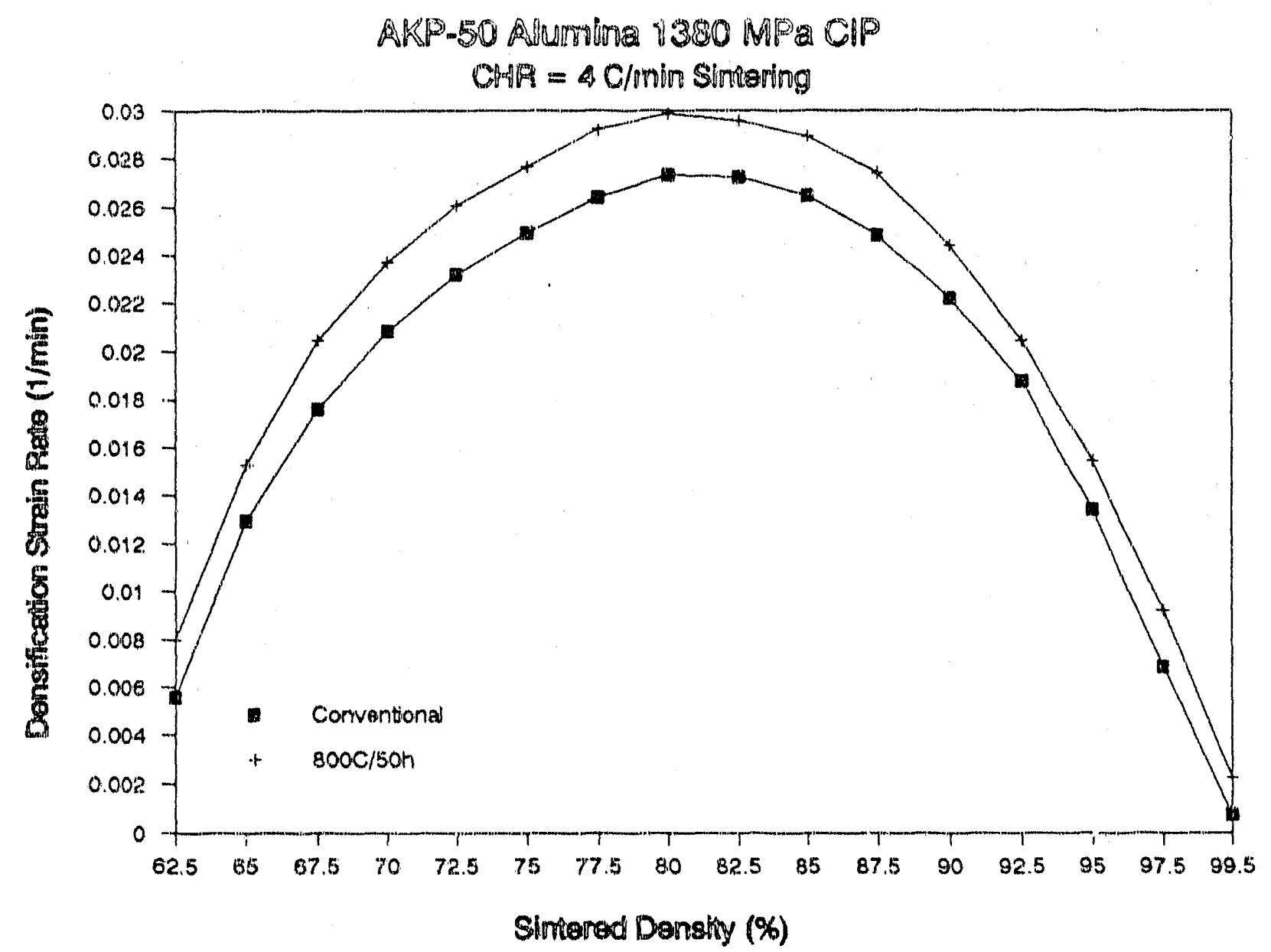

Figure 4.8 Plot of densification strain rate as a function of sintered density for the conventional and the homogenized sintered in air at a constant heating rate of $4^{\circ} \mathrm{C} / \mathrm{min}$. to $1450^{\circ} \mathrm{C}$ without soaking. 

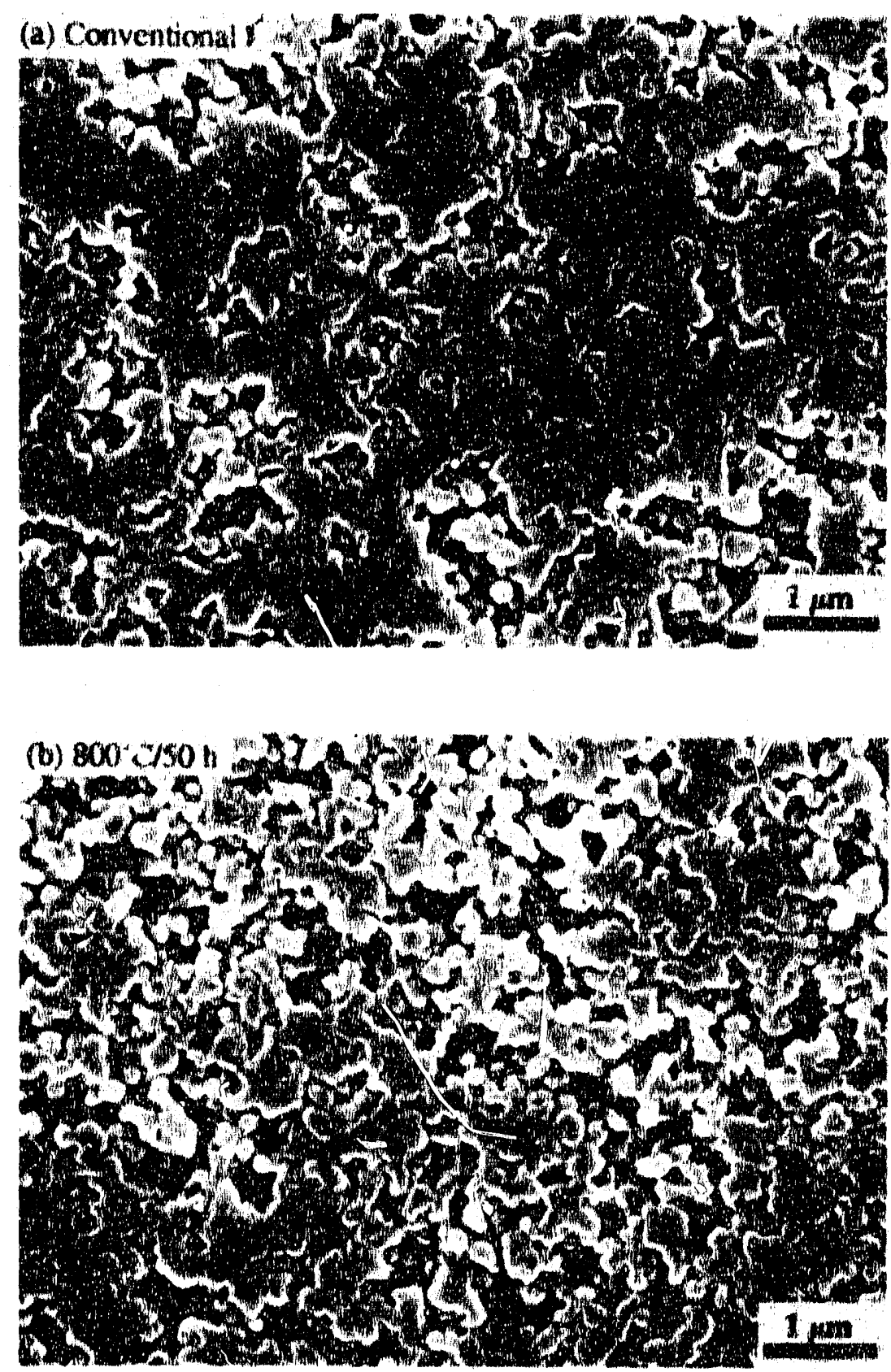

Figure 4.9 Scanning electron micrographs of polished and thermally etched surfaces of $\mathrm{Al}_{2} \mathrm{O}_{3}$ samples sintered at a heating rate of $4^{\circ} \mathrm{C} / \mathrm{min}$. $101200^{\circ} \mathrm{C}$ : (a) conventional sample, $\rho_{f}=0.76$ T.D.; (b) $800^{\circ} \mathrm{C} / 50$ h homogenized sample, $\rho_{f}=0.73$ T.D. 

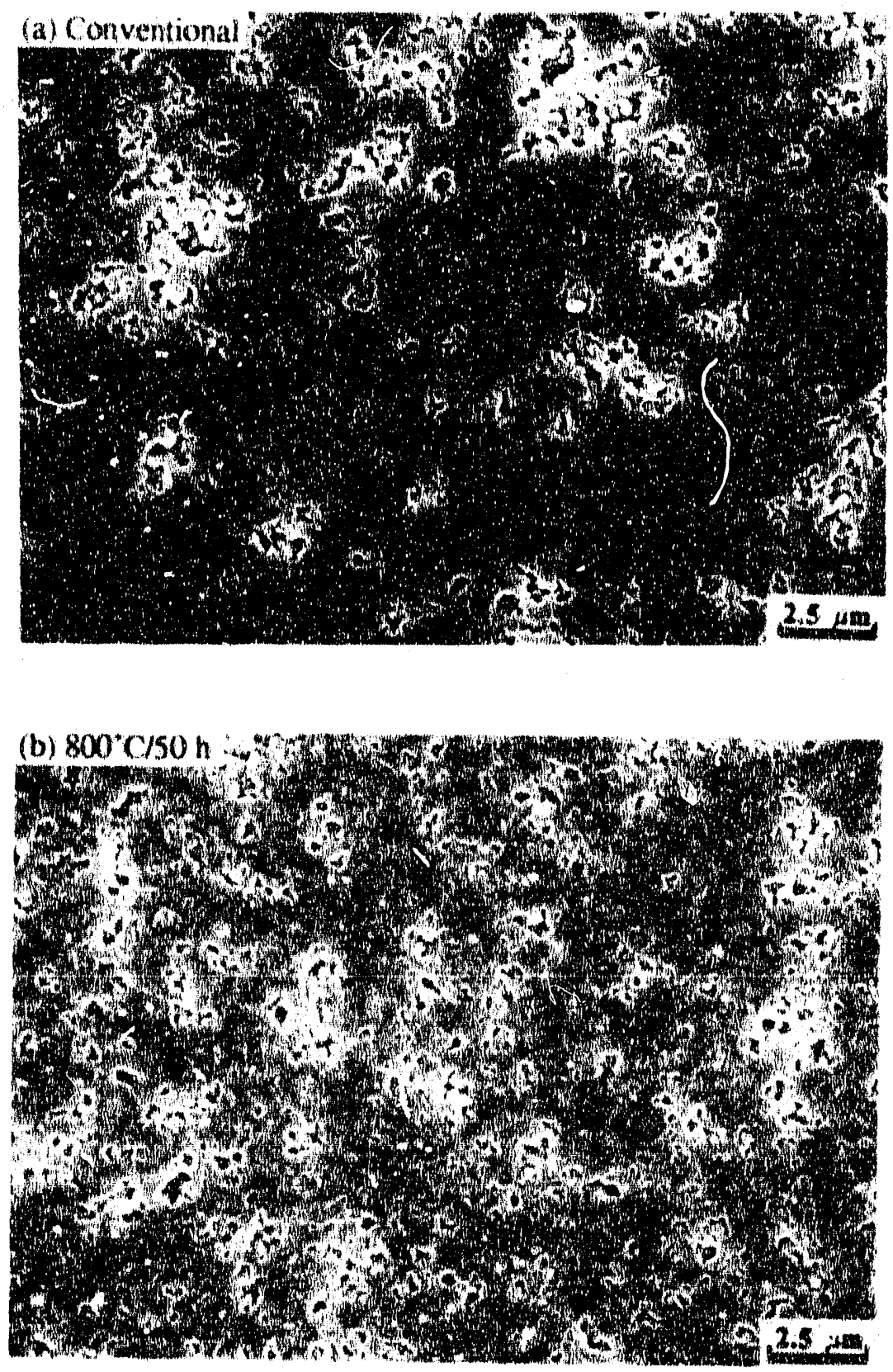

Figure 4.10 Scanning elictron micrographs of polished and the rmally etched surfaces of $\mathrm{Al}_{2} \mathrm{O}_{3}$ samples sintered at a heating rate of $4^{\circ} \mathrm{C} / \mathrm{min}$. to $1350^{\circ} \mathrm{C}$. Dense regions are surrounded by large pores in (a) conventional sample; pore size is small and uniformly distributed in (b) $800^{\circ} \mathrm{C} / 50 \mathrm{~h}$ homogenized sample. 

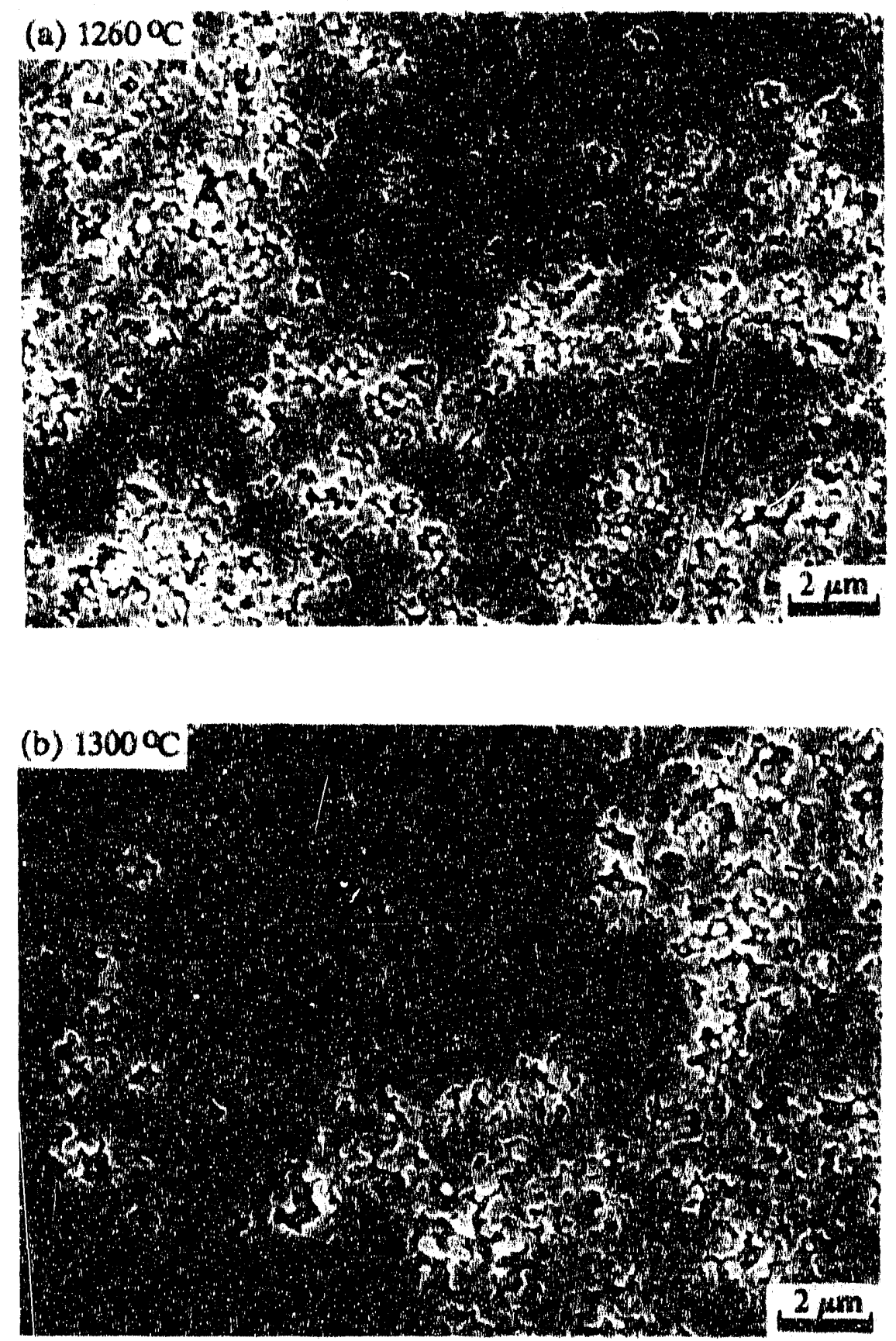

Figure 4.11 Scanning electron micrographs of the conventional samples sintered at a constant heating rate of $4^{\circ} \mathrm{C} / \mathrm{min}$. to different final temperatures: (a) $1260^{\circ} \mathrm{C}$; (b) $1300^{\circ} \mathrm{C}$; (c) $1350^{\circ} \mathrm{C} ;$ (d) $1400^{\circ} \mathrm{C}$ 

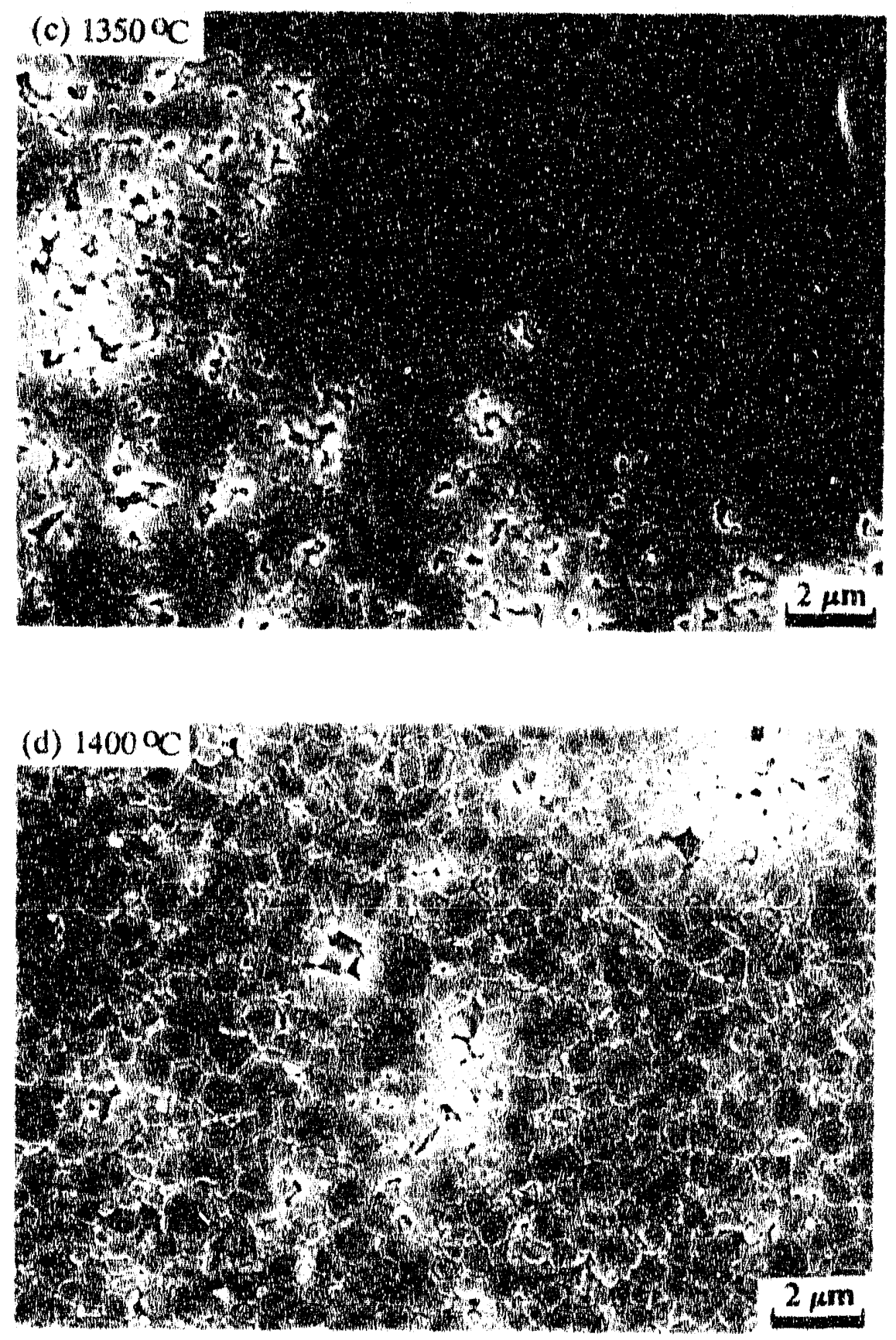

Figure 4.11 (Continued) Scanning electron micrographs of the conventional samples sintered at a constant heating rate of $4^{\prime \prime} \mathrm{C} / \mathrm{min}$. to different linal temperatures: (a) $1260^{\circ} \mathrm{C}$; (b) $13000^{\circ} \mathrm{C}$; (c) $13500^{\circ} \mathrm{C}$; (d) $140(1)^{\circ} \mathrm{C}$. 

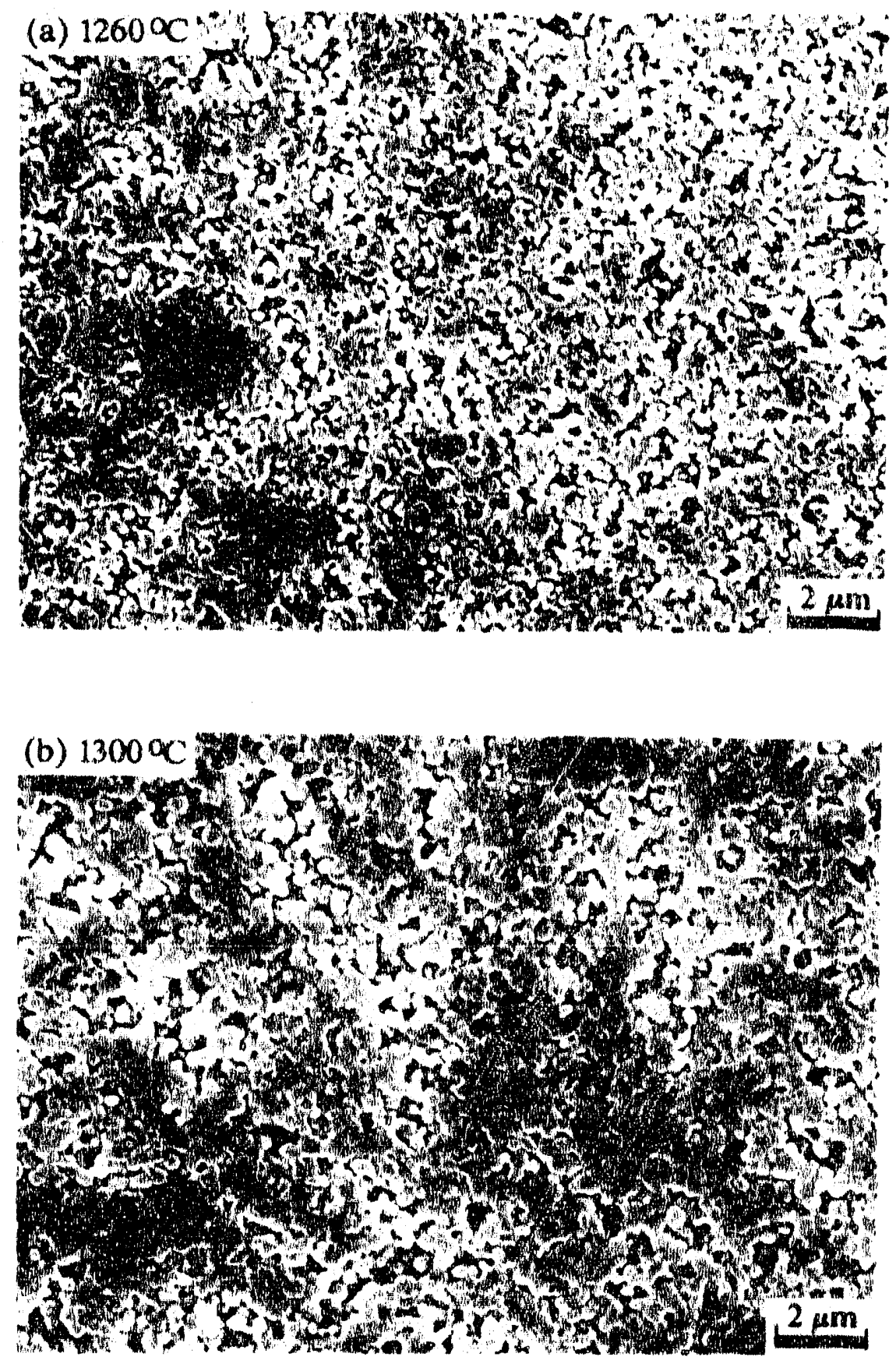

Figure 4.12 Scanning electron micrographs of the $800^{\circ} \mathrm{C} / 50$ h homogerized samples sintered at a constant heating rate of $4^{\circ} \mathrm{C} / \mathrm{min}$. to different final temperatures: (a) $1260^{\circ} \mathrm{C}$; (b) $1300^{\circ} \mathrm{C}$; (c) $1350^{\circ} \mathrm{C}$; (d) 1400$)^{\prime \prime} \mathrm{C}$. 

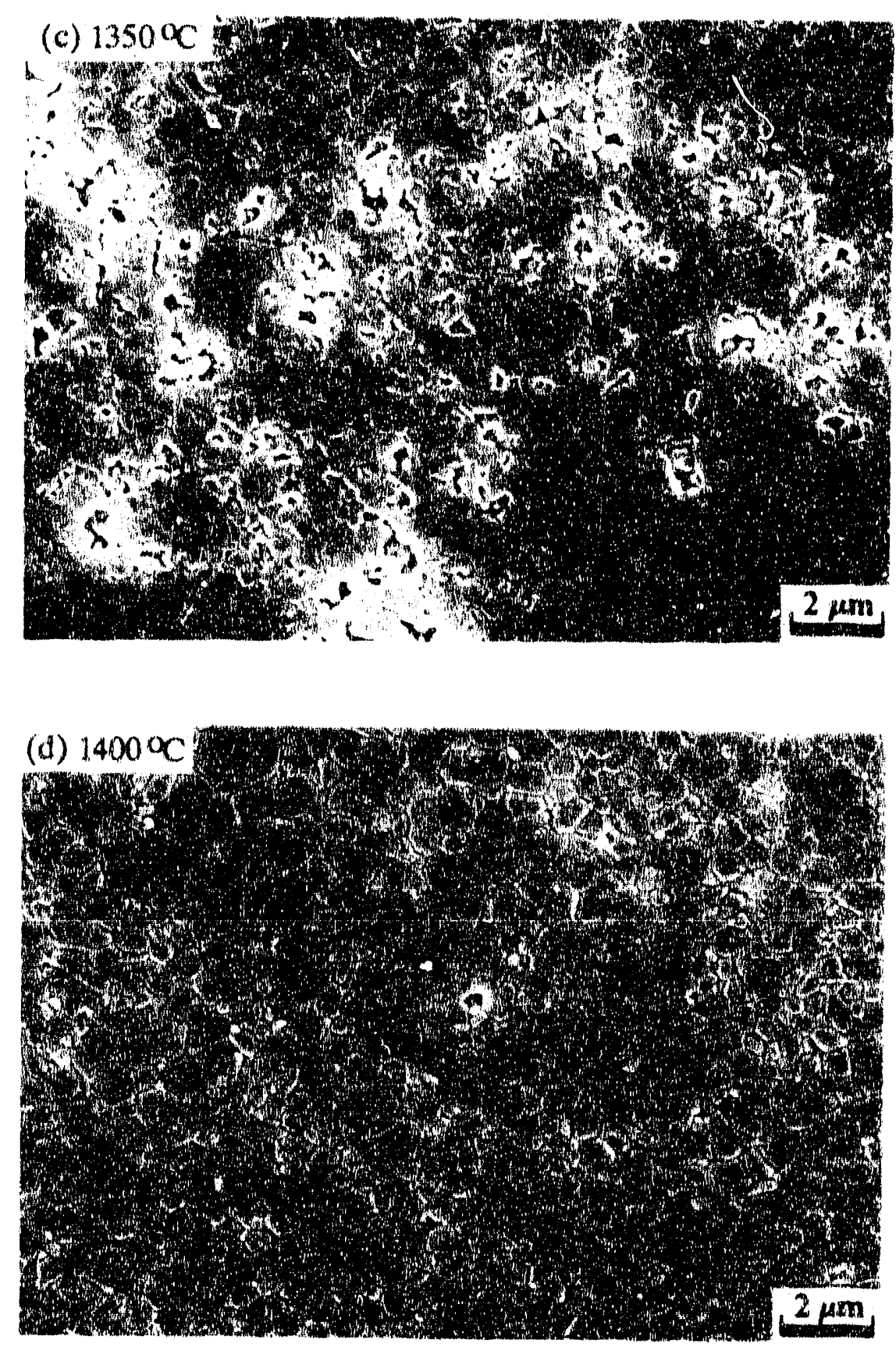

Figure 4.12 (Continued) Scanning electron micrographs of the $800^{\circ} \mathrm{C} / 50 \mathrm{~h}$ homogenized samples sintered at a constant heating rate of $4^{\circ} \mathrm{C} / \mathrm{min}$. to different final temperatures: (c) $1350^{\circ} \mathrm{C}$; (d) $1400^{\circ} \mathrm{C}$. 


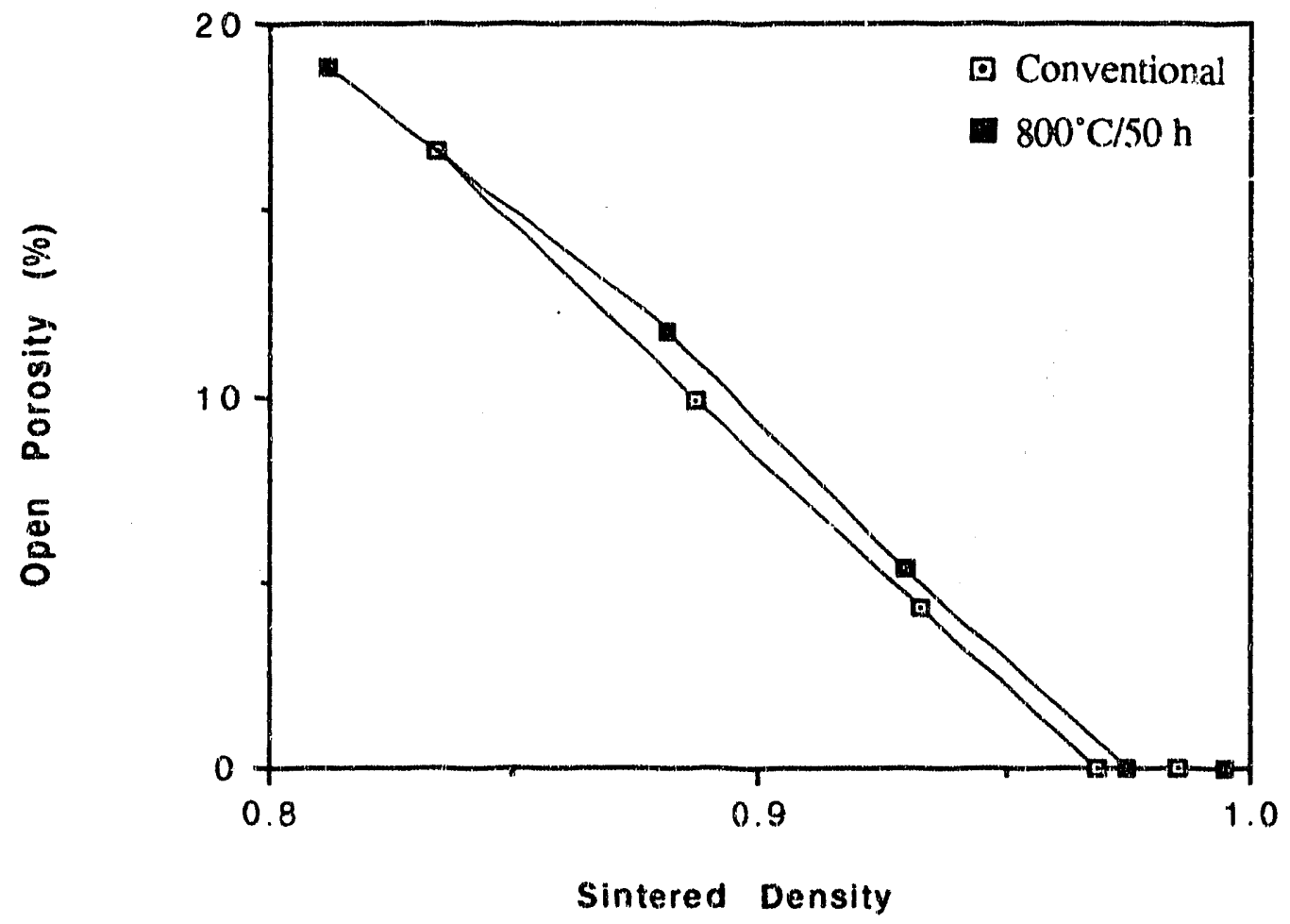

Figure 4.13 Variation of open porosity as a function of sintered density for the conventional and the homogenized samples sintered at a constant heating rate of $4^{\circ} \mathrm{C} / \mathrm{min}$. 


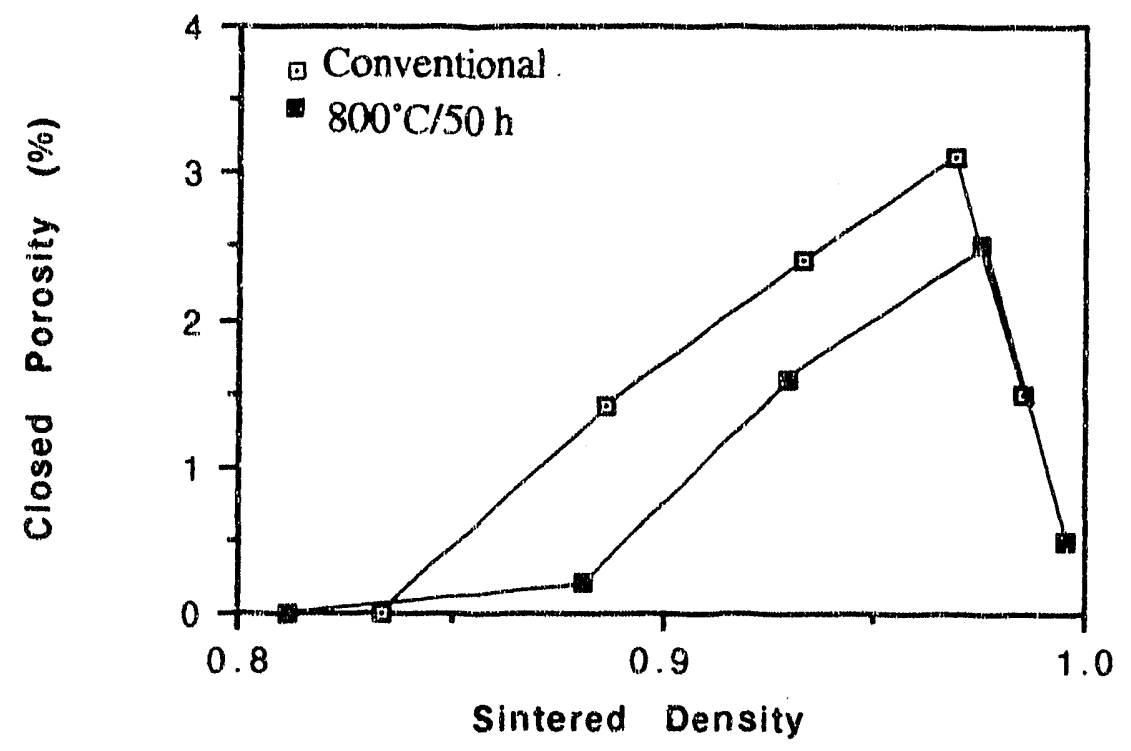

Figure 4.14 Variation of clos porosity as a function of sintered density for the conventional and the homogenized samples sintered at a constant heating rate of $4^{\circ} \mathrm{C} / \mathrm{min}$. 


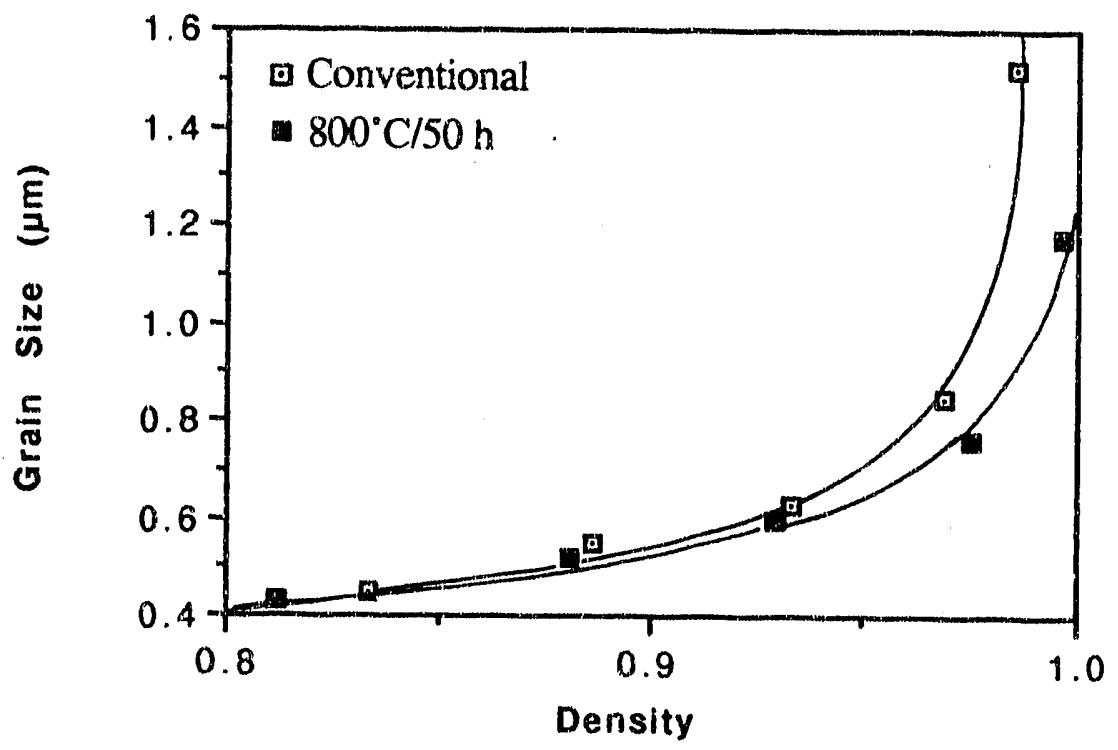

Figure 4.15 Plot of average grain size as a function of sintered density for the conventional and the $800^{\circ} \mathrm{C} / 50 \mathrm{~h}$ homogenized samples. The average grain size is significantly reduced at higher densities through the use of the homogenization heat treatment. 

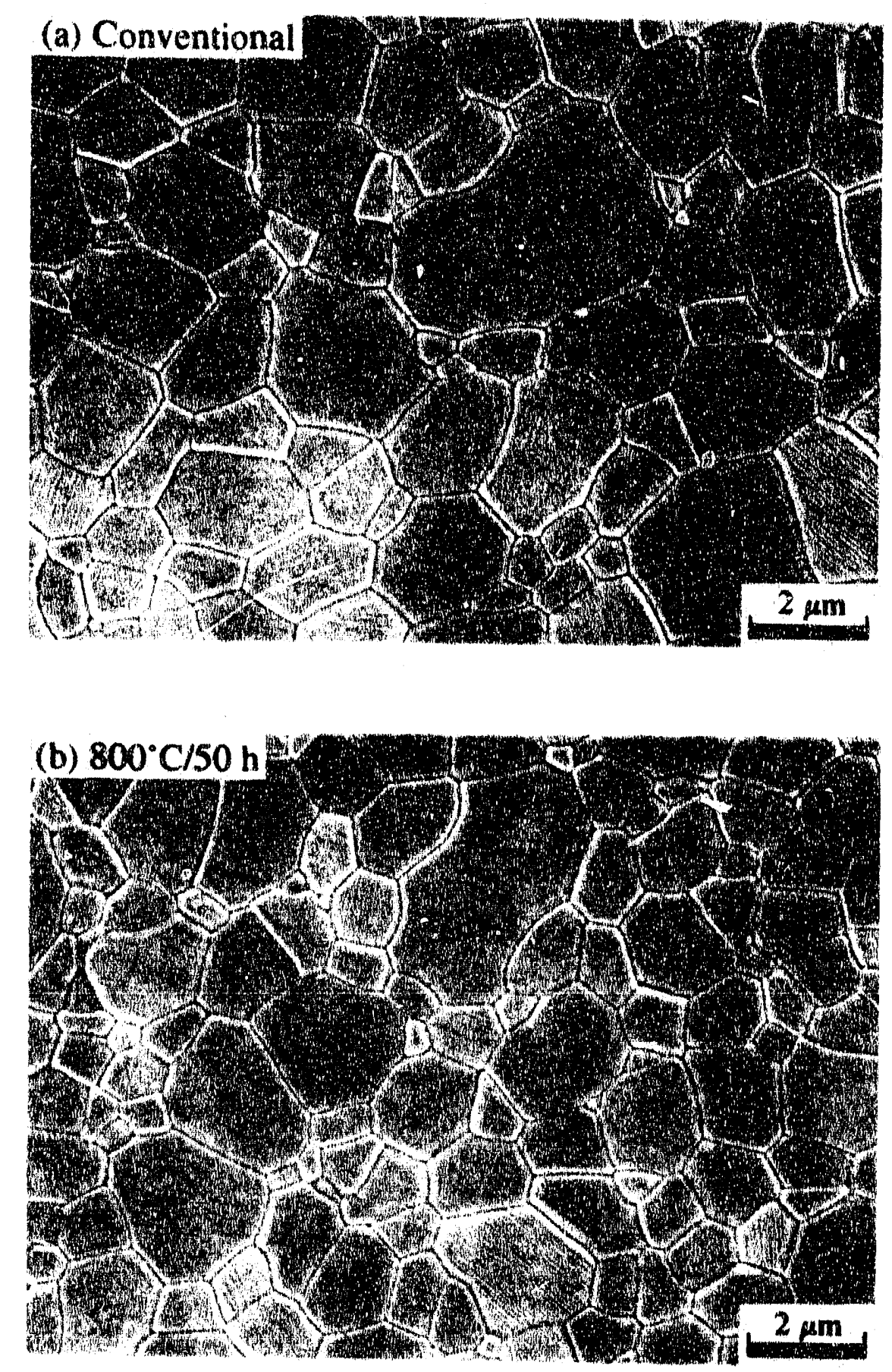

Figure 4.16 Scanning electron micrographs of polished anu ucumally etched surfaces of slip cast $\mathrm{Al}_{2} \mathrm{O}_{3}$ samples sintered at a heating rate of $4^{\circ} \mathrm{C} / \mathrm{min}$. to $1450^{\circ} \mathrm{C}$ without soaking: (a) conventional sample, mean grain size is $2.16 \mu \mathrm{m}$; (b) $800^{\circ} \mathrm{C} / 50 \mathrm{~h}$ homogenized, mean grain size is $1.84 \mu \mathrm{m}$. 


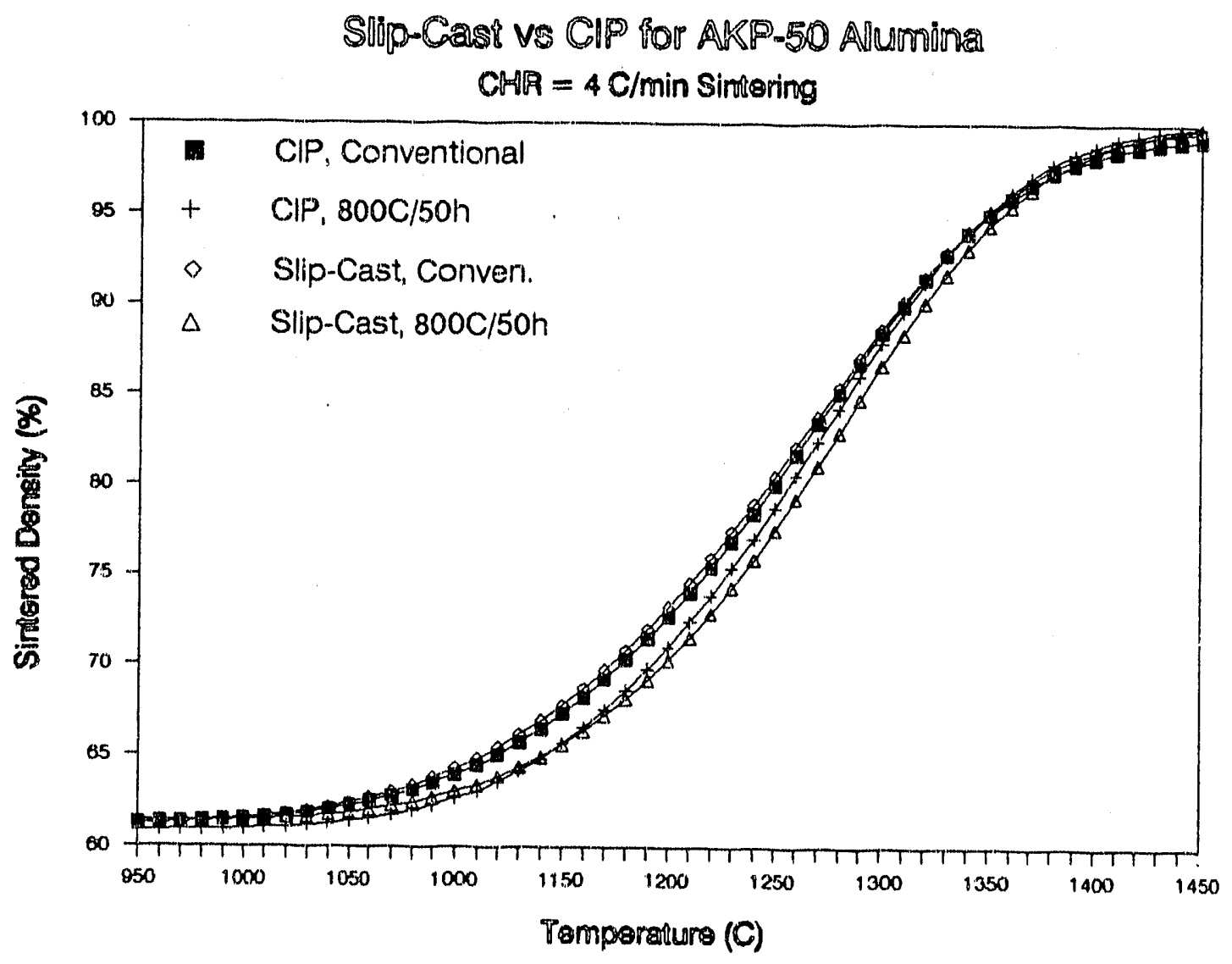

Figure 4.17 Sintered density is plotted as a function of temperature for powder compacts formed by isostatic pressing and slip casting techniques. Sintering was conducted for the conventional and the homogenized samples at a constant heating rate of $4^{\circ} \mathrm{C} / \mathrm{min}$. to $1450^{\circ} \mathrm{C}$ in air. 


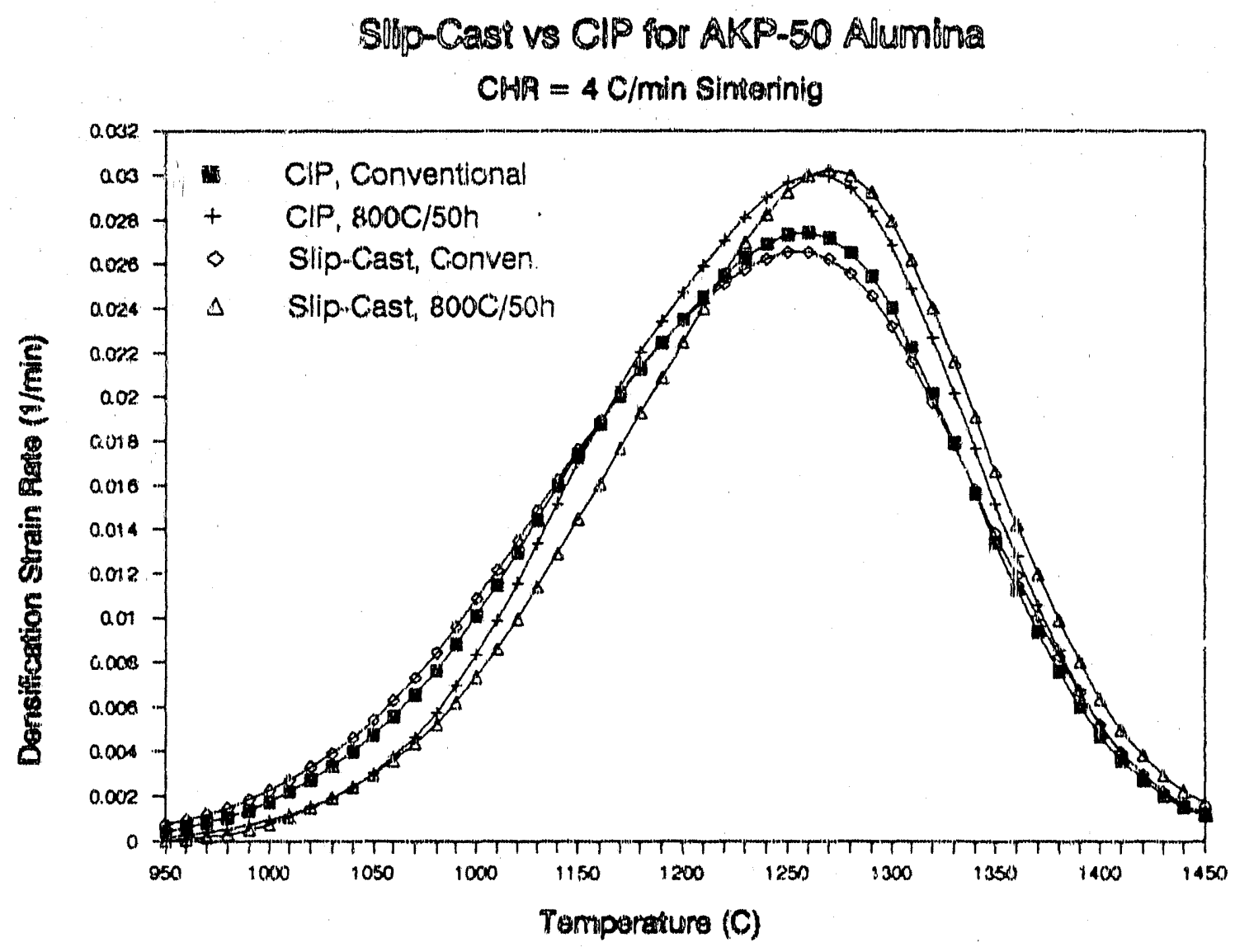

Figure 4.18 Densification rate is plotted as a function of temperature for powder compacts formed by isostatic pressing and slip casting techniques. Sintering was conducted for the conventional and the homogenized samples at a constant heating rate of $4^{\circ} \mathrm{C} / \mathrm{min}$ to $1450^{\circ} \mathrm{C}$ in air. 


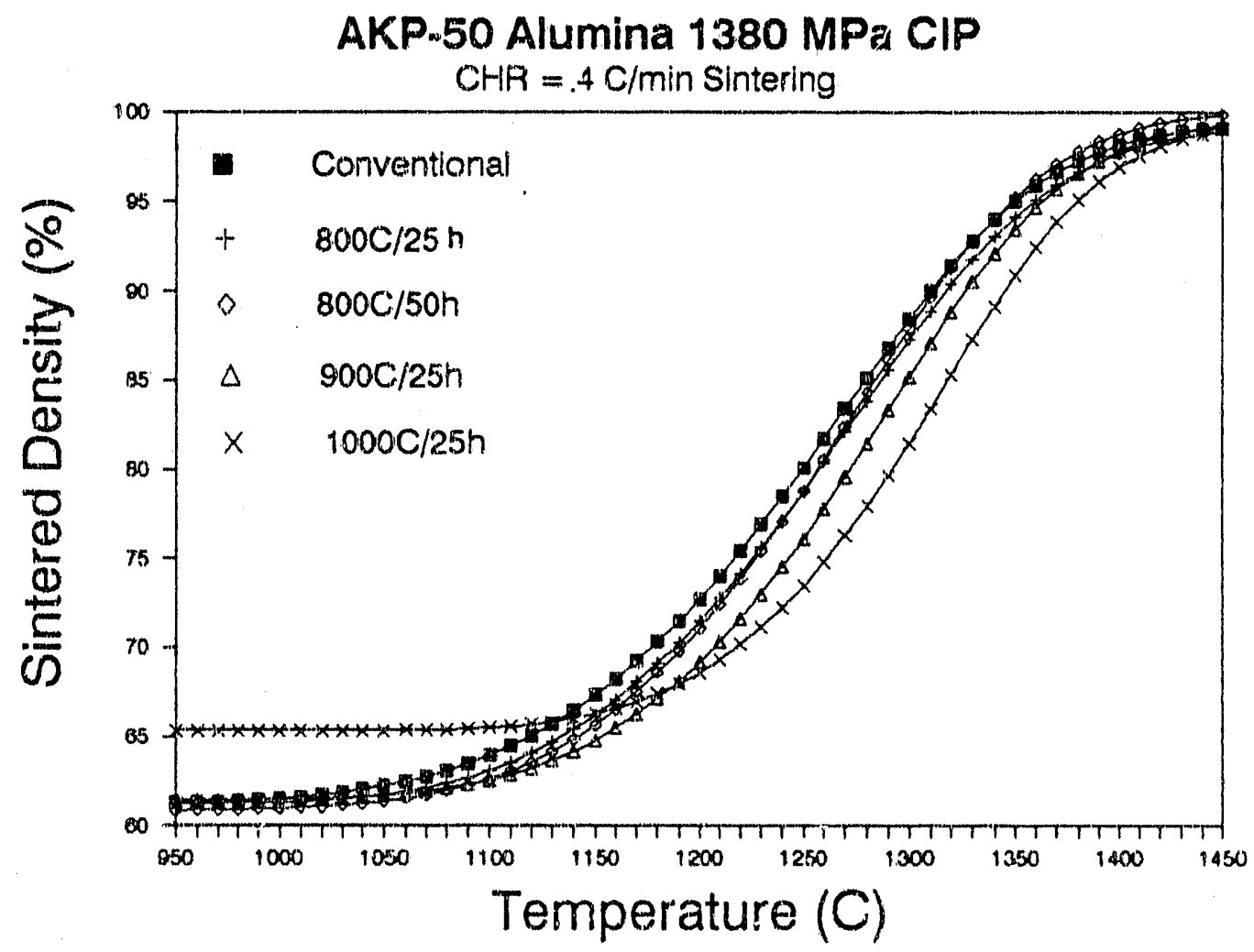

Figure 4.19 Sintered density is plotted as a function of temperature for powder compacts formed by isostatic pressing. Sintering was conducted at a constant heating rate of $4^{\circ} \mathrm{C} / \mathrm{min}$ to $1450^{\circ} \mathrm{C}$ in air. 


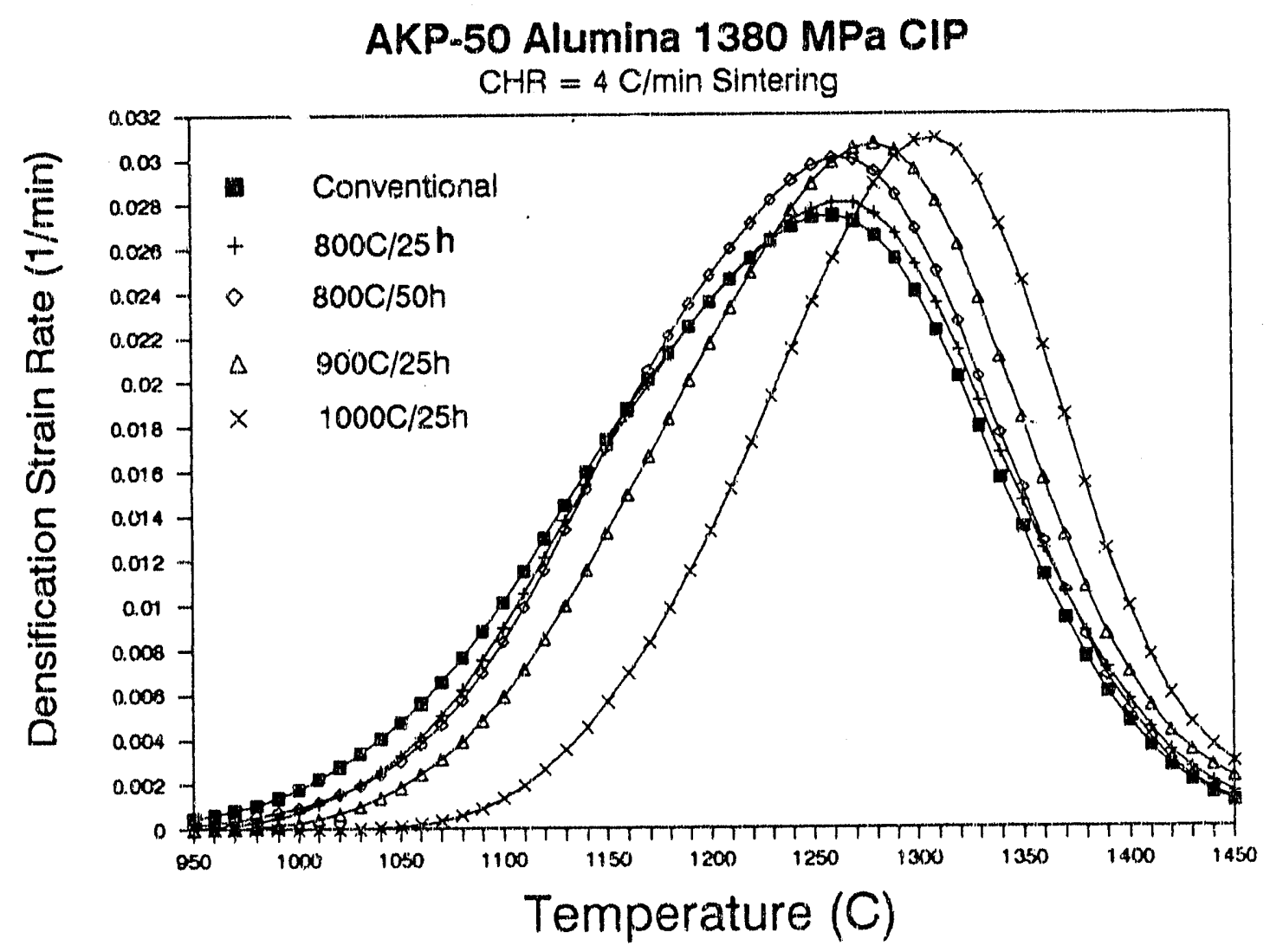

Figure 4.20 Densification rate is plotted as a function of temperature for powder compacts formed by isostatic pressing $(\approx 1380 \mathrm{MPa})$. Sintering was conducted at a constant heating rate of $4^{\circ} \mathrm{C} / \mathrm{min}$. to $1450^{\circ} \mathrm{C}$ in air. 

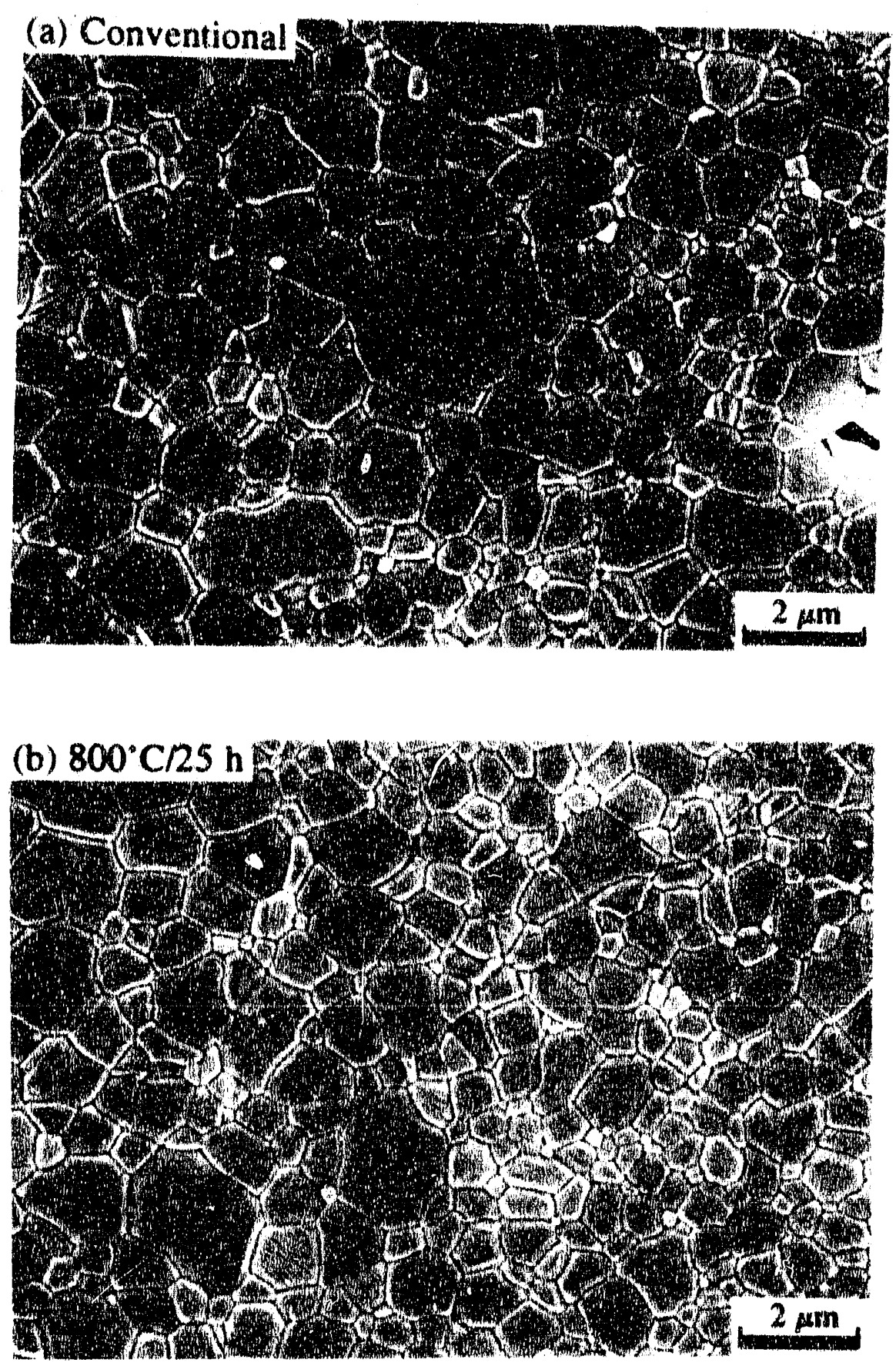

Figure 4.21 Scanning electron micrographs of polished and thermally etched surfaces of $\mathrm{Al}_{2} \mathrm{O}_{3}$ compacts sintered at a constant heating rate of $4^{\circ} \mathrm{C} / \mathrm{min}$, to $1400^{\circ} \mathrm{C}$ : (a) conventional sample; (b) $800^{\circ} \mathrm{C} / 25 \mathrm{~h}$ homogenized; (c) $800^{\circ} \mathrm{C} / 50 \mathrm{~h}$ homogenized; (d) $900^{\circ} \mathrm{C} / 25 \mathrm{~h}$ homogenized; (e) 1000$)^{\circ} \mathrm{C} / 25$ h homogenized. 

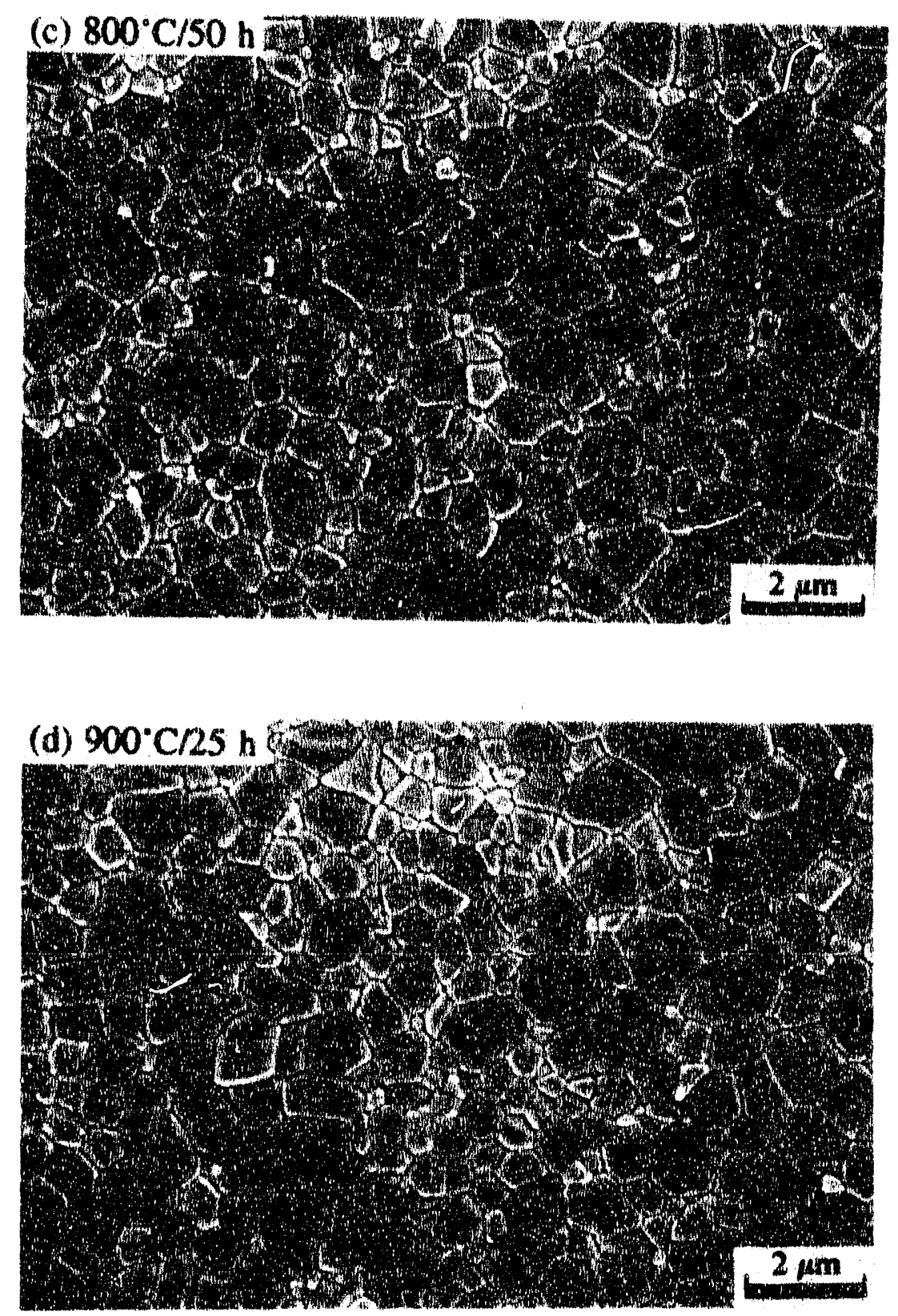

Figure 4.21 (Continued) Scanning electron micrographs of polished and thermally etched surfaces of $\mathrm{Al}_{2} \mathrm{O}_{3}$ compacts sintered at a constant heating rate of $4^{\circ} \mathrm{C} / \mathrm{min}$. to $1400^{\circ} \mathrm{C}$ : (a) conventional sample; (b) $800^{\circ} \mathrm{C} / 25 \mathrm{~h}$ homogenized; (c) $800^{\circ} \mathrm{C} / 50 \mathrm{~h}$ homogenized; (d) $900^{\circ} \mathrm{C} / 25 \mathrm{~h}$ homogenized; (e) $1000^{\circ} \mathrm{C} / 25$ h hornogenized. 


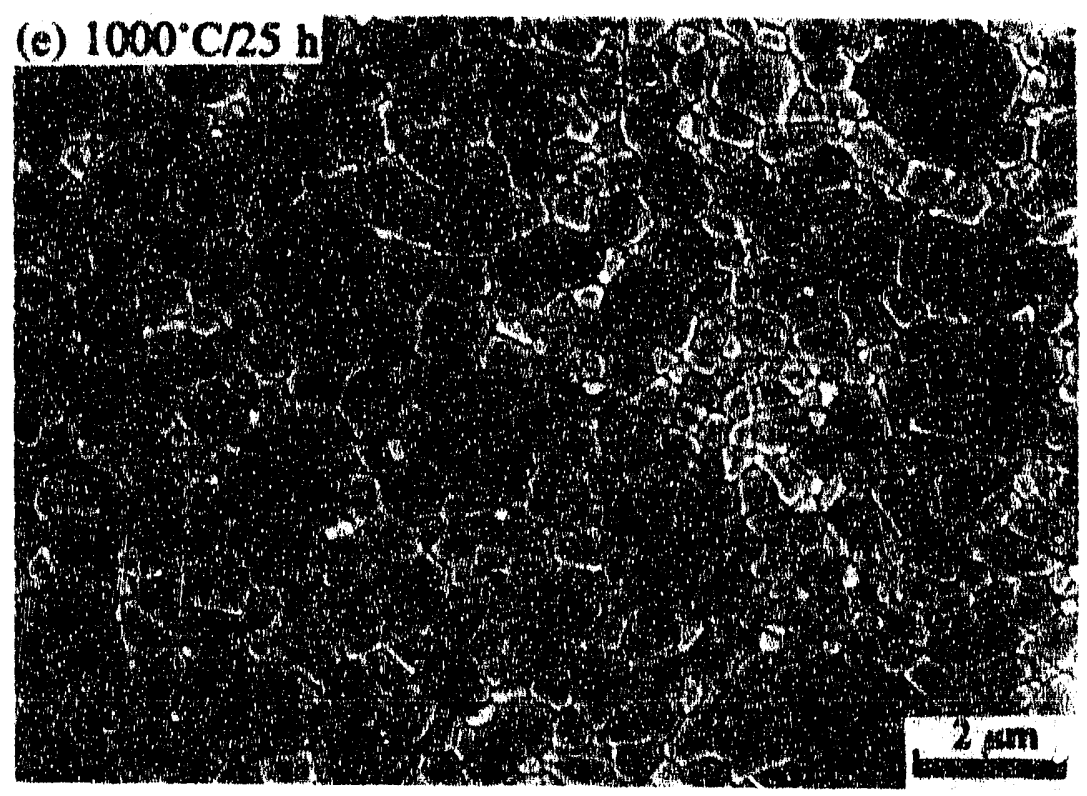

Figure 4.21 (Continued) Scanning electron micrographs of polished and thermally etched suri ses of $\mathrm{Al}_{2} \mathrm{O}_{3}$ compacts sintered at a constant heating rate of $4^{\circ} \mathrm{C} / \mathrm{min}$. to $1400^{\circ} \mathrm{C}$ : (a) conventional sample; (b) $800^{\circ} \mathrm{C} / 25$ h homogenized; (c) $800^{\circ} \mathrm{C} / 50$ h homogenized; (d) $900^{\circ} \mathrm{C} / 25$ h homogenized; (e) $10(X)^{\circ} \mathrm{C} / 25 \mathrm{~h}$ homogenized. 

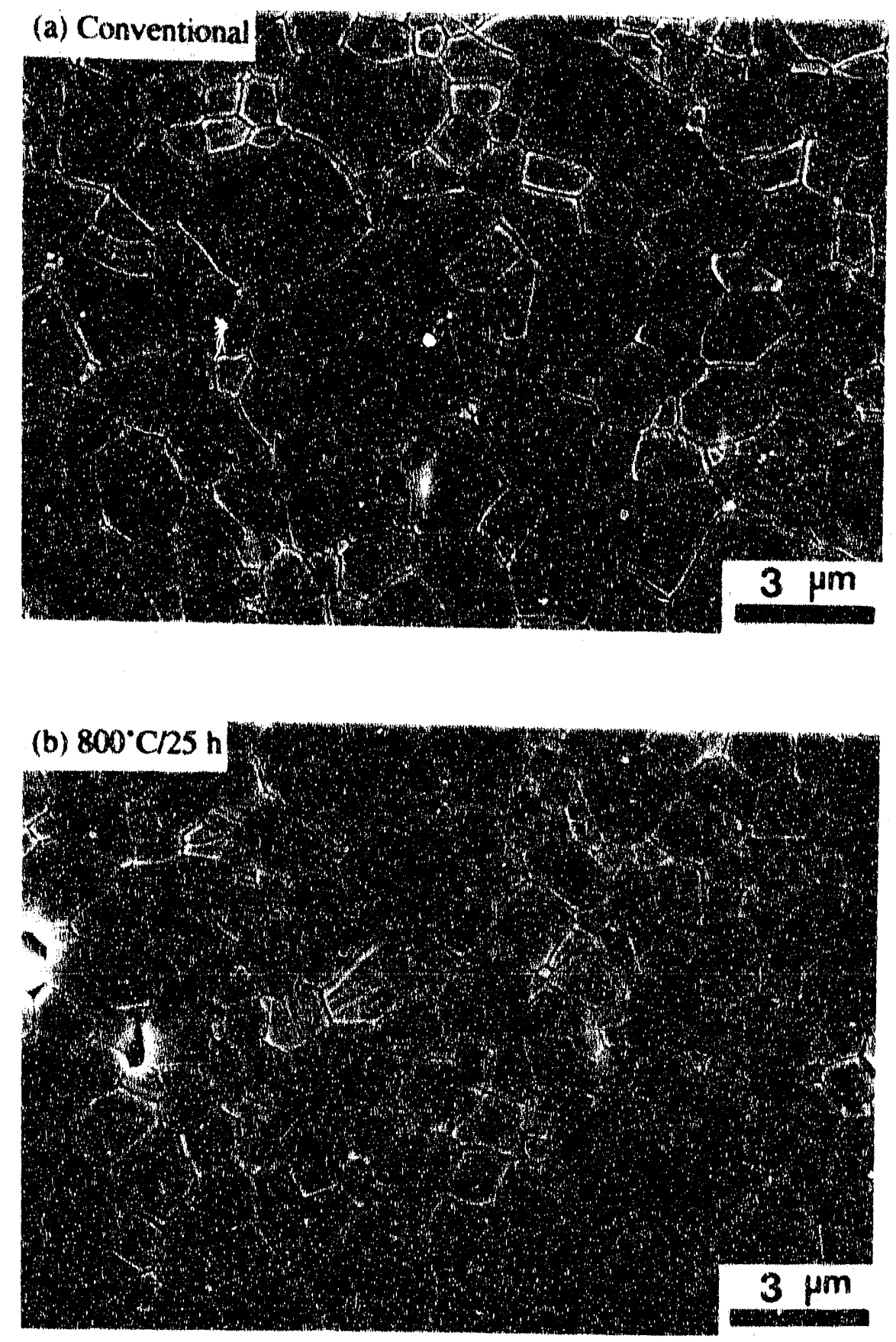

Figure 4.22 Scanning electron micrographs of polished and thermally etched surfaces of $\mathrm{Al}_{2} \mathrm{O}_{3}$ compacts sintered at a constant heating rate of $4^{\circ} \mathrm{C} / \mathrm{min}$. to $1450^{\circ} \mathrm{C}$ : (a) conventional sample; (b) $8\left(10^{\circ} \mathrm{C} / 25 \mathrm{~h}\right.$ homogenized; (c) $800^{\circ} \mathrm{C} / 50 \mathrm{~h}$ homogenized; (d) $900^{\circ} \mathrm{C} / 25$ h homogenized; (e) 100()$^{\circ} \mathrm{C} / 25$ h homogenized. 

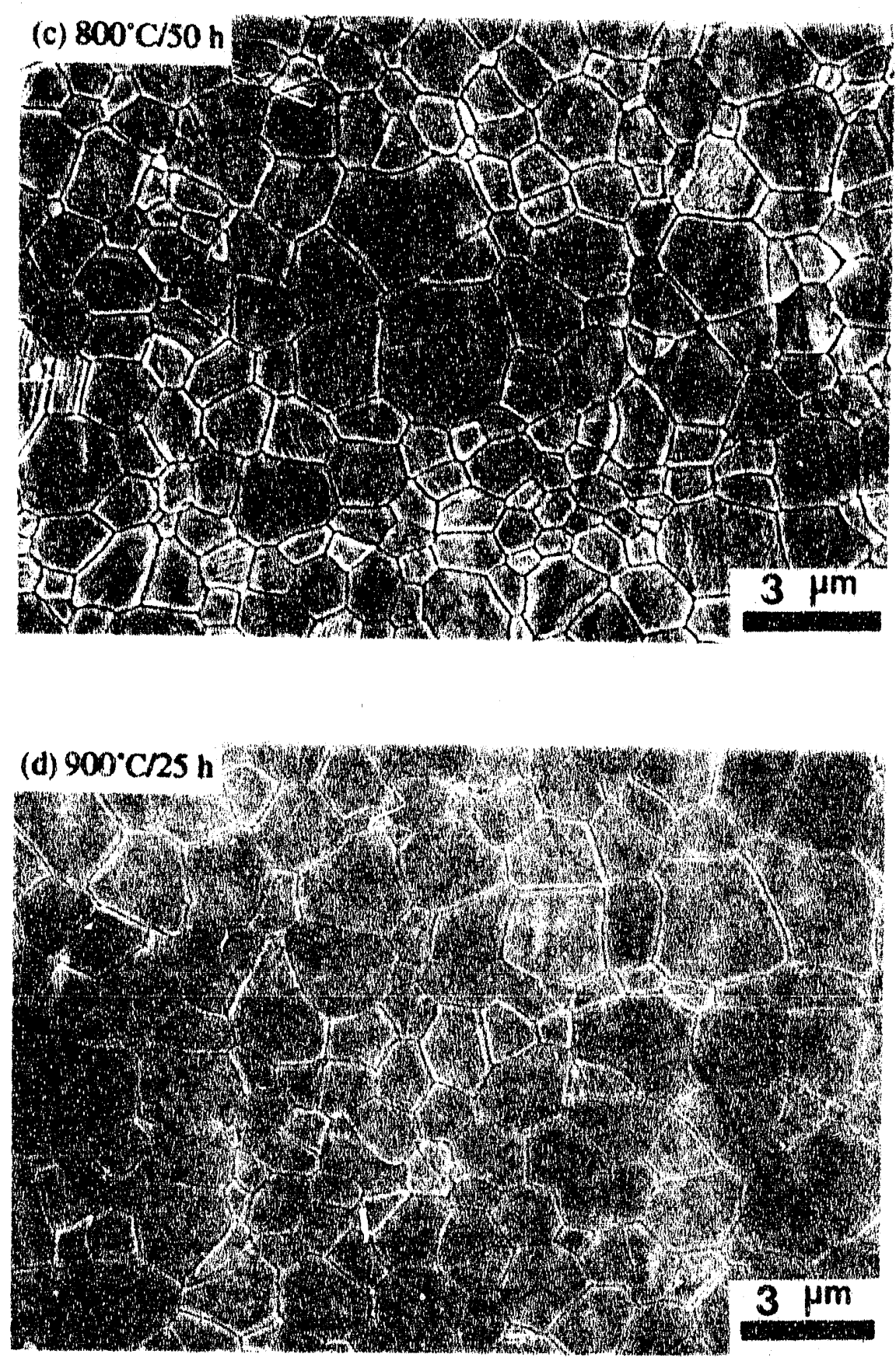

Figure 4.22 (Continued) Scanning electron micrographs of polished and thermally etched surfaces of $\mathrm{Al}_{2} \mathrm{O}_{3}$ compacts sintered at a constant heating rate of $4^{\circ} \mathrm{C} / \mathrm{min}$. to $1450^{\circ} \mathrm{C}$ : (a) conventional sample; (b) $800^{\circ} \mathrm{C} / 25 \mathrm{~h}$ homogenized; (c) $800^{\circ} \mathrm{C} / 50 \mathrm{~h}$ homogenized; (d) $900^{\circ} \mathrm{C} / 25 \mathrm{~h}$ homogenized; (e) $10000^{\circ} \mathrm{C} / 25 \mathrm{~h}$ homogenized. 


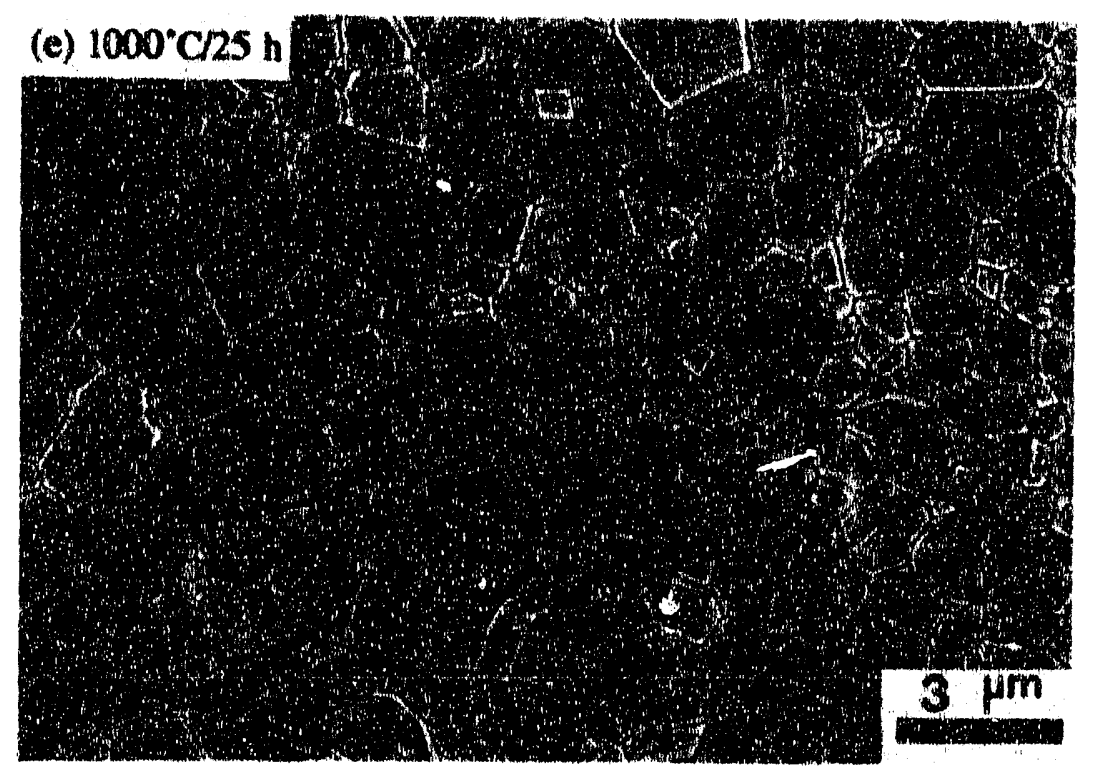

Figure 4.22 (Continued) Scanning electron micrographs of polished and thermally etched surfaces of $\mathrm{Al}_{2} \mathrm{O}_{3}$ compacts sintered at a constant heating rate of $4^{\circ} \mathrm{C} / \mathrm{min}$. to $1450^{\circ} \mathrm{C}$ : (a) conventional sample; (b) $800^{\circ} \mathrm{C} / 25$ h homogenized; (c) $800^{\circ} \mathrm{C} / 50$ h homogenized; (d) $900^{\circ} \mathrm{C} / 25$ h homogenized; (e) $10 \times()^{\circ} \mathrm{C} / 25$ h homogenized. 

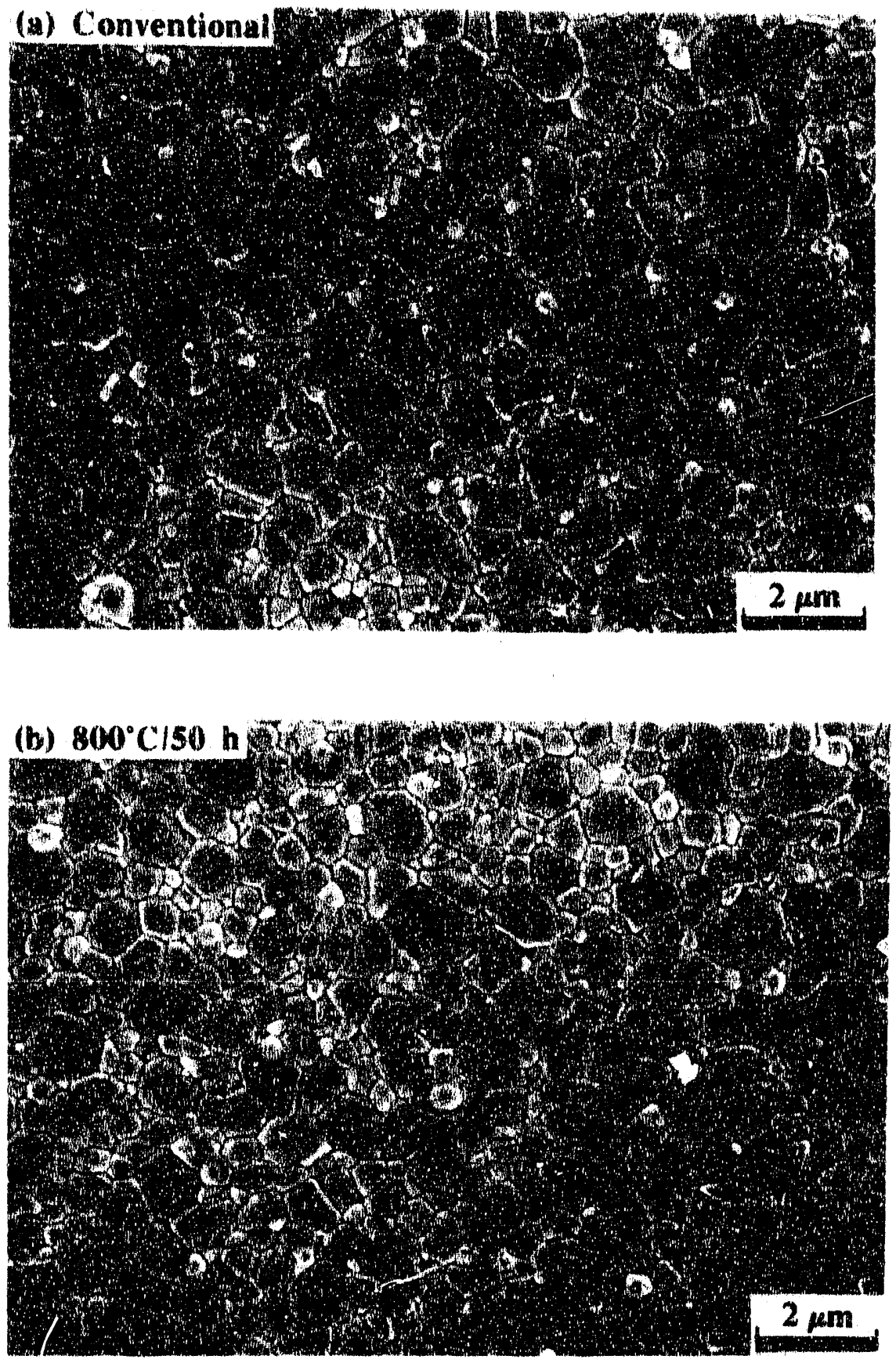

Figure 4.23 Scanning electron micrographs of polished and thermally etched surfaces of $250 \mathrm{ppm} \mathrm{MgO}$-doped $\mathrm{Al}_{2} \mathrm{O}_{3}$ compacts formed by isostatic pressing. Sintering was conducted at a constant heating rate of $5^{\circ} \mathrm{C} / \mathrm{min}$. lo $1450^{\circ} \mathrm{C}$ : (a) conventional sample; (b) $800^{\circ} \mathrm{C} / 50 \mathrm{~h}$ homogenized; (c) $800^{\circ} \mathrm{C} / 100 \mathrm{~h}$ homogenized; (d) $800^{\circ} \mathrm{C} / 200 \mathrm{~h}$ homogenized. 

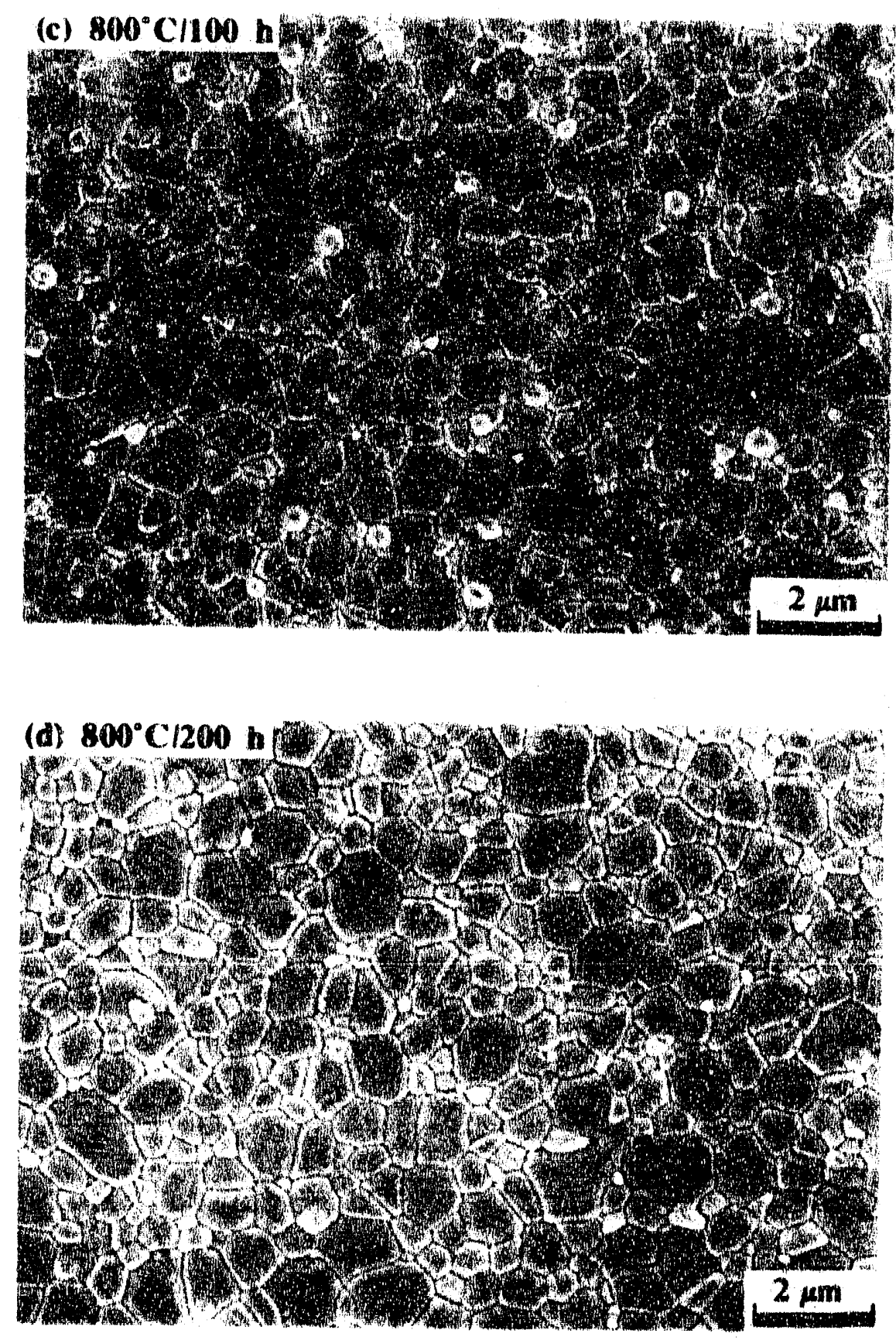

Figure 4.23 (Continued) Scanning electron micrographs of polished and thermally etched surfaces of $250 \mathrm{ppm} \mathrm{MgO}$-doped $\mathrm{Al}_{2} \mathrm{O}_{3}$ compacts formed by isostatic pressing. Sintering was conducted at a constant heating rate of $5^{\circ} \mathrm{C} / \mathrm{min}$. to $1450^{\circ} \mathrm{C}$; (c) $800^{\circ} \mathrm{C} / 100$ h homogenized; (d) $800^{\circ} \mathrm{C} / 200 \mathrm{~h}$ homogenized. 


\section{(a) Conventional}

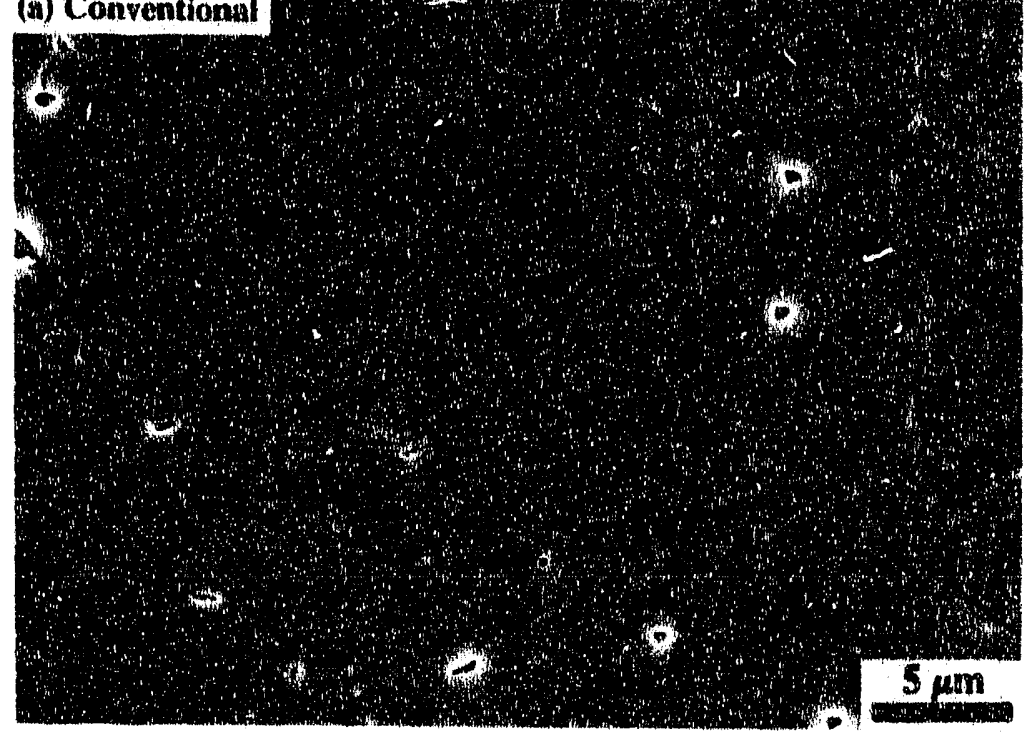

Figure 4.24 Scanning electron micrographs of polished and thermally etched surfaces of $\mathrm{MgO}$-doped $\mathrm{Al}_{2} \mathrm{O}_{3}$ samples fast fired in vacuum at a heating rate of $340^{\circ} \mathrm{C} / \mathrm{min}$. to $1750^{\circ} \mathrm{C}$ and held for 5 minutes: (a) conventional sample; (b) $800^{\circ} \mathrm{C} / 50 \mathrm{~h}$ homogenized; (c) $800^{\circ} \mathrm{C} / 100 \mathrm{~h}$ homogenized. 


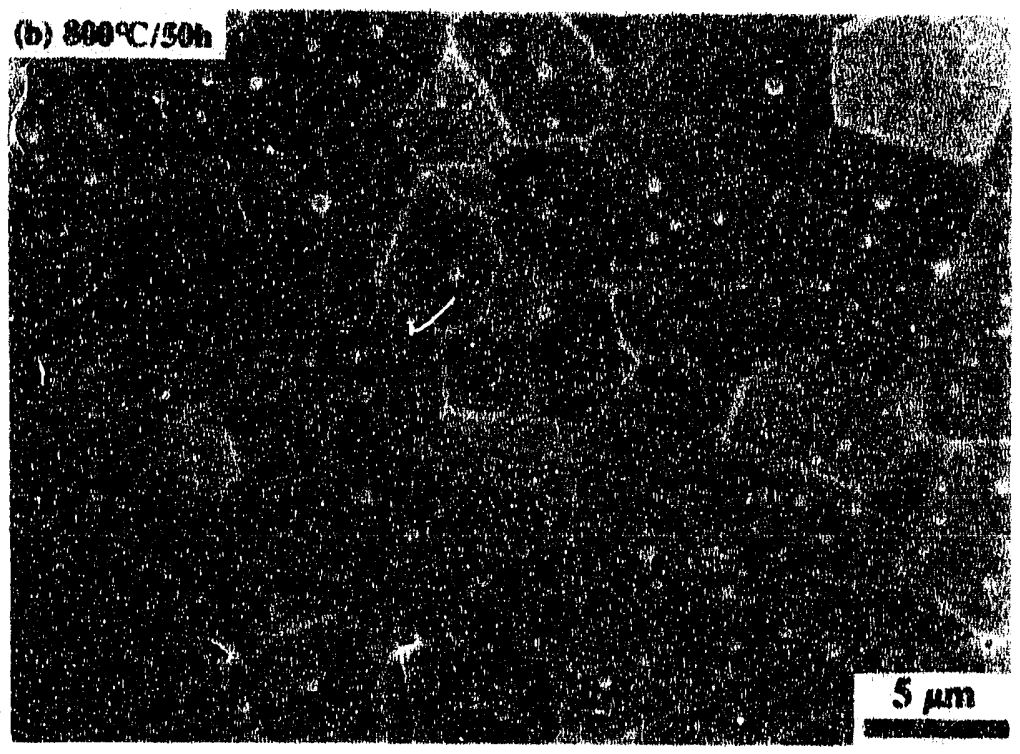

Figure 4.24 (Continued) Scanning electron micrographs of polished and thermally etched surfaces of $\mathrm{MgO}$-doped $\mathrm{Al}_{2} \mathrm{O}_{3}$ samples fast fired in vacuum at a heating rate of $340^{\circ} \mathrm{C} / \mathrm{min}$. to $1750^{\circ} \mathrm{C}$ and held for 5 minutes: (a) conventional sample; (b) $800^{\circ} \mathrm{C} / 50 \mathrm{~h}$ homogenized; (c) $800^{\circ} \mathrm{C} / 100 \mathrm{~h}$ homogenized. 


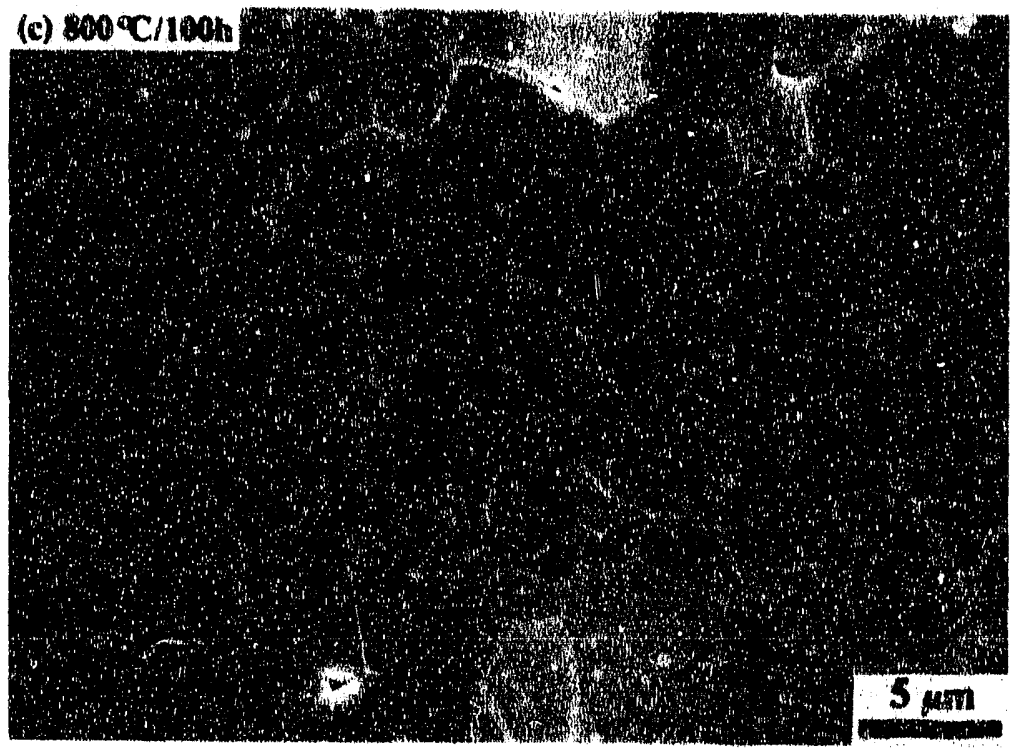

Figure 4.24 (Continued) Scanning electron micrographs of polished and thermally etched surfaces of $\mathrm{MgO}$-doped $\mathrm{Al}_{2} \mathrm{O}_{3}$ samples fast fired in vacuum at a heating rate of $340^{\circ} \mathrm{C} / \mathrm{min}$. to $1750^{\circ} \mathrm{C}$ and held for 5 minutes: (a) conventional sample; (b) $800^{\circ} \mathrm{C} / 50 \mathrm{~h}$ homogenized; (c) $800^{\circ} \mathrm{C} / 100 \mathrm{~h}$ homogenized. 

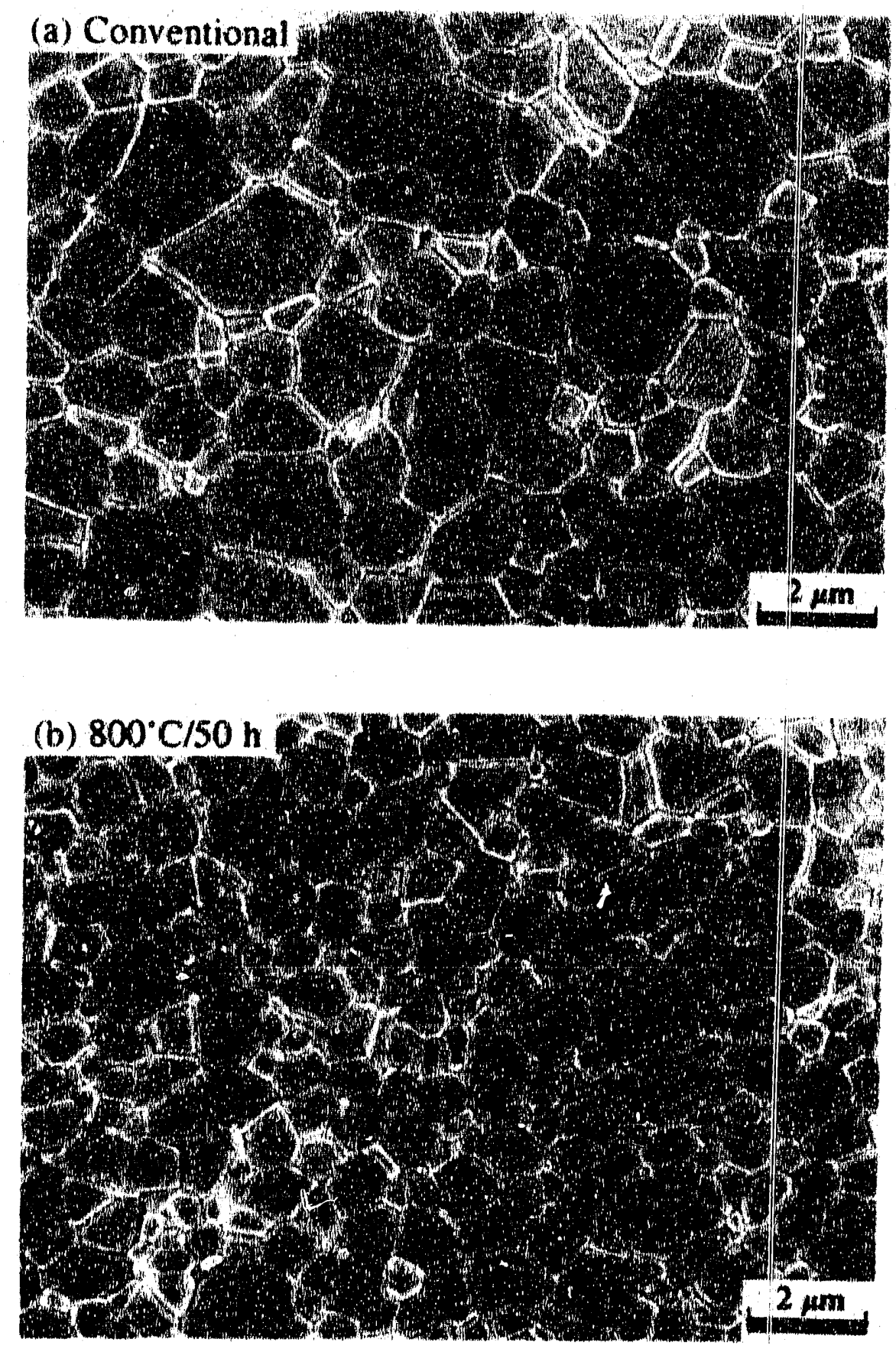

Figure 4.25 Scanning electron micrographs of polished and thermally tched surfaces of $250 \mathrm{ppm} \mathrm{MgO}$-doped $\mathrm{Al}_{2} \mathrm{O}_{3}$ compacts formed by isostatic pressins $(\approx 1380 \mathrm{MPa})$. Sintering was conducted at a constant heating rate of $4^{\circ} \mathrm{C} / \mathrm{min}$. to $1450^{\circ} \mathrm{C}$ in air: (a) conventional sample, mean grain size is $1.44 \mu \mathrm{m}$; (b) 800$)^{\circ} \mathrm{C} / 50 \mathrm{~h}$ homogenized, mean grain size is $1.07 \mu \mathrm{m}$. 


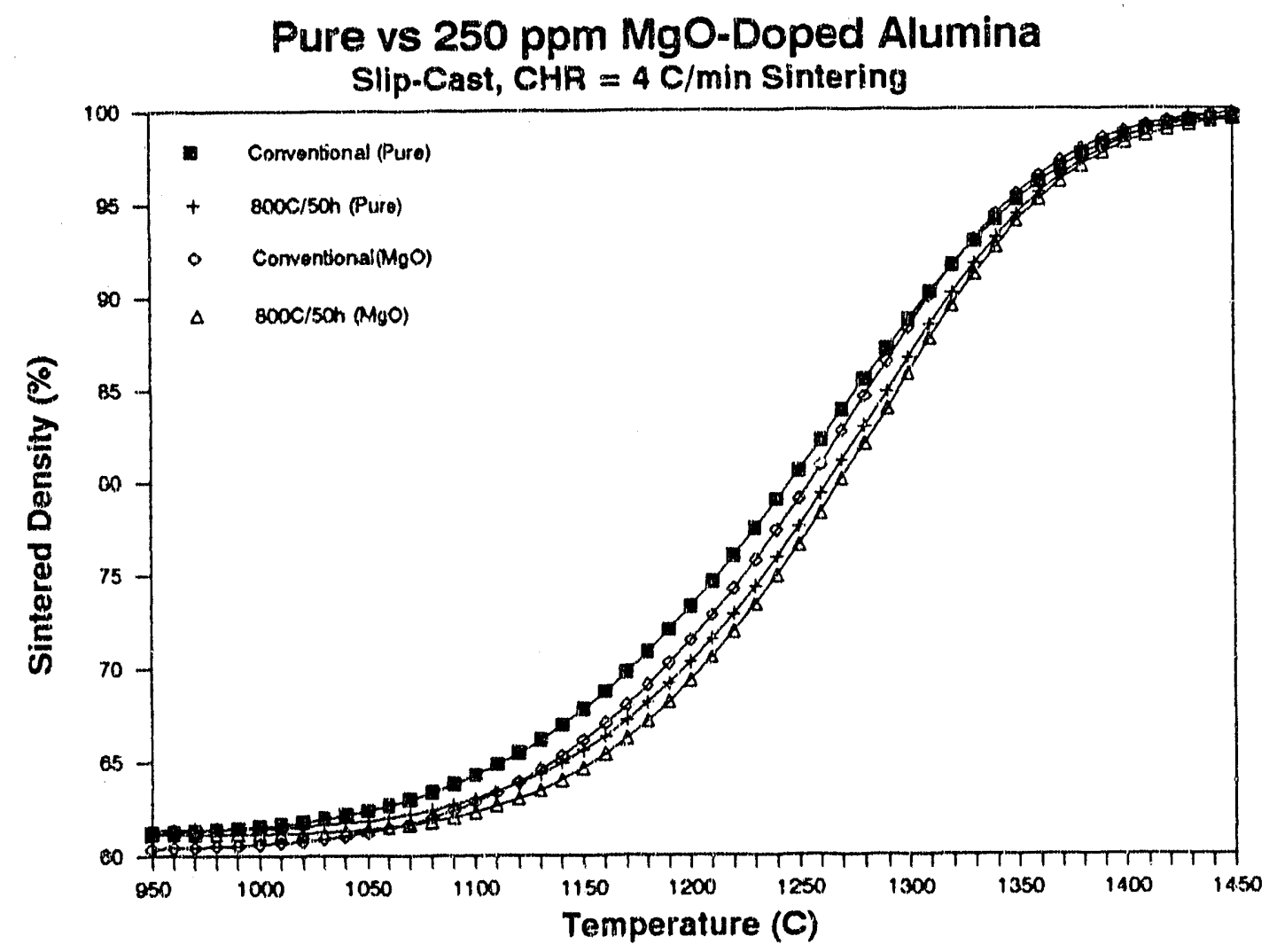

Figure 4.26 Sintered density is plotted as a function of sintering temperature for undoped and $\mathrm{MgO}$-doped $\mathrm{Al}_{2} \mathrm{O}_{3}$ powder compacts formed by isostatic pressing ( $\approx 1380 \mathrm{MPa}$ ). Sintering was cond.cted for the conventional and the homogenized samples at a constant heating rate of $4^{\circ} \mathrm{C} / \mathrm{min}$. to $1450^{\circ} \mathrm{C}$ in air. 


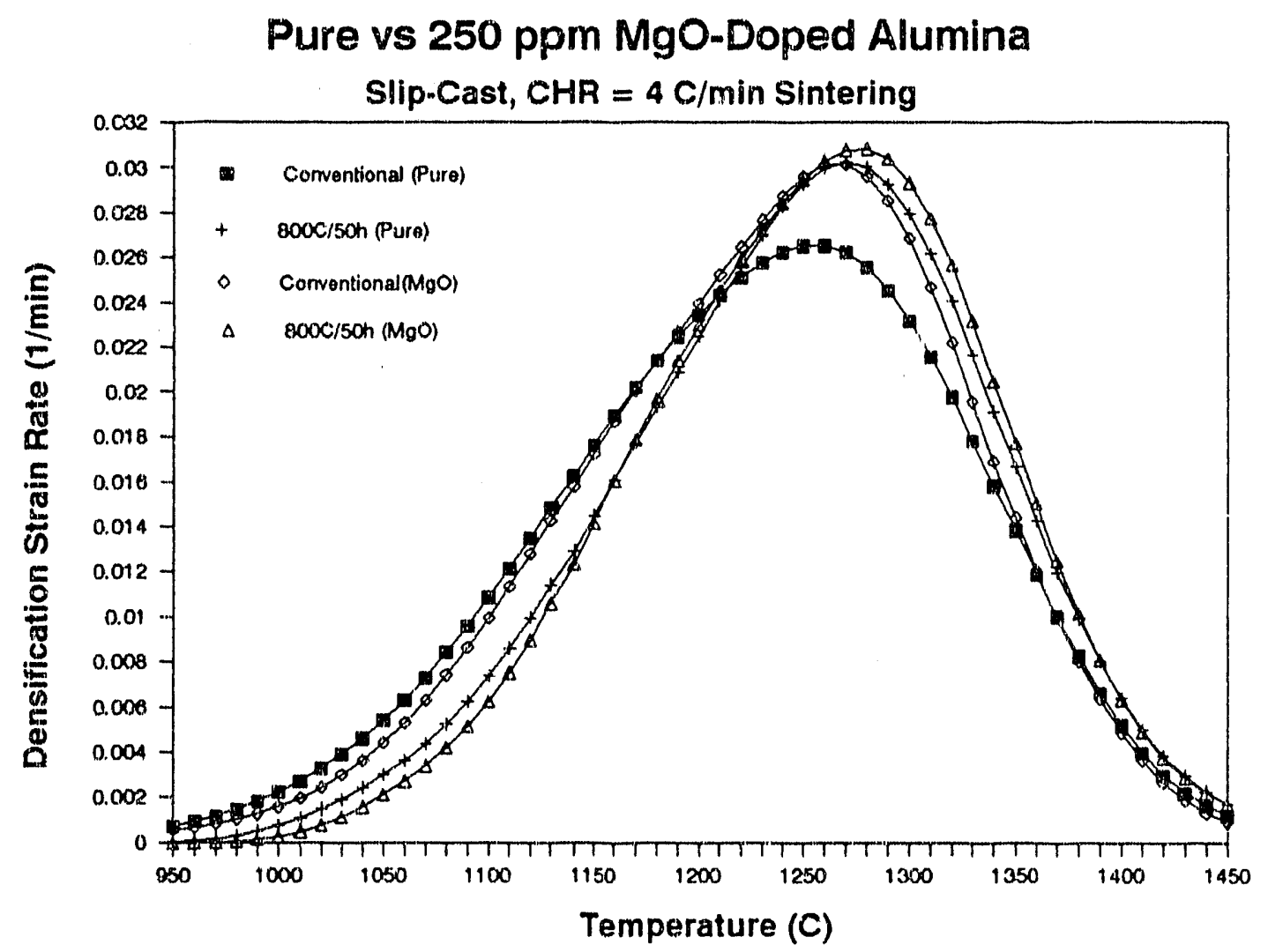

Figure 4.27 Densification rate is plotted as a function of temperature for undoped and $\mathrm{MgO}$-doped $\mathrm{Al}_{2} \mathrm{O}_{3}$ powder compacts formed by isostatic pressing ( $\approx 1380 \mathrm{MPa}$ ). Sintering was conducted for the conventional and the homogenized samples at a constant heating rate of $4^{\circ} \mathrm{C} / \mathrm{min}$. to $1450^{\circ} \mathrm{C}$ in air. 

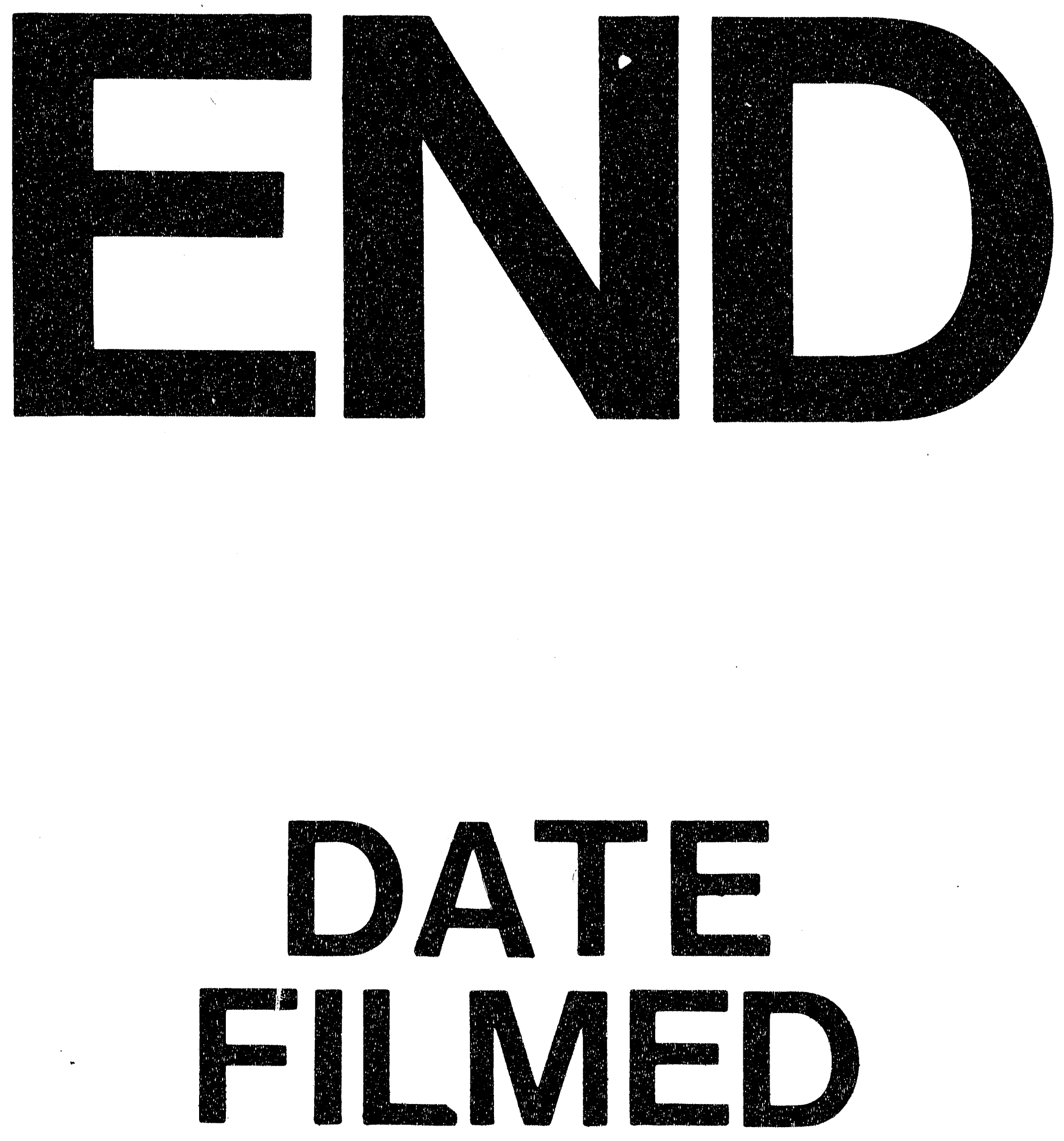

事

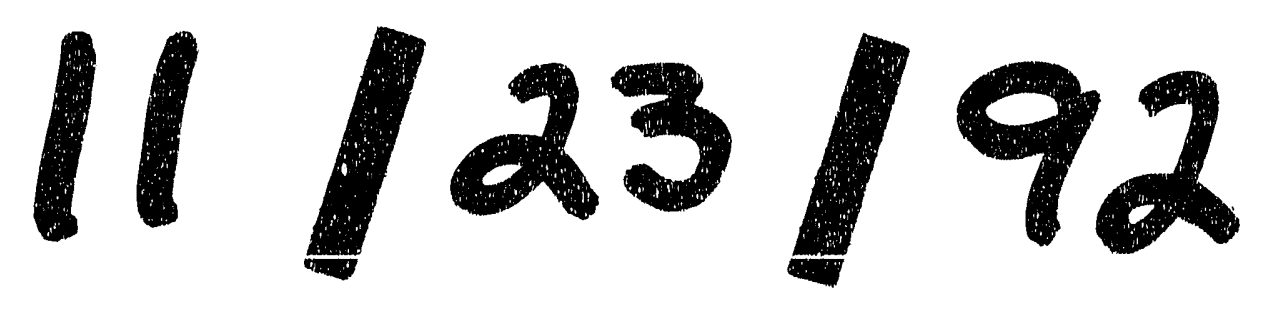


